Florida International University FIU Digital Commons

5-20-1994

\title{
An after tax economic analysis of home equity conversion for the elderly
}

Lowell James Cramer

Florida International University

DOI: $10.25148 /$ etd.FI14061537

Follow this and additional works at: https://digitalcommons.fiu.edu/etd

Part of the Business Administration, Management, and Operations Commons

\section{Recommended Citation}

Cramer, Lowell James, "An after tax economic analysis of home equity conversion for the elderly" (1994). FIU Electronic Theses and Dissertations. 2654.

https://digitalcommons.fiu.edu/etd/2654

This work is brought to you for free and open access by the University Graduate School at FIU Digital Commons. It has been accepted for inclusion in FIU Electronic Theses and Dissertations by an authorized administrator of FIU Digital Commons. For more information, please contact dcc@fiu.edu. 
FLORIDA INTERNATIONAL UNIVERSITY

Miami, Florida

\begin{abstract}
AN AFTER TAX ECONOMIC ANALYSIS OF HOME EQUITY CONVERSION FOR THE ELDERLY
\end{abstract}

A dissertation submitted in partial satisfaction of the requirements for the degree of

DOCTOR OF PHILOSOPHY

IN

BUSINESS ADMINISTRATION

by

Lowell James Cramer 
To: Dean Harold E. Wyman

College of Business Administration

This dissertation written by Lowell James Cramer, and entitled AN AFTER TAX ECONOMIC ANALYSIS OF HOME EQUITY CONVERSION FOR THE ELDERLY, having been approved in respect to style and intellectual content, is referred to you for judgement.

We have read this dissertation and recommend that it be approved.

Gary Anderson

Rolf Auster

Joel Barber

Yong s. Choe

Amy Dickinson

Lewis F. Davidson, Major Professor

Date of Defense: May 20, 1994

This dissertation of Lowell James Cramer is approved.

Dean Harold E. Wyman

College of Business Administration

Dean Richard L. Campbell

Division of Graduate Studies

Florida International University, 1994 


\section{ACKNOWLEDGEMENTS}

I would like to express my gratitude to the many individuals who provided assistance, guidance and encouragement to me during my Ph.D. program at Florida International University. I particularly appreciate the effort expended on my behalf by the members of my dissertation committee which was comprised of Professors Gary Anderson, Rolf Auster, Joel Barber, Yong Choe, and Lewis Davidson of Florida International University and Amy Dickinson of Florida Atlantic University. I would especially like to acknowledge the continual guidance and support received from Professor Davidson who served as the chairman of the committee. I would also like to acknowledge Professors Anderson and Barber for their help and guidance relating to the simulation programs and statistical analysis.

Finally, I wish to thank Mr. Edward J. Szymanoski, Economist, Housing Finance Analysis Division, office of Policy Development and Research, U.S. Department of Housing and Urban Development for his encouragement, advice, and comments. 


\begin{abstract}
OF THE DISSERTATION
AN AFTER TAX ECONOMIC ANALYSIS OF HOME

EQUITY CONVERSION FOR THE ELDERLY
\end{abstract}

by

Lowell James Cramer

Florida International University, 1994

Miami, Florida

Professor Lewis F. Davidson, Major Professor

The FHA program to insure reverse mortgages has brought additional attention to the use of home equity conversion to increase income to the elderly. Using simulation, this study compares the economic consequences of the FHA reverse mortgage with two alternative conversion vehicles: sale of a remainder interest and sale-leaseback. An FHA insured plan is devised for each vehicle, structured to represent fair substitutes for the FHA mortgage. In addition, the FHA mortgage is adjusted to allow for a 4 percent annual increase in distributions to the homeowner. The viability of each plan for the homeowner, the financial institution and the FHA is investigated using 
different assumptions for house appreciation, tax rates, and homeowners' initial ages. For the homeowner, the return of each vehicle is compared with the choice of not employing home equity conversion. The study examines the impact of tax and accounting rules on the selection of alternatives. The study investigates the sensitivity of the FHA model to some of its assumptions.

Although none of the vehicles is Pareato optimal, the study shows that neither the sale of a remainder interest nor the sale-leaseback is a viable alternative vehicle to the homeowner. While each of these vehicles is profitable to the financial institution, the profits are not high enough to transfer benefits to the homeowner and still be workable. The effects of tax rate, house appreciation rate, and homeowner's initial age are surprisingly small. As a general rule, none of these factors materially impact the decision of either the homeowner or the financial institution. Tax and accounting rules were found to have minimal impact on the selection of vehicles. The sensitivity analysis indicates that none of the variables studied alone is likely to materially affect the FHA's profitability. 
TABLE OF CONTENTS

I. INTRODUCTION AND STATEMENT OF THE PROBLEM . . . . . 1

II. BACKGROUND AND PERSPECTIVE . . . . . . . . . . . . 7

Economic Basis for Home Equity Conversion . . . . 11

Need for Home Equity Conversion . . . . . . . . 15

Policy Issues . . . . . . . . . . . . . . . 24

Accounting Issues . . . . . . . . . . . . 25

Income Tax Issues . . . . . . . . . . . . . 28

Social Welfare Issues... . . . . . . . . . 29

Liquidity Issues . . . . . . . . . . . . . . 30

Profitability Issues . . . . . . . . . . 31

Home Equity Conversion Mortgages . . . . . . . . 33

Conventional HECM Products . . . . . . . . 37

The FHA HECM .................. 46

Accounting for the Insured HECM . . . . . . 62

Taxation of the HECM . . . . . . . . . . . 62

Split Interest . . . . . . . . . . . . . . . . . 64

History of the SI Plan . . . . . . . . . 65

Accounting for the SI Plan ......... 70

Taxation of the SI Plan . . . . . . . . . 72

Other Policy Aspects of the SI Plan . . . . . 74

Sale-Leaseback . . . . . . . . . . . . . . 76

History of the Sale-Leaseback Plan . . . . 77

Accounting for the Sale-Leaseback . . . . . 79

Taxation of Sale-Leasebacks . . . . . . . 80

Other Policy Aspects of the Sale-Leaseback • 83

III. METHODOLOGY . . . . . . . . . . . . . . 85

Overview of the Methodology . . . . . . . . 87

Descriptions of the HEC Plans . . . . . . . . . 88

FHA Home Equity Conversion Mortgage . . . . 89

Growth Home Equity Conversion Mortgage . . . 89

Split Interest . . . . . . . . . . . . 91

Sale-Leaseback . . . . . . . . . . . . . 92

Variables and Assumptions of the Model . . . . . 92

Model Variables and Assumptions . . . . . . . . 94

Actuarial Assumptions . . . . . . . . . . 94

Death Year . . . . . . . . . . . . 96

Move-out Year . . . . . . . . . . . . 96

Interest Rate . . . . . . . . . . . . . 97

FHA Insurance Rate . . . . . . . . . . . . 97

closing Costs.............. . 98

Home Appreciation Rate . . . . . . . . . 98

Inflation Rate . . . . . . . . . . . 98 
Discount Rate . . . . . . . . . . . . 99

Property Operating Costs . . . . . . . . . 99

Plan Servicing Costs . . . . . . . . . . . 99

Tax Rate .................. 100

Accounting Rules ............... . 101

Tax Rules.................... 101

Annualization . . . . . . . . . . . . . 102

Computation of Annuities . . . . . . . . . 102

Model Tests and Hypotheses . . . . . . . . . . 104

Plan Comparison ............... . 104

Tax Policy Assumptions . . . . . . . . 106

Sensitivity of FHA Assumptions . . . . . . 108

IV. DATA ANALYSIS AND EMPIRICAL RESULTS . . • . . . .110

Plan Comparison . . . . . . . . . . . . . 110

Homeowner . . . . . . . . . . . . . . . 111

Financial Institution . . . . . . . . . 121

The FHA . . . . . . . . . . . . . . . 124

Tax Policy Questions . . . . . . . . . . . . 125

Sensitivity of the FHA Model . . . . . . . . . 127

V. CONCLUSION . . . . . . . . . . . . . . . . . . 163

Summary . . . . . . . . . . . . . . . . . 163

Homeowners . . . . . . . . . . . . . . 164

Adverse Selection . . . . . . . . . . . 164

Tax Policy ................. . 165

Accounting Policy . . . . . . . . . . . . 165

FHA Assumptions .. . . . . . . . . . . . 165

Recommendations ................ . . . 167

FHA Recommendations . . . . . . . . . . 167

Public Assistance Recommendations . . . . . 167

Tax Recommendations . . . . . . . . . . 168

Limitations

168

REFERENCES . . . . . . . . . . . . . . . . . . . . . 172

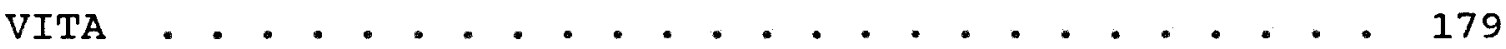


TABLE

\section{LIST OF TABLES}

1. ATTRIBUTES OF HEC VEHICLES . . . . . . . . . . 10

2. HOMEOWNER'S INITIAL ANNUAL PAYMENT . . . . . . . 131

3. HOMEOWNER'S NPV OF EXPECTED CASH FLOW . . • • • 132

4. HOMEOWNER'S NPV OF EXPECTED CASH FLOW RANK • • . 135

5. TIMES PLAN HAD HIGHEST TWO NPVS TO HOMEOWNER • • . 138

6. TIMES PLAN HAD LOWEST TWO NPVS TO HOMEOWNER . • • 141

7. HOMEOWNER'S EXPECTED RANK BY AGE . . . . . . . . 144

8. HOMEOWNER'S EXPECTED RANK BY TAX RATE . . . . . . 144

9. HOMEOWNER'S EXPECTED RANK BY HOME APPRECIATION

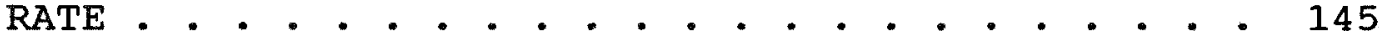

10. TIMES HOMEOWNER'S NPV EXCEEDS DOING NOTHING • . 146

11. FINANCIAL INSTITUTION'S NPV OF EXPECTED CASH FLOW 147

12. FINANCIAL INSTITUTION'S IRR OF EXPECTED CASH FLOW 151

13. FINANCIAL INSTITUTION'S NPV OF ACCOUNTING INCOME - 154

14. FHA'S NPV OF EXPECTED CASH FLOW . . . . . . . 157

15. FHA BREAK-EVEN RETURN ON INVESTMENTS . . . . . . 158

16. EFFECT OF DISCOUNT RATE ON FHA'S EXPECTED NPV • . 159

17. EFFECT OF MOVE-OUT RATE ON FHA'S EXPECTED NPV • 160

18. EFFECT OF SALES PRICE DISCOUNT ON FHA'S EXPECTED NPV . . . . . . . . . . . . . . . . . 161

19. EFFECT OF HOME APPRECIATION RATE ON FHA'S EXPECTED NPV •. . . . . . . . . . . . . . . . . 162

20. EFFECT OF APPRECIATION'S STANDARD DEVIATION ON FHA'S EXPECTED NPV . . . . . . . . . . . . . . 
CHAPTER I

INTRODUCTION AND STATEMENT OF THE PROBLEM

The growth of the elderly population in the United states $^{1}$ has focused attention on the financial plight of the aged. During this era of large budget deficits, home equity conversion, the use of a person's home equity to increase funds available for retirement ${ }^{2}$, allows the elderly to consume annually from the value of their real estate without government outlay. Although home equity conversions ("HEC"s) date from the 1970's (Archer and Nye 1987, 1), they had not gained widespread attention until the Department of Housing and Urban Development ("HUD") started providing Federal Housing Administration ("FHA") ${ }^{3}$ insurance for home equity conversion mortgages ("HECM"s) ${ }^{4}$. In 1987 Congress authorized

${ }^{1}$ In 1930 , the elderly (those over age 65 ) represented 5.4 percent of the U.S. population. In 1980, the percentage increased to 11.3 percent. In 2030 , the elderly are expected to constitute 21.8 percent of the population. (U.S. Senate Subcommittee on Aging et al. 1991, 7).

${ }^{2}$ This is a narrow definition. Under a broader definition, home equity conversion would also include standard home equity mortgages used as lines of credit by working individuals.

${ }^{3}$ Throughout this paper HUD and FHA will be used interchangeably.

${ }^{4}$ HECMs are commonly called reverse mortgages. This paper will use the two terms interchangeably. 
a demonstration project in which HUD could insure 2,500 HECMs through september 30, 1991 (HUD 1990, I-3). This program was later increased to allow 25 thousand HECMs through september 30, 1995 (Roma 1991).

The objective of this study is to evaluate the need for the FHA to insure additional forms of home equity conversion, namely a growth mortgage, split interest plan, and a saleleaseback. These vehicles are discussed in chapter 2 . There are five major issues relating to the objective:

- The expected economic consequences to the homeowner;

- The expected economic consequences to the financial institution;

- The expected economic consequence to the FHA;

- Suggested legislative changes by the government; and

- Accounting problems relating to these proposals. The study compares the costs and benefits of these additional vehicles to the FHA HECM mortgage. In general, the net present value of expected cash flow is used to measure the results, but other measures are used. To date there has been no study comparing the costs and benefits of these alternative HEC vehicles.

Interest in home equity conversion is extremely strong. For example, FHA received 28 thousand inquiries on the HECM project in the interval before the start of the program (HUD 1990, p. 1-5). Actual demand has been less than expressed 
interest. Prior to the FHA program, only about 2,500 HECMs had been written, one thousand by a single private issuer and the reminder by government or nonprofit organizations (HUD 1990, p. 3-1). In the first nine months of operation, lenders took only 572 FHA HECM mortgage applications and only 257 loans were closed. This led one critic (Sichelman 1991) to note that at that rate, the 25 thousand mortgage limit would not be exceeded for fifty years.

While the HECM mortgage is designed to give the homeowner a monthly payment, not generally indexed for inflation, the split interest ("SI") and the sale-leaseback ("SL") can result in lower monthly payments, but provide inflation protection. HECMS, SLs, and SIs are described in chapter 2 . It is possible that the elderly homeowner may be as interested in inflation protection as current cash receipts. A comparison of the three models shows the advantages and disadvantages to the homeowner, the financial institution and the insurer (FHA) •

This research uses Monte Carlo simulation to compare the FHA HECM mortgage with similarly constructed and insured split SI and SL arrangements and a growth HECM mortgage. Simulation is used because there are a large number of variables, some of which act differently in different situations. The FHA does not presently insure the SI, SL, or growth HECM mortgages. The research examines the economic effects on the homeowner, 
the financial institution and the FHA on before- and after-tax bases assuming different ages and property appreciation rates. It examines the accounting flows of the different alternatives, to learn whether current and future cash flows are reflected. In addition, the financial viability of the FHA model and the sensitivity of the model to several of its assumptions are explored.

The outcome of this research should provide homeowners and financial institutions information to better compare the four forms of HEC being examined. A second purpose is to examine certain policy aspects of the plans. Additionally, information is provided to the insurer regarding the economic viability of the plans. The reason for testing the FHA plan is to learn whether the plan is likely to break even.

This research should be of interest to those organizations and governmental agencies interested in promoting home equity conversion for the elderly. It will provide information to assess the usefulness of expanding the FHA HEC (or the establishment of private programs) to include one or more of the three model plans. Moreover, this research should be useful to the FHA for determining whether it can carry out any of the three alternative plans without loss of revenue or without adverse selection risk. ${ }^{5}$ Private

${ }^{5}$ For example, if plan A is more favorable than plan B to the FHA given low appreciation rates, but plan $B$ is more favorable given high appreciation rates, homeowners and 
companies should find this research useful in deciding whether to offer their own HEC plan or to insure the HEC plans of others.

Accounting rules may have economic consequences that discourage financial institutions from offering the plans. To maintain regulatory capital and earnings, financial institutions, such as banks, will often be suffer reduced cash flows to increase reported profits (Scholes, wilson and Wolfson 1989). If either the split interest or sale-leaseback plan is adopted, accounting rules may have to be modified to allow for the insured nature of the plans. This is a concern to special interest groups interested in promoting home equity conversion. For example the SEC's decision to change the accounting for non-insured HECMs in 1992 was questioned by the American Association of Retired Persons ("AARP").

This research is of interest from a tax perspective because

- it examines the effect of taxes on HEC choices of the homeowner and the financial institution;

- it examines for policy makers the need to change the tax law and regulations to encourage new forms of $\mathrm{HEC}$; and

- it aids homeowners and financial institutions in evaluating the HEC choices on an after-tax basis.

institutions may be encouraged to use plan B if the property is unlikely to appreciate and use plan $A$ if the property is likely to appreciate. 
This research does not examine the legal requirements for each type of HEC under state or federal laws. It assumes that each type of procedure is legal or can be made legal by appropriate legislation or ruling. For example, it is likely that banks and other financial institutions (other than insurance companies) are not presently allowed to issue annuities. This research assumes that a program to increase HECs would include authorization for financial institutions to issue annuities with a qualified HEC.

The remainder of this paper is divided into the following chapters:

Background and perspective;

Methodology;

Results; and

Conclusion.

The conclusion includes (1) a summary, (2) public policy recommendations, and (3) research limitations, including areas for further research. 
CHAPTER II

\section{BACKGROUND AND PERSPECTIVE}

Home equity conversion is broadly defined as the use of home equity (i.e., the value of the home) to provide cash to the homeowner. A traditional home equity loan meets this broad definition. However, it is defined more narrowly in this research to include only those home equity conversion vehicles ("HEC"s) that are designed to provide additional cash flows for elderly homeowners, to enable them to continue to live in their present (or desired future home) without fear of being forced out. The three principal forms of HEC are the home equity conversion mortgage ${ }^{6}$ ("HECM"), the split interest ("SI"), and the sale-leaseback ("SL"). Each of these forms are explained in this chapter. The primary purpose of this research is to explore certain public policy implications of encouraging additional HEC vehicles for the elderly. Specifically examined are the economic consequences of extending the FHA Home Equity Conversion Mortgage program to allow for the following additional vehicles: (1) a growth HECM, (2) an SI, and (3) a SL. Although other forms of HEC

${ }^{6}$ The "home equity conversion mortgage" is often referred to as a "reverse mortgage." The two terms will be used interchangeably in this study. 
are available to certain segments of the elderly or poor in some states, they are not part of this study due to their limited availability. Several states have also established HEC mechanisms for the poor or elderly that permit either deferral of property tax or maintenance costs (Scholen 1992, 155-79). These are also not a part of this study.

This research is limited to HEC mechanisms that could be made available through financial institutions. Not considered are such items as intra-family HEC vehicles or changes in life style, e.g., renting a room or house sharing. 7

A rational decision model for pursuing any issue relating to a particular national policy would require (1) an examination of the reasons for the existing or proposed policy, (2) possible solutions to the issues raised by the policy, and (3) results of past alternatives implemented or tried. The purpose of this chapter is to provide such background on the issue of home equity conversion for the elderly consistent with this framework.

The chapter begins with a discussion of the economic theory of the lifetime consumption function, followed by a

${ }^{7}$ Pastalan (1983) observed that alternative living arrangements, such as leasing a room and building an accessory apartment would produce a larger increase in the homeowner's disposable income than a typical reverse mortgage. Pastalan fails to note that in many cases alternative living arrangements can be combined with a reverse mortgage (or other form of HEC) to further increase disposable income. 
discussion of the need for home equity conversion. Next, some special policy issues of home equity conversion are mentioned. The next three sections discuss the three major home equity conversion vehicles being examined in this research: (1) the home equity conversion mortgage, (2) the split interest, and (3) the sale-leaseback. Each section describes (Table 1 summarizes the significant attributes of the three plans):

- the vehicle,

- examples of programs using the vehicle, and

- policy issues, such as accounting, taxation, and other issues of special interest. 
TABLE 1

\section{ATTRIBUTES OF HEC VEHICLES}

\begin{tabular}{|c|c|c|c|}
\hline AMRTBURs & MortaAG & SPLIT TMREREST & BancK \\
\hline $\begin{array}{l}\text { HOMB } \\
\text { GRTPL }\end{array}$ & 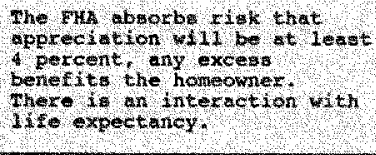 & 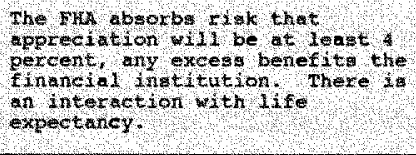 & 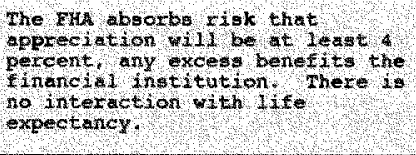 \\
\hline 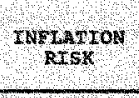 & 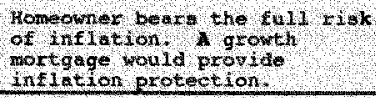 & 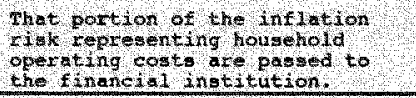 & 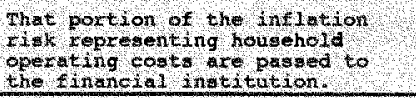 \\
\hline $\begin{array}{l}\text { wexpe } \\
\text { cos? }\end{array}$ & 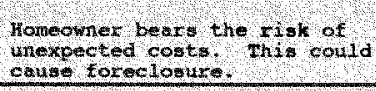 & 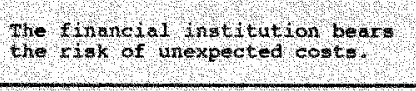 & 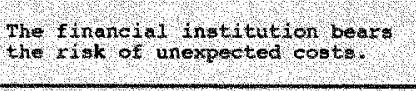 \\
\hline 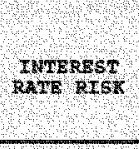 & 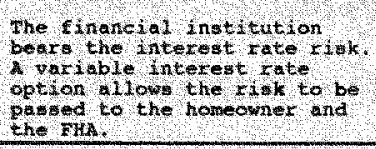 & The tincresal institation bears & 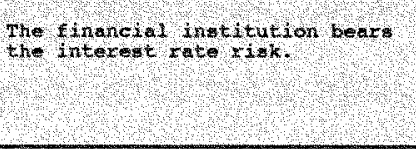 \\
\hline $\begin{array}{c}\text { XNCOM } \\
\text { TREATHEN }\end{array}$ & 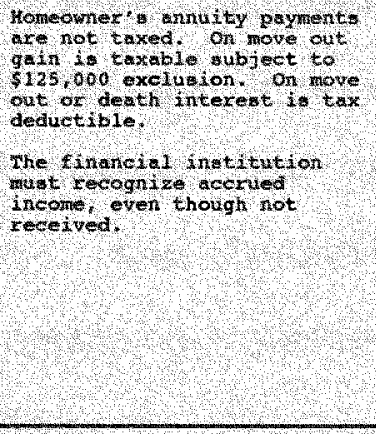 & 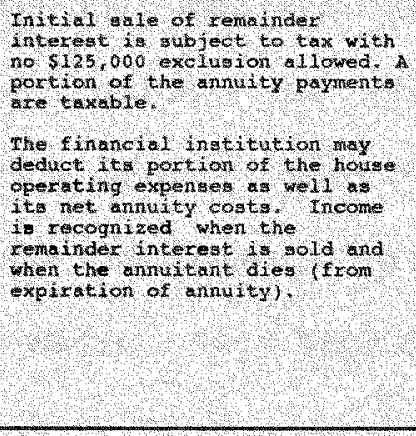 & 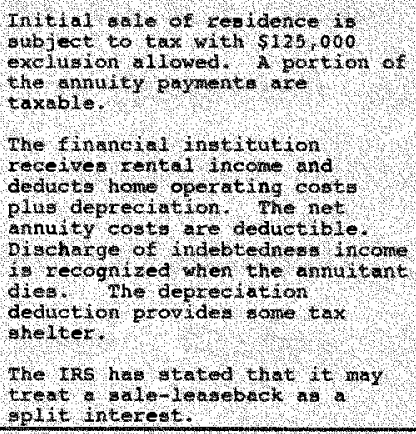 \\
\hline $\begin{array}{l}\text { ACCDUATRA } \\
\text { TREATHEAT }\end{array}$ & 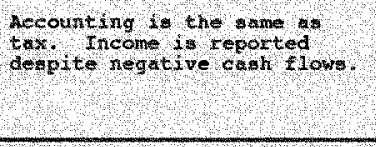 & 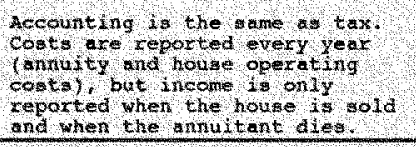 & 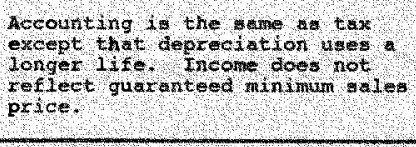 \\
\hline LTOUTDTOK & 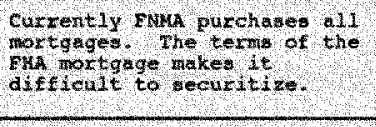 & 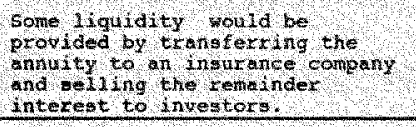 & 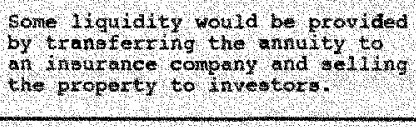 \\
\hline & 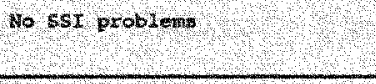 & 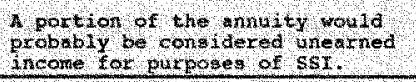 & 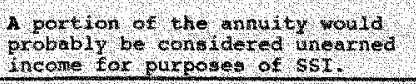 \\
\hline MOR $\mathrm{AlNT}$ & 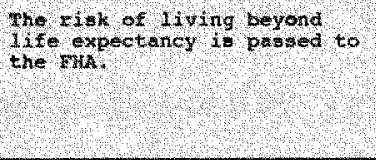 & 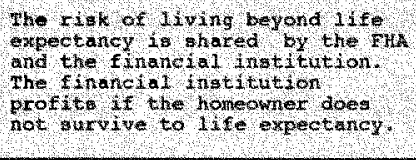 & 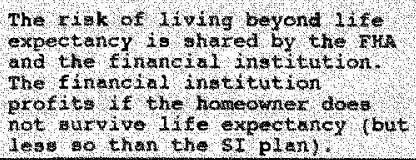 \\
\hline
\end{tabular}


The socio-economic need for home equity conversion can be deduced from Modigliani and Brumberg's (1954) life cycle hypothesis. The life cycle hypothesis ("LCH") states that individuals during their productive years will increase their wealth and during their non-productive years will deplete that wealth. As explained by Modigliani (1975), if one dismisses the bequest motive then all individuals have a lifetime marginal rate of consumption of one (i.e., consumption equals income). During the working years, individuals allocate their income between consumption and savings based on the present value of future expected income, so that consumption can remain constant for the person's entire lifetime. After retirement, the individual depletes the wealth accumulated during working years with no appreciable change in consumption.

Shortly after the formulation of the LCH, Friedman (1957) introduced the permanent income hypothesis ("PIH"). The PIH assumes that each household possesses an array of assets, human and non-human, from which it expects to receive a stream of returns. Returns from each asset are discounted by an appropriate discount rate; the rate for non-marketable assets may be extremely high (as high as 33.3 percent). The discounted returns produce a value to each asset. Each asset's value is multiplied by its appropriate discount rate 
to derive the permanent income from that asset. The sum of the permanent income from all assets is the household's permanent income. Friedman suggested that consumption is dependent on the household's permanent income.

Modigliani and Ando (1960) suggested that although the two hypotheses are different, they lead to many of the same results. ${ }^{8}$ For example, they noted that under both hypotheses the saving income ratio increases with income (p. 93). They recognize that it is extremely difficult to test the two hypotheses, since both are based largely on unobservable variables. Consequently, many researchers test for a reduction in wealth during retirement.

The LCH assumes that wealth will be depleted during retirement, while the PIH assumes wealth will remain constant. Research findings have not been conclusive. One problem is that facts can often be interpreted differently. Disparate interpretations may support conflicting conclusions. For example Mirer (1979) and Dicks-Mireaux and King (1984) argued that when the actuarial value of social security and other annuity income is included in the calculation of wealth, there is clear evidence that wealth does decline during retirement. In contrast, Bernheim (1987) argued that in testing the hypotheses, the capitalized value of the current return from

${ }^{8}$ Modigliani (1975) reinforced these views and noted that assuming expected lifetimes were infinite, PIH and LCH lead to about the same results. 
annuities should be used. ${ }^{9}$ It may be inappropriate to use annuities to compare the two hypotheses. Under the PIH, the entire annuity would likely be considered permanent income although it is a depleting asset.

Based on the LCH, one would conclude that home ownership would increase with age and then decrease after retirement. As indicated by two studies, the evidence is mixed. Li (1977) used logit analysis to find the factors that influence home ownership in Boston and Baltimore. The variables examined were income, age of head of household, family size, and race. Li found a life cycle effect. As a family gets older and larger during the early years of marriage, the probability of home ownership increases, as family size gets smaller from ages 45-64, the probability decreases. The probability decreases further for two-person households over age 65 . While consistent with a life cycle effect on savings and overall consumption, these studies are not conclusive. The results may be confounded by a life cycle effect of housing needs.

Chen and Jensen (1985) used a logit model to estimate the likelihood of "using" home equity by employing various

${ }^{9} \mathrm{He}$ argues that if annuities yielded more than the appropriate interest rate, then a person would put all of their assets in annuities. However, This argument does not appear to persuasive. Insurance companies sell their annuity products on the basis of achieving a higher current return than could be earned by investing in bonds. 
measures of demographic characteristics, as well as income, and wealth. of the 1,706 households studied, 77 or 4.5 percent used their home equity. Using home equity included (1) taking out a second mortgage, (2) adding a home addition or repair into an existing mortgage, or (3) using home equity as security for a consumer loan. Mortgage refinancing would have been included had there been any cases in the data set. They found that elderly had a low likelihood of using equity regardless of marital status, retirement status, or income level. They concluded that older homeowners do not rely on dissavings to fund current consumption. The authors noted that there are two important limitations to their research due to the lack of available data: (1) the inability to include sale of the home as a use and (2) the inability to find whether a use was voluntary or involuntary. An interesting finding in the study is that even given the same wealth, higher income persons are more likely to borrow than middle income persons. Low income persons are most likely to borrow. The authors theorize that this may be due to higher income individuals being more likely to take on risk (p. 51) or that financing is more available to upper income individuals (p. 55). Artle and Variya (1978) using a theoretical model hypothesized that consumer durables have a constraining effect on consumption allocation. The restricted ability to borrow against equity in the home leads to 
discontinuities in the life cycle consumption profile. This hypothesis is inconsistent with the findings of chen and Jensen (1985). Chen and Jensen concluded that the liquid to total asset ratio is not a significant predictor in their model.

From the aforementioned discussion, one might infer that for home equity conversion to be effective, the LCH must be correct. After all, if the elderly do not decrease wealth over time, they do not need home equity conversion. However, under Friedman's PIH, home equity conversion would be useful. If home equity were to be converted into a life annuity, the stream of income from the annuity would be included in the homeowner's permanent income, thereby, increasing the homeowner's consumption. In short, home equity conversion would increase consumption under either theory.

2.2 Need for Home Equity Conversion

Underlying home equity conversion is the premise that the home is a major source of wealth of many, if not most, elderly Americans. Home equity represents over 40 percent of the net worth of the elderly (U.S. Senate committee on the Aging et al. 1991, 75). Home equity conversion provides a mechanism for the elderly to consume their home equity during retirement without having to give up their home. Much of the research on the need for home equity conversion is based on demographic data. For example, springer (1985) also pointed out that home 
equity represented 42 percent of the elderly's net worth in 1975. He also noted that a 1979 survey showed that over 70 percent of the elderly owned their own homes and of the 70 percent, over 80 percent owned their homes without a mortgage. Some, primarily the unmarried, have no home equity at all. But, for those that do, home equity conversion could increase household income up to 40 percent (those with the lowest incomes).

Similarly, Howard (1987) analyzed the raw data on 351 homeowners in Columbus, Ohio, selected from the public-use data tape of the 1982 Annual Housing survey. Subjects selected were all over 65 and owned a home. She examined three possible plans: deferred loans for home repairs, SI and SL. Thirty-one percent of the single homeowners and 10 percent of the married homeowners lived below the poverty line and older persons had lower incomes than younger persons (showing a LCH effect). There was a significant, but not extremely large correlation between home equity and income $(r=.52)$, suggesting that a substantial number of the elderly poor live in homes with substantial value. She found that 25 percent of the sampled population indicated an interest in a HEC plan. She concluded that due to the diversity of the needs of the elderly, none of the plans can be assumed to be superior to the others. 
Gasper (1984) simulated the addition of a ten-year term reverse mortgage ${ }^{10}$ on data received from the social security Administration's Longitudinal Retirement History study which began in 1969. Annuity payments would have resulted in an 11 to 18 percent increase in median real cash flow and between 25 and 35 percent of the individuals in poverty would have moved above the poverty line due to the payments. Median net worth would have increased 33 percent over the decade, while only 12 percent of the individuals would have reduced their net worth. Speare (1992) used data from the 1984 Panel of the Survey of Income and Program Participation developed by the Bureau of Census. He adjusted the data to assume that elderly homeowners would have received a 9 percent FHA home equity conversion mortgage (with $\$ 1,500$ of closing costs and $\$ 25$ per month service fee). Speare found that the percentage of households increasing their household income (after adjustment for existing mortgage payments) increased from 6.9 percent of those between 65 and 69 to 66.8 percent of those aged 85 and over. Also, 22 percent of the households with household income below the poverty threshold would now be above the threshold with the home equity conversion mortgage. This is much lower than Gasper (1984), but still significant.

10 Annuity payments were computed to result in a mortgage balance of eighty percent of the current value of the home at the end of the ten-year period. This mortgage is far less attractive to the homeowner than the FHA plan. 
Jacobs (1987) found that the homeowner's additional annuity obtained from home equity conversion would be an effective way to finance long term care for the elderly. Jacobs assumed that the money obtained from the annuity would be used for long term care. Two econometric studies suggest that Jacob's assumption may not be valid. Katsura et al. (1989) combining simulation with a proprietary econometric model examined the impact on the quality of housing of four alternative policies: (1) expanded housing vouchers for lowincome elderly renters, (2) housing vouchers for elderly homeowners, (3) expanded availability of HECMs, and (4) congregate housing vouchers for low-income impaired elderly. They concluded that expanded HECMs would not significantly improve the quality of housing, because most of the cash received would be used for living expenses and not re-invested in housing. Rivlin et al. (1988) explored various alternatives for financing long-term (i.e., nursing home) care for the elderly. A HECM was added to a proprietary econometric model. They wanted to know if the availability of the HECM would appreciably affect the purchase of long term care insurance. They found that the percentage of the elderly purchasing long term care insurance would not increase significantly unless the proceeds of the annuity were specifically designated for the insurance. 
Although there may be a need for home equity conversion, the research does not indicate that there is a large demand. Chen (1973) surveyed a stratified sample of 455 homeowners aged 55 to 75 in Los Angeles County. He found that only 9 percent of those interviewed would be interested in a HEC program similar to an SI in which the homeowner would be responsible for all expenses. There may be several reasons for this apparent lack of interest. Among them could be (1) emotional ties to the homestead, (2) poor information or understanding of the plan, and (3) a perception that chen's proposal made poor economic sense. Seventeen percent indicated that they would not live long enough to get money out of the plan and 16 percent indicated that there was not enough income. Weinrobe (1987) analyzed the data using a probit model and found that older and poorer persons were more likely to convert and single persons were more likely to convert than married persons. Elderly who rely on a child as a principal advisor were unlikely to convert.

More recent studies have shown an increase in homeowner interest in these plans. About four years later, a study in Ithaca, New York, modeled on Chen's work, found that 31 percent of homeowners over age 65 were interested in home equity conversion (Nelson 1980, 15). Nelson suggests that two reasons may account for the difference in results: the Ithaca 
survey was limited to those over age 65 and there was rapid inflation during the intervening period.

A survey of 549 Wisconsin homeowners aged 65 and over indicated that 44 percent were "interested" or "very interested" in one or more of the following HEC plans: reverse mortgage [term mortgage], reverse annuity mortgage [tenure mortgage], SL, and tax postponement (Nelson 1980). The SL model was the most popular with over 27 percent interest; 26 percent had an interest in tax postponement; and 16 percent showed interest in each of the mortgage plans. Nelson noted that those with the greatest need for home equity conversion (widows over 75 living alone with income of less than $\$ 5,000)$ were the least likely to be interested. He surmised that this might be due to lack of understanding of the plans. Kummerow (1980), using the same data, found that interest in HEC plans, and in particular the tax postponement plan, increases with income and education. This may be similar to the effect found in Chen and Jensen (1985) and suggests that upper income homeowners may be interested in home equity conversion as an additional vehicle in personal financial planning.

Venti and Wise (1990) developed a simultaneous equations model for estimating the desire to change principal residences. An assumption of the model is that a household evaluates its optimal housing needs against its current 
housing each period, based on its current circumstances. The family moves if the household receives an economic benefit from moving, above the transaction costs (which includes parameters for family status). Venti and Wise ("V\& W") then applied the model to 3,423 families in the social security Retirement History Survey, which covered the years 1969 to 1979 in bi-annual increments. They found that only 7.5 percent of the retired homeowners tended to move during a twoyear period, with 15 percent moving during periods of shocks (such as change in marital status or retirement). Contrary to the life cycle hypothesis, $V \& W$ concluded that there is no evidence that the elderly wish to reduce their housing equity; rather, there is a tendency to want to increase housing equity. Although some families, particularly those with low income and high housing equity, reduce their equity, this is more than offset by other elderly that increase their equity. $\mathrm{V} \& \mathrm{~W}$ further noted that transaction costs may prevent some families from reducing home equity. This could be corrected by home equity conversion, but they questioned whether the demand was sufficient to support an active market. There are two significant biases in their research. First, they exclude families that moved to a rental unit on their first move from the sample. Considering the low probability of moving, the elimination of those that clearly reduced their housing equity is a significant bias. In addition, the results may be biased 
due to the inflation in housing values during the period combined with a poor stock market. Changes in housing wealth may be due more to fluctuating prices than increasing housing stock. $\quad V \& W$ (1991) further explored the viability of reverse mortgages. First, they replicated the 1990 experiment using the 1984 Survey of Income and Program Participation, provided by the Bureau of the census and found consistent results. As additional evidence they show that housing wealth among homeowners is relatively constant with age (with a very small downward drift). They also found that the correlation between liquid wealth and housing wealth was almost zero, suggesting no substitution effect. From this they conclude that the elderly would not want reverse mortgages, even if they could get them. They concluded that the amount of a reverse mortgage annuity is not large enough to be significant to the average elderly homeowner. Speare (1992) pointed out that this conclusion assumes a much lower interest rate than is normally used to discount the value of the house. Speare suggested that although the lower rate is appropriate for commercial annuities, it may not be appropriate for reverse annuity mortgages. Speare also noted that the conclusion is biased, since $V \& W$ include persons aged 55 to 64 in some of their calculations. Higgins and Folts (1992) computed the annuity payable using various reverse mortgage plans and concluded that, except for the extremely elderly, the equity 
of most "house rich cash poor" elderly would not support large annuity payments. However, they note:

The real value of a small increase in monthly disposable income is a matter of perspective. For someone who lives at the margin of economic independence, an additional several dollars each month may represent much, indeed. (p. 199).

$V \& W(1991)$ acknowledge that the vast majority of the elderly's wealth is in social security (89 percent receive benefits) and private pensions (59 percent receive benefits). The decline in the value of the benefits with age, and therefore the total wealth of the elderly, is consistent with the life cycle hypothesis. The importance of pension benefits may also suggest that although the elderly may not want additional income, they may be interested in the inflation protection of the SL and SI plans.

The conclusions of Venti and Wise $(1990,1991)$ are not surprising. Convenient forms of HEC for the elderly are not generally available. The standard home mortgage and the home equity loan generally have the following characteristics that make them inappropriate to use as a HEC device:

(1) They do not provide for life tenancy. If payments are not made when due, foreclosure can force the homeowner from the home.

(2) They require the homeowner to establish that the loan can be repaid from future income (and not out of the equity in the home). 
The essence of home equity conversion is that the elderly homeowner generally will not take any action that will affect life tenure in the home. In addition, the homeowner does not have the income to repay the loan and must rely on the equity in the home itself for repayment. The use of prior data may be inappropriate. since home equity conversion was unavailable, the data may be biased by home equity conversion's omission from the database. The reason for homeowners failure to reduce home equity may be due to unavailability of an acceptable vehicle for doing so.

\section{$2.3 \quad$ Policy Issues}

To a large extent, the success of home equity conversion may depend more on certain policy issues than on whether it is a viable product. For example, if the income tax rules are uncertain, then financial institutions would be reluctant to offer products and homeowners may be unwilling to consider that which is offered.

The policy issues discussed are:

Accounting issues;

Income tax issues;

Social welfare issues;

Liquidity issues; and

Profitability issues. 


\subsubsection{Accounting Issues}

Accounting policy issues center on two areas. First is clarity of the accounting treatment. If the accounting treatment of a HEC vehicle is either uncertain or cumbersome, financial institutions may resist offering that vehicle. The second issue is whether the accounting treatment for a vehicle reflects its ability to generate future cash flows. If the accounting treatment differs from the expected cash flows, not only will this conflict with the precepts of FASB statement of Accounting Concepts No. 1 (Para. 25), but may discourage financial institutions from offering the vehicle. It has been shown that regulated financial institutions will sacrifice cash flow so as to maintain regulatory income. (Scholes, Wilson, and Wolfson 1989).

An example of the effects of uncertain and unfavorable accounting rules is Providential corporation, the first publicly held company formed for the purpose of issuing conventional (non-insured) reverse mortgages. It issued its prospectus on February 10, 1992. There was no problem with the company's accounting treatment of its reverse mortgage portfolio. In a letter dated July 14, 1992, the securities and Exchange Commission ("SEC") notified the company that it must change it method of accounting for reverse mortgages. The SEC advised that in accruing income from reverse mortgages, the company was permitted to incorporate actual 
increases in underlying property values, but was required to incorporate decreases in projected property values. Projected increases in property values were precluded. After the announcement, Providential stock dropped from around 11 to 6 $1 / 2$, although it had actual cash of $\$ 11$ per share. ${ }^{11}$ After negotiations, the company agreed that the new rules would be effective for loans issued after January 1, 1992. For prior loans, interest could continue to accrue until the loan balance exceeds 70 percent of the home's fair market value (Providential 1992b).

Due to pressure from the American Association of Retired Persons (AARP), the SEC changed its mind, issuing a memorandum outlining its new position (Harney 1992). The nine point memorandum, which applies to uninsured reverse mortgages, permits the use of projected property values in computing income (SEC 1992). It requires an annual calculation of the actual and expected return from each mortgage pool using appropriate statistical techniques (Monte Carlo simulation is specifically mentioned) for projected future cash flows. If the expected return from a pool is either higher or lower than the previous year, the income from the pool is adjusted appropriately. For example, assume a mortgage pool was projected to return 9 percent at the end of 1992. After

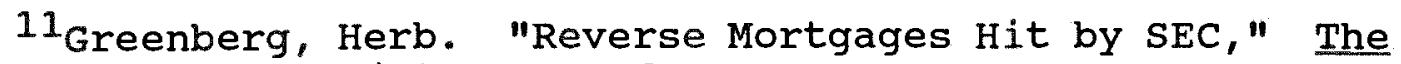
San Francisco Chronicle, 29 July 1992, B1. 
including actual 1993 cash flow and revising assumptions on projected home values and based on actual life expectancy, the return is expected to be 10 percent. The financial institution would report income from reverse mortgages in 1993 as the total amount that would have accrued since the beginning of the mortgage using a rate of 10 percent less the total amounts accrued in 1992 and prior years.

The memorandum also provides seven disclosures that are required in the footnotes of the financial statement. These include, for example, the accounting policy used, statistical methods, and nature and source of significant assumptions. It also requires a sensitivity analysis showing the impact on the effective yield, net income and retained earnings assuming property values do not change or that property values increase at one percentage point less than projections.

According to the President's letter in Providential's 1992 annual report, the new rules did not significantly affect Providential's earnings. Providential stock closed at $83 / 4$ at the end of 1992. Providential claims that potential lenders are weary about extending financing, fearing that the SEC might change its mind. ${ }^{12}$ The SEC rulings may have hurt others in the industry as well. American Homestead Inc. had been the first reverse mortgage lender in 1983, but had been

12 "Reverse Mortgage Lender still Has Trouble," National Mortgage News, 3 May 1993, p. 5. 
inactive for a few years. An initial public offering was registered with the SEC in May 1992.13 A year later, the stock has not been issued. Capital Holding, a large insurance company, abandoned its reverse mortgage program after five years. One reason given was that the new accounting rules diminish the profitability of the mortgages (Manning 1993). 2.3.2 Income Tax Issues

There are four basic tax policy issues that relate to this research. These are: (1) ambiguous law, (2) horizontal equity, (3) vertical equity, and (4) tax subsidy. If the tax law relating to a HEC vehicle is ambiguous, then both homeowners and financial institutions will avoid the vehicle or seek a higher return in exchange for the higher risk. The tax treatment by the homeowner or the financial institution may be ambiguous because of lack of guidance from the tax authorities or because of an adverse, but challengeable, position taken by the tax authorities. An adverse position by the tax authorities may also raise the question of horizontal equity. Horizontal equity seeks to tax similar transactions in a similar way. Vertical equity seeks to impose tax based on ability to pay; persons with a greater ability to pay should pay a higher tax. If the government provides a tax

${ }^{13} \mathrm{~W}$., Michael, "Company Known for Reverse Mortgages Sets IPO," Philadelphia Business Journal, sec. 1 p. 13. 
incentive for a particular transaction, it is known as a tax subsidy. Tax subsidies are often called tax expenditures.

Issues of ambiguous law and horizontal equity are addressed along with each plan discussed in this chapter. Tax equity and tax subsidy are tested and are discussed in the next two chapters. It is not possible to test horizontal equity statistically, because each vehicle has different risk characteristics.

\subsubsection{Social Welfare Issues}

The median household income of FHA HECM mortgagor is only $\$ 7,572$ and their median Social security income is $\$ 7,005$ (HUD 1992). Thus, it is likely that many of the homeowners using home equity conversion are eligible for public assistance. The form of HEC affects the supplemental security income (SSI) and other public assistance. SSI has an asset test and an income test. None of the HEC plans affects the asset test; the value of the home and other assets that are not controlled by the recipient (e.g., annuities) are excluded from the test. However, income received from the annuities from SLs and SIs could be considered income for purposes of the income test, and therefore possibly reduce SSI assistance [Scholen 1991, 45, citing 20 CFR Sec. 416.1121(c)]. There is evidence that the Social Security Administration may be flexible on this point. The Social Security Administration issued a favorable determination that annuity payments from an SI plan sponsored 
by Arkansas would not be included in income for purposes of eligibility for SSI (ABA 1986). Since the HECM is a loan, it is not included in the income test. Note, however, that if part of the annuity received by the homeowner under any of the three plans is not expended, then the cash received and the income thereon is included in the asset and income tests. Although state assistance laws often follow federal standard, some state assistance programs might have different qualifying tests.

\subsubsection{Liquidity Issues}

There is anecdotal evidence suggesting that one obstacle to increased availability of home equity conversions is the lack of liquidity to the financial institution. As of August 1992, the Federal National Mortgage Association (FNMA) purchased about 94 percent of the FHA HECM mortgages issued (HUD 1992, p. 3-14). The remaining 6 percent are either in process or are loans that FNMA would not accept. HUD (pp. 314 to 15) recognizes the importance of the secondary market in developing the product (implying that FNMA has essentially dictated the market terms). HUD also notes the importance of securitization. It further notes that FNMA does not believe that the FHA mortgage can be securitized. Therefore, HUD concludes that due to the annuity-like structure of reverse mortgages, insurance companies are likely to be the only investors comfortable with the variable payment stream. 


\subsubsection{Profitability Issues}

The FHA HEC project is designed to break-even (HUD 1990, p. 3-10). If the project is unprofitable, the cost will be borne by the taxpayer. In addition, government programs normally should be employed to supplement and not compete with the private sector. An unprofitable FHA program may discourage private companies from entering into the home equity conversion market.

The FHA program has been criticized for being too liberal in its assumptions (see, e.g., speare (1992). Phillips (1991, 37), an executive of Capital Holding Corporation, a private HECM lender (at that time), had the following comments:

[B]eing in the reverse mortgage business is sort of like being in the jungle with an 800 pound gorilla. As long as the gorilla is going the way you want him to, it's helpful to follow along through a cleared path. But if the gorilla decides to turn on us, we're dead. . . . FHA is largely confining its activities to the neediest homeowners whose home values are too small to make a private program worthwhile, at least for now. . . . So far, segmentation has limited most of our cost and design concerns about the FHA program to a question of how much it will ultimately cost us as taxpayers.

Szymanoski (1992), who developed the FHA plan, admits that some FHA assumptions may be too liberal and cites two reasons for this. First, liberal assumptions are counterbalanced by conservative assumptions. For example, not all homeowners will use the maximum benefits allowed under the plan, either by election or by owning a home with a value of 
over the FHA limits. Second, whereas the forward FHA program provides for a refund to qualifying homeowners of excess premiums collected, this does not exist for the HECM program. Such a policy imposes a greater duty to avoid overcharging premiums, particularly where the borrowers are poor and elderly.

Expanding on this duty, szymanoski (1993b) appears to make the argument that the FHA's market is the elderly poor and that the private market should limit itself to the upper and middle classes:

I smile when I recall Bill [Phillips'] metaphor of the 800 pound gorilla. Bill's comments I think were made in the context of a business "competitor" who did not really appreciate the market segmentation between his product and the FHA program. He is not the only person to have pointed out some of FHA's generous assumptions. . ., but he clearly has not recognized that FHA's market is much lower in income than Capital Holding's market. I've always felt that this market segmentation justifies FHA's use of more liberal underwriting assumptions, particularly with regard to mortality assumptions.

Even if it is assumed that liberal assumptions are permitted, it is important to know what the effects of the assumptions are to the profitability of the entire model. The overview of the assumptions of the FHA model later in this chapter will include the specific criticisms of the model. 
The home equity conversion mortgage ("HECM") is the most common form of home equity conversion. The HECM is often called a reverse mortgage because it is the opposite of a normal (forward) mortgage. In a forward home mortgage, the borrower receives a lump-sum payment equal to the value of the loan (a percentage of the home's value) in exchange for a contractual set of payments to be made in the future. By combining two formulas, 14 The amount of each periodic payment for a standard self-amortizing mortgage is:

${ }^{14}$ The computation is based on the standard formula for the present value of an annuity of $\$ 1$ per period (Reilly 1985, 871):

$$
P V A_{\$ 1}=\frac{1-\frac{1}{(1+k)^{n}}}{k}
$$

and the formula for the periodic payment is

$$
A=\frac{P}{P V A_{\$ 1}}
$$

Where

$A$ is the required periodic payment;

$\mathrm{PV}_{\$ 1}$ is the present value of $\$ 1$ per period;

$\mathrm{n}$ is the number of periodic payments required;

$k$ is the periodic interest rate; and

$P$ is the amount borrowed.

The computation of the formulas for determining the maximum line of credit and the periodic payment for a term mortgage are combined in a similar manner. The underlying components of these mortgages will not be separately stated. 


$$
A=\frac{P k}{1-\frac{1}{(1+k)^{n}}}
$$

Where

$A$ is the amount of the periodic payment:

$\mathrm{P}$ is the amount borrowed;

$\mathrm{n}$ is the number of periodic payments to be made; and

$\mathrm{k}$ is the interest rate per period.

The repayments include interest on the outstanding loan balance and the repayment of the principal for the mortgage term. Over time, the loan balance is reduced and at the end of the mortgage term, the loan is paid off. In the HECM, the borrower receives no lump-sum payment at the inception of the loan. Instead, the borrower receives money periodically from the lender, and the outstanding loan balance increases over time due to the periodic payments and the accrual of interest. The loan is paid-off in a lump-sum when the borrower either moves or dies, or at a contracted future term date.

There are three types of HECMs, namely line of credit, term, and tenure. A line of credit home equity conversion mortgage is similar to a standard home-equity loan. The principal difference is that the line of credit HECM by its terms need not be repaid until the borrower vacates the home or dies. In addition, a line of credit HECM is likely to be without recourse. The general formula for the amount of a line of credit HECM is 


$$
P=\frac{F}{(1+k)^{n}}
$$

Where

$P$ is maximum allowed line of credit;

$k$ is the interest rate per period;

$\mathrm{n}$ is the number of periods before the loan is due;

and

$\mathrm{F}$ is the amount due at the end of $\mathrm{n}$ periods.

A home equity conversion term mortgage, makes periodic payments to the borrower up to a fixed due date, or the date the borrower vacates or dies (if earlier). If the borrower remains in the home at the due date, most HEC term mortgages require that the mortgage balance be repaid; however, the FHA HEC term mortgage does not require repayment until the borrower vacates or dies. The formula for determining the periodic payments of a standard home equity conversion term mortgage (which must be repaid on a fixed date) is

$$
A=\frac{F k}{(1+k)^{n}-1}
$$

Where

$A$ is the periodic annuity payment; 
$k$ is the periodic interest rate;

$\mathrm{n}$ is the number of periods the annuity is paid; and

$F$ is the mortgage balance at the end of period $n$.

The tenure mortgage, pays (actually lends) the borrower a fixed annuity for life or until the house is vacated; it does not matter if the mortgage principal increases above the value of the home. At the end of the mortgage term, the house is sold and the mortgage is repaid. The monthly payment for a tenure mortgage is computed in the same way as a term mortgage, except that the mortgagee uses a formula to determine $\mathrm{n}$ (the expected number of periods the annuity is to be paid). Since tenure mortgages are generally without recourse, if the value of the home at the end of the mortgage term is less than the mortgage principal, the property is handed over to the lender.

The risks to a lender are different for a tenure mortgage than for a normal forward mortgage. Since the borrower makes no mortgage payments, default risk is limited to the borrower's inability to pay for property taxes, insurance, or maintenance costs of the home. The major risk is that the borrower will outlive his/her life expectancy, which is diversifiable, or that the home value at term will be less than projected at mortgage origination, which is partially 
diversifiable $e^{15}$. In a forward mortgage the borrower is not concerned with the financial stability of the lender, at most, the lender can misappropriate the borrower's escrow account. In a HECM mortgage, the borrower is concerned that the lender won't meet its contracted future annuity payments. One advantage of an insured HECM mortgage over a conventional mortgage is that the insurance protects both the financial institution and the borrower.

The remainder of this discussion is divided into the following sections:

Conventional HECM products;

The FHA HECM;

Accounting for the insured HECM; and Taxation of the HECM.

2.4.1 Conventional HECM Products

It should be noted at the outset that detailed information on conventional mortgage products is often not available. Some programs no longer exist and most of those that do exist often only provide the minimum amount of

${ }^{15}$ The risk that an individual property increases in value at a rate lower than the increase for property values in general is largely diversifiable. That portion of the risk that represents a skewness in expected returns in relation to the variance in property value increases is not diversifiable. In addition, the risk that overall property values do not increase at the rate expected is a non-diversifiable market risk. 
disclosure required by law. Details of specific assumptions and methods are considered proprietary.

The earliest reverse mortgage programs often looked much like their forward mortgage counterparts. A prominent example of this type of program was the Reverse Annuity Mortgage ("RAM") Program of the San Francisco Development Fund. The RAM program was structured so that the agency acted as a broker between the elderly homeowner and the provider of funds. The total number of loans originated under the plan was 234 (Weinrobe 1988). These were fixed rate mortgages with a maximum maturity of 12 years (but 10 years was the longest term generally suggested). Loans were due at maturity even if the homeowner were still living in the house. The maximum final loan balance was limited to the smaller of 80 percent of the initial property value or $\$ 150,000$. Loans with a final balance of less than $\$ 50,000$ were not accepted. Loans generally provided for level monthly payments for the period of the loan, although a graduated payment schedule (in which payments increased by 6 percent per year) was also available (Weinrobe 1987).

Assuming the home is an investment, Tate (1987) examined HECMs from the homeowner's perspective. An underlying assumption was that the home is leased to a third party at fair market value). First, he found that the internal rate of return ("IRR") of a typical home in orlando, Florida is 8.92 
percent plus the inflation rate, yielding an expected return of 13.12 percent with a standard deviation of about 1 percent (after transaction costs). He then added a HECM with a 10 percent interest rate. In general, he found, as would be expected, that if the IRR on the property is higher than 10 percent, the HECM results in a higher rate of return on the investment. Surprisingly, the addition of the HECM did not materially affect the expected return its standard deviation. Finally, he concluded that the risk adjusted rate of return on home ownership was favorable when compared to alternative investments (the risk free investment and the $S \& P 500$ index). His study suggests that from an investment standpoint, using home equity for additional income is preferable to disposing of the equity and using the proceeds to rent.

The typical term reverse mortgage had drawbacks to both the homeowner and the financial institution. If the homeowner lived beyond the term of the loan the homeowner could be forced out of the house by foreclosure. Due to the conservative terms of the mortgages, the financial institution had little default risk on the mortgages (see Weinrobe 1988). However, it was placed in the unenviable position of being the "Scrooge" that evicts an elderly widow from her home (see Archer and Nye 1987). Two economic studies of home equity conversion investigated the insurance premium needed to insure 
a term HECM. Weinrobe (1988) noted that the Florida Home Equity Conversion Act, Sections 697.202 - 697.206 Florida Statutes (1986) authorized an insurance program to guarantee lenders against default for a term HECM with requirements similar to that in the RAM program. ${ }^{16}$ As noted by Weinrobe (p. 647), this would only insure against depreciating home values. Using simulation, he explored the economics to the insurer of three possible insured plans: (1) a ten-year term HECM with the full amount due at the end of the term (similar to the Florida program); (2) a term HECM with ten years of annuity payment and deferred repayment when tenure is completed; and (3) a tenure mortgage. In addition, he investigated a modified second plan in which the insurer is assumed to purchase the mortgage at the end of the term instead of providing insurance. In each of the four cases, an annuity payment would be provided that results in a mortgage balance equal to 80 percent of the current home value at the end of the term (or the homeowner's life expectancy with a tenure mortgage). He examined the required premium for these models for a 75 year old woman assuming various rates of increase in the value of the home. For example, he found that a tenure mortgage would require an up-front insurance charge

${ }^{16}$ The insurance program was never implemented (July 10, 1993 telephone interview with Mary Ann Hoffman, Community Assistance Consultant, Florida Housing Finance Agency). 
of 5.8 percent of the home value, or an annual fee of 0.6 percent of the disbursements paid.

Archer and Nye (1987) developed a model for pricing the insurance for an unusual HECM; the model assumes the lender is the insurer. They assumed that a lump-sum HECM, in which a lump-sum is provided which would result in a terminal value equal to the expected value of the home when tenure is deemed to end and would produce an insurance premium of zero. Like Weinrobe (1988), they used simulation, varying the assumptions of their model. They noted that the maximum net benefit (i.e., the lump-sum payment) is sensitive to changes in assumptions, particularly for younger homeowners. For example, they found that a one percentage point increase in pre-death terminations would increase the maximum net benefit by over 10 percent for homeowners under age seventy. Also, by using an annuity table to find life expectancy instead of life tables would reduce payments by 22 percent for ages 60-69 and 13 percent for ages over 90 .

American Homestead, Inc. was one of the first to offer a HECM that guaranteed payments for life. American Homestead began research on HECMs in 1981 (when the RAM program began). In late 1983 American Homestead introduced its reverse shared appreciation mortgage (RSAM), which it called The century 
Plan $^{\mathrm{TM}}$ (Leban 1984).17 Garnett and Guttentag (1984) developed a simulation model to evaluate a RSAM based on American Homestead's parameters. Clearly the model, which was essentially a capital budgeting model, was used to develop American Homestead's plan. The main features of Homestead's RSAM were that it guaranteed life tenure in the home and life time payments (unless the homeowner sold the home). To provide a reasonable income to the homeowner, the lender participated in the appreciation of the house (a 50 and 100 percent options were available). Life expectancy was determined using sex based 1971 Annuity Tables. An undisclosed factor for move-outs was used, but the probability for move-out was reduced as the amount of the homeowner's equity was reduced. American Homestead no longer offers a reverse mortgage product. As discussed in section 2.3.1, American Homestead registered an initial public offering with the SEC in early 1992, presumably to begin offering more reverse mortgages, but the stock was never issued.

In 1985, Capital Holding Corporation, a large insurance company, instituted its HECM, which it called the Home Income Security plan. The plan provided a tenure home equity conversion mortgage (i.e., the payments continued and the loan was not repaid until the homeowner dies, sells the house, or

${ }^{17}$ Leban, Vice President and Corporate Counsel of American Homestead Mortgage Corporation, also summarizes the problems, including legal problems, in developing the product. 
permanently moves away). The plan charged an up front "fixed premium" of 7 percent of the home value to pay for risk pooling. In addition it charged a $\$ 100$ application fee and $\$ 3,000$ in closing costs. If cash advances did not exceed the premium plus closing costs at the end of the mortgage, the excess was refunded. Interest accrued at 2.5 percentage points over the ten-year U.S. Treasury securities rate and was adjusted annually. At the end of the loan, the amount that must be repaid was the least of the following three amounts: (1) the loan balance; (2) 93 percent of the fair market value of the house when the loan is repaid; or (3) the initial value of the house at the time the loan was made increased by a rate equal to the increase in the Consumer Price Index plus 1.3 percent. The company allowed a homeowner to mortgage only a certain portion of the property. For example, a homeowner may set aside 25 percent of the value of the home. All mortgage calculations would be made on 75 percent of the value. When the home is sold, again all mortgage calculations would be based on a 75 percent interest in the home; twenty-five percent of the sale proceeds would go to the homeowner or the homeowner's beneficiaries (Scholen 1991; 1992, 250-260). As stated in Section 2.3.1, in April 1993, Capital Holding decided to cease its HECM product. It cited as reasons (1) the lack of consumer interest, (2) an expected lower increase in home values, and (3) unfavorable accounting rules, 
particularly relating to the 7 percent "fixed premium" (Manning 1993).

Providential corporation markets a tenure reverse mortgage, primarily in california. It introduced its first tenure mortgage in 1988. The mortgage was similar to that offered by American Homestead (Klein and Sirmans 1993, 34). The mortgage contains a set aside feature similar to Capital Holding's. Unlike Capital Holding, the mortgage is a fixed rate mortgage that generally has a higher rate than typical forward mortgages. In addition, mortgages issued before 1991 contained a shared appreciation provision, which Providential calls a "Premium." Providential suspended funding of its reverse mortgage in October 1990 due to lack of funding. During the three-year period it made 748 loans (out of 30,000 inquiries). As stated in Section 2.3.2, Providential made an initial public offering in early 1992 to provide funding for additional loans. According to its prospectus (Providential 1992), it expects that new loans will be similar to the pre1991 loans, except that the Premium will be a fixed charge payable over the term of the mortgage instead of a percentage of the appreciation in the property.

In March 1993, Transamerica announced that it was entering the reverse mortgage market with the Home Income Plan. This plan is interesting because it was specifically designed to be securitized. The mortgage generally requires 
an initial home value of at least $\$ 125,000$, which is generally above the FHA limit. The mortgage is divided into three parts: (1) a lump-sum payment, (2) a reserve account, and (3) a life annuity. The lump-sum payment for a previously unmortgaged home must be at least $\$ 1,000$ and less than 8 percent of the loan value. The reserve account, which is limited to the lesser of $\$ 7,500$ or 3 percent of the equity in the home, is designed to cover unexpected expenses. Unlike a line of credit, the reserve account cannot be reborrowed; once drawn, amounts can be repaid, but not reborrowed. The unused portion of the reserve account available increases by 3.5 percent a year. The annuity feature of the mortgage is different from other reverse mortgages. Instead of the lender making monthly payments to the borrower, the lender purchases an annuity from an insurance company. An advantage of this is that the annuity is for life and does not end if the house is sold. (Transamerica Homefirst [1993]). Transamerica fails to mention three major disadvantages to the use of an annuity:

(1) The annuity not only has an initial closing fee, but probably is based on a lower interest rate than the mortgage;

(2) Unlike mortgage payments, the annuity payments may not be considered income for purposes of computing public assistance eligibility; and 
(3) Unlike mortgage payments, the interest portion of the annuity payments is subject to federal and possibly state income taxes.

Ignoring property value limitations, payments under the Transamerica plan, given the same interest rates, are similar to FHA's. Using an example furnished by the company, 18 monthly payments would be about 4 percent lower than under the FHA plan.

\subsubsection{The FHA HECM}

In 1987 Congress authorized a demonstration project in which HUD could insure 2,500 HECMs through september 30, 1991 (HUD 1990, I-3). This program was later increased to allow 25 thousand HECMs through september 30, 1995 (Roma 1991). As of mid-August 1992, 2,155 loans had been closed and 367 loans were being processed and there were 52 lenders ${ }^{19}$ in 38 states offering the FHA HECM mortgage (FHA 1992, ES-1 and ES2). As stated in section 2.3.4, nearly all HECM loans are eventually purchased by the Federal National Mortgage Association (FNMA). Wendover Funding, a North Carolina firm manages servicing for most HECM lenders. Wendover services or sub-services loans for 45 of the 57 institutions that have participated in the program.

${ }^{18}$ Data comes from a one page undated news announcement by Transamerica Homefirst.

${ }^{19}$ since inception, 57 lenders have participated in the program. 
Apparently most lenders do not consider the reverse mortgage program to be a major profit center, since most lenders transfer both the mortgages and servicing to a third party, Although many lenders are interested in the future market potential of the product, most lenders view public service as the primary reason for participation, according to the FHA. Lenders subject to the Community Reinvestment Act ("CRA") view the program as a safe way to improve their CRA ratings. Finally, lenders believe that they receive positive public relations from participating in the program (HUD 1992, pp. 3-1 to $3-5)$.

The FHA demonstration project provides the homeowner with a choice of three non-recourse mortgages: (1) a line of credit mortgage, (2) a term mortgage, and (3) a tenure mortgage. Under the FHA program, the homeowner is required to repay the loan only if the homeowner dies or if the property is not owned and properly maintained 20 as the homeowner's principal residence, 21 but may be pre-paid, without penalty,

${ }^{20}$ The lender can foreclose on the property if taxes and insurance are not being paid or if the homeowner fails to make repairs necessary to keep the property in an "acceptable" condition (HUD 1989, p. 9-16).

${ }^{21}$ Homeowners are required to certify annually that the home is maintained as a principal residence and should advise the lender of all absences from the home in excess of two months (HUD 1989, p. 9-15). HUD notes that if the mortgage balance exceeds the value of the property, borrowers or their heirs may be tempted to fraudulently claim the house as a principal residence. HUD suggests that after the program is active for a number of years, it may wish to check residence 
at any time (HUD 1989, pp. 9-14 to 9-16). For term and tenure mortgages, the borrower may elect a line of credit set aside, but no set aside from the lien of a portion of the house (as allowed by Capital Holding and Providential) is permitted. 22 The line of credit can be combined with either a term or tenure mortgage. Of the initial 2,155 borrowers, 51.2 percent elected the line of credit mortgage, 15.7 percent elected the term mortgage and 10.4 elected the tenure mortgage; the remaining 22.7 percent elected a term or tenure mortgage with a line of credit set aside (HUD 1992, p. 2-18).

The remaining part of this section describe the borrower qualifications and loan limits, interest and other charges, FHA's model assumptions, and computation of the FHA HECM. 2.4.2.1 Borrower Qualifications and Loan Limits

To be eligible for a reverse mortgage, a borrower must be at least age 62 and occupy the home as a principal residence. The property must be a single family residence 23 free of prior liens and must meet HUD property standards (including HUD qualification of condominium associations and planned unit

information against social security and tax records.

${ }^{22} \mathrm{~A}$ lien set aside is probably not a significant feature due to the low property limits on FHA loans.

$23_{\text {HUD }}(1990$, p. 4-7) notes that a self contained rental unit in the home would disqualify the property, but a rented room would not. Although a duplex would generally not qualify for a mortgage, if a separate legal description can be written for one half the property, then the HECM mortgage can be written for the half occupied by the eligible homeowner. 
developments). The program allows proceeds of the loan to be used to pay off existing mortgages or to (a certain extent) pay for repairs necessary to meet HUD property standards. (HUD 1990, p. 2-2). Loans may be made to joint owners, providing all owners are over age 62 . Once made the loan would continue to qualify as long as the home was a qualified residence for at least one joint owner. For example, the HUD (1990, p.4-3) provides as an example that four unrelated friends would be eligible for the loan. 24

FHA bases its computations on a house's "maximum claim amount." Generally, the FHA HECM loan uses the current appraised value of the house to determine the maximum claim amount. However, if the home value exceeds the maximum FHA mortgage for a given area, the maximum claim amount equals the amount of the FHA maximum mortgage limitation. The FHA maximum mortgage limitation varies from $\$ 67,500$ to $\$ 151,725$ (HUD 1992, p. 1-12).

The statute authorizing the HECM demonstration requires potential borrowers to receive counseling from an approved third party independent of the lender (HUD 1992, p. 1-10). Counseling focuses on the different types of HECMs available, the suitability of the HECM for the borrower, and alternatives to the HECM (HUD 1989, p. 1-5). Due to the shortage of

${ }^{24}$ It is not totally clear what would happen if one or more of the co-owners transferred their interest to a non-coowner of the property. 
counselors, the counseling requirement has been widely criticized as creating a bottleneck in the system. HUD recognizes that this problem has made it difficult to begin offering FHA HECM mortgages in some areas, particularly rural areas (HUD 1992, pp. 4-3 to 4-4). Most of the qualified counseling organizations are governmental agencies or nonprofit organizations that are prohibited from charging the homeowner. The law prohibits a lender from financing the counseling. While HUD reimburses these outside counselors, it admits that the reimbursement may be less than actual costs (HUD 1992, p. 4-5).

\subsubsection{Interest and other Charges}

The FHA does not establish required interest rates. Interest rates may be either fixed or variable. For variable rates, the lender must use the one year constant maturity, U.S. Securities, as the base rate. The rate may be adjusted annually with a 2 percentage points annual cap and a 5 percentage points lifetime cap. Or, it may adjust monthly with no annual cap and a lifetime cap set by the lender (HUD 1989, p. 1-4). Since FNMA purchases all FHA HECM mortgages, its policies are critical. FNMA will only purchase variable rate mortgages (HUD 1992, p. 3-14). FNMA requires that mortgages that adjust annually be set 160 basis points above the base rate and mortgages that adjust monthly be set 105 
basis points above the base rate (Barriere 1991).25 Interest accrues using the variable rate. However, for purposes of determining amounts that may be loaned, the mortgage is treated as if it were a fixed rate mortgage. The "as if" rate is the U.S. Treasury securities rate adjusted to a constant maturity of ten years plus the lender's margin (HUD 1989, p. 1-2). For example, for purposes of determining the amount of a tenure HECM annuity that would be paid, an annually adjusted loan purchased by FNMA would be considered a fixed rate loan with an interest rate 160 basis points above the U.S. Treasury securities rate adjusted to a constant maturity of ten years. Interest would continue to accrue at a variable rate based on the U.S. Treasury securities rate adjusted to a maturity of one year.

A shared appreciation mortgage is also available, but the amount of the appreciation cannot exceed 25 percent of original appraised value and cannot cause the effective interest rate for the last twelve months of the loan to exceed 20 percent (HUD 1989 , pp. 6-11 to 6-12). Lenders must also co-insure shared mortgages. Due in part to these limitations, and because FNMA does not purchase shared appreciation mortgages, not one shared appreciation mortgage has been issued (HUD 1992, p. 3-15).

${ }^{25}$ Monthly adjustment will maximize the homeowner's loan available under the program. 
Lenders may charge borrowers for out-of-pocket costs, such as appraisal and title fees plus an origination fee. origination fees are designed to cover the lender's cost for originating and closing the loan. Under FHA's forward mortgage program, origination fees are limited to 1 percent of the mortgage amount. Under the reverse mortgage program the fee itself is not regulated; however, the amount that can be financed by the mortgage is limited to 1 percent of the maximum claim amount. HUD reports median closing costs of FHA HECM mortgages at $\$ 2,962$, with ranges from $\$ 2,000$ to $\$ 4,400$ (HUD 1992, p. 2-25).

FHA permits, but does not require, lenders to charge borrowers a flat monthly fee for servicing the loan. The fee is accrued monthly as earned. The standard fee structure ranges from $\$ 25$ to $\$ 35$ per month (HUD 1992, p. 3-13).

The FHA mortgage insurance premium is 2 percent of the maximum claim amount on origination and a monthly fee of $1 / 2$ percent per year on the mortgage balance (HUD 1989, pp.6-8 to 6-9). This is a lower premium than that computed by Weinrobe (1988), discussed in section 2.4.1. FHA offers a shared premium option, in which the lender participates in the insurance premium in exchange for taking part of the risk, but no lender to date has agreed to participate under this option. Under this option, the lender must hold the mortgage until maturity. If the premiums are not shared, the lender may 
assign the loan to the FHA any time after the balance of the loan exceeds 98 percent of the maximum claim amount. (HUD 1992, pp. 1-15 to 1-16). Thus, for a $\$ 100,000$ house, under the FHA limit, the lender would have a "put" on the mortgage once the mortgage balance exceeds $\$ 98,000$. This effectively puts a limit on the term of the loan.

\subsubsection{FHA Model Assumptions}

The FHA program has five major model assumptions, all of which can be questioned. The first assumption, just discussed, is the method of converting variable interest rate mortgages to a theoretical fixed rate mortgage for computing allowable mortgage amounts. FHA contends that the ten year constant maturity rate is the market's best estimate of the average interest rate over a ten year period using the one year constant maturity rate (Szymanoski 1990, 25). The problem with this method is that the FHA receives no premium for taking the interest rate risk. If the average interest rate is below the ten year rate, the borrower gets the benefit. The FHA incurs the loss if the average rate is above the ten year rate. Consistent with the FHA's reasoning from financial theory, it should charge an additional premium for the difference between the one year and the ten year rates.

The second assumption is that property values will increase by 4 percent per annum. This rate is less than that used by other programs. For example, as explained in section 
2.4.1, Capital Holding assumed that property value would increase by 1.3 percentage points higher than the consumer Price Index. The FHA assumed rate of increase is lower than Capital Holding's for increases in the Consumer Price Index in excess of 2.7 percent. Speare $(1992,4)$ argues that the elderly are likely to have different changes in property values than the population at large. They are more likely to live where property values are declining or where the rate of appreciation is low. Szymanoski (1990) stated that the FHA did not find evidence to support this hypothesis. Using data from the national longitudinal sample of the Annual Housing Surveys from 1974 to 1983, he found that average home appreciation was .083 for all homeowners $(\sigma=.017)$ and .076 $(\sigma=.016)$ for the elderly. He concluded that the two rates were not significantly different (pp. 30-31).

Additionally, speare argues that housing values will not increase in the future at the same rate as in the last two decades, due to the demographics of the "baby boomers." speare is not the only person concerned with the future growth of home values. Mankiw and Weil (1988) concluded in their econometric study that real housing prices will fall by 47 percent by the year 2007. It was also pointed out by Capital Holding that one of the reasons for ending its reverse mortgage program was a concern over the future growth rate of home values. 
Speare further notes that even if FHA's estimate of average housing appreciation is correct, the program may still lose money due to the variance of the appreciation rate. While FHA may incur a loss if a house appreciates less than 4 percent, it can receive no gain if a house appreciates more than 4 percent. He notes, for example, that Wyoming's average appreciation rate from 1980 to 1990 was less than 0.5 percent per year.

To show the effects of changes in house prices and variances, speare computed the break-even annuity payment that would be made under the current FHA model, the FHA model with the standard deviation doubled, and the FHA model with the house appreciation cut in half. For purposes of computing the standard deviation, he assumed that homes which deviate from the mean appreciation will continue to do so. FHA uses a 10 percent standard deviation and a random walk for the progression of values on a particular house. He found that a 2 percent standard deviation under his method provided approximately the same monthly annuity as the FHA model. He found that annuity payments are extremely sensitive to both the standard deviation and the average appreciation rate, particularly at younger ages.

Although not pointed out by Speare, his data reveals that payments were about twice as sensitive to a reduction in the mean appreciation rate than to a proportional increase in the 
standard deviation of returns. For example, a 4 percent standard deviation would reduce payments by approximately onequarter and a reduction in the average appreciation rate would reduce payments by almost half. At age 80 , the higher standard deviation would reduce payments by approximately oneseventh while the lower average appreciation rate would reduce payments by approximately one-quarter. Szymanoski (1990) also points that the model is extremely sensitive to changes in average property appreciation and somewhat less sensitive to changes in its variance.

FHA decided to use the U.S. Decennial Life Tables for 1979 (female) to compute mortgage payments (Szymanoski 1990, 11). Gender specific tables are outlawed by the Civil Rights Act of 1968; female tables were chosen as a conservative measure (females have longer life expectancy than males) and because they expected a large majority of female borrowers (HUD 1990, p.5-2). Speare (1992) showed that the model is sensitive to mortality assumptions. Speare computed mortality using (1) the combined rate of mortality and institutionalization observed for females in the Longitudinal study on Aging from 1984 to 1990 and (2) the lowest mortality assumed in the Bureau of the Census projections of the U.S. population for the year 2005, plus one-half of the rate of entering institutions in the Longitudinal study. He found that payments would be significantly reduced using either of 
the assumptions. This is hardly surprising, Archer and Nye (1987), discussed in section 2.4.1, had similar conclusions. Szymanoski $(1990,38-42)$ in developing the FHA plan addressed two issues relating to the use of the life mortality table: (1) adverse selection and (2) trends in future mortality. He argued that there is no evidence that the plan would be effected by adverse selection or that future trends in mortality will significantly benefit the poor elderly. He suggested that the mortality assumptions may need to be revised based on the actual data from the demonstration project.

Since the FHA reverse mortgage becomes due if the homeowner moves, the FHA model incorporates a move-out within the mortality factor. Szymanoski (1990, 11-12) noted that studies for the general population suggest that move-out rates in relation to mortality decrease with age and range from 51.9 percent of mortality for those between ages 65-69 to 47 percent of mortality for those over age 85. The FHA model takes an even more conservative position by assuming a constant move-out rate of 30 percent of mortality for all age groups, since those who take out a reverse mortgage are less likely to move out than the general population. Thus, the 
probability of program termination $(T)$ at a given age $(x)$ is 1.3 times the probability of death (q) at the given age: 26

$$
T_{x}=1.3 q_{x}
$$

Despite the apparently conservative assumption Speare (1992) questions whether it is conservative enough. This is important because Szymanoski $(1990,54)$ found that "the model

${ }^{26}$ Combining the move-out rate into the mortality rate in this manner tends to overstate the move-out rate; the amount of the overstatement increases with age. This is the result of the law of probabilities. Where $q$ (dying) and $m$ (moving) are independent, but not mutually exclusive events, the probability of $\mathrm{q}$ or $\mathrm{m}$ occurring can be stated as:

$$
P_{q+m}=P_{q}+P_{m}-P_{q} P_{m} .
$$

By substituting $1.3 \mathrm{q}$ for $\mathrm{P}_{\mathrm{q}+\mathrm{m}}$ (from the FHA model), and solving for $\mathrm{P}_{\mathrm{m}}$ the following relationship is obtained:

$$
P_{m}=\frac{.3 P_{q}}{1-P q}
$$

As the denominator of the above fraction decreases with age, the probability of moving becomes a larger percentage of the probability of dying. The relationship at various ages is as follows:

$\begin{array}{rc}\text { Age } & \underline{P}_{\mathrm{m}} / \mathrm{P}_{\mathrm{q}} \\ 65 & .304 \\ 70 & .307 \\ 75 & .311 \\ 80 & .318 \\ 85 & .331 \\ 90 & .352 \\ 95 & .383 \\ 100 & .418\end{array}$


is quite sensitive to changes in the move-out rate." The model can also be criticized for not adjusting move-out rates for changes in home equity as was done by American Homestead (see section 2.4.1).

The FHA model makes no adjustment for joint ownership. Instead, mortgage assumptions for joint ownership are based on the youngest joint owner. This is clearly the easiest assumption to attack. Szymanoski defends the assumption on the bases that (1) the joint lives of owners with a wide age disparity are close to the single life of the youngest owner; (2) no one can predict whether the death or move-out of a joint owner will increase the likelihood of move-out by the other owner; and (3) the use of female tables is a conservative assumption that offsets this risk, in part. The primary reason for the assumption is administrative convenience. In a report to congress (HUD 1990, p. 5-2), HUD said that the use of joint mortality tables would increase the complexity of the computations (which it admits is complicated enough) for a group that was expected to obtain only 25 percent of the mortgages. 27 To summarize HUD's position: "Joint borrowers with similar ages do have higher joint mortalities, but correcting for this effect at this stage is unlikely to substantially affect the actuarial soundness of

27 The estimate was fairly accurate. According to HUD (1992, p. 2-7), approximately 29 percent of all loans are to joint owners. 
the program and would introduce a kind of spurious precision given the lack of program experience to guide the choice of actuarial assumptions."

4.2.2.4 Computation of the FHA HECM

The backbone of the FHA model is the concept of "principal limit" (See HUD 1989, pp. 6-1 to 6-4). For a house under the FHA limit, the principal limit is computed by taking the present value of the house at the expected termination date. The discount rate is the expected interest rate plus the monthly insurance rate. It is also assumed that the house will increase in value by 4 percent per year. For example, assuming annual rather than monthly calculations, if a homeowner with an expected termination date in ten years obtains a 9.5 percent mortgage on a $\$ 100,000$ house, the principal limit is $\$ 57,070$, computed in two steps. First, the expected value of the home on the termination date is the future value of the house in ten years using a 4 percent appreciation rate; this is $\$ 148,024$. The $\$ 148,024$ is discounted to its present value at 10 percent (interest plus insurance premium) to arrive at $\$ 57,070$. Initial costs, including the 2 percent up-front insurance premium, closing costs, and repair costs are subtracted from the principal limit to arrive at the "net principal limit." Assuming that initial costs include $\$ 2,000$ of insurance premiums and $\$ 2,000$ of other costs, the net principal limit would be $\$ 53,070$. The 
net principal limit becomes the maximum line of credit allowed. For a line of credit mortgage, the net principal limit is increased each period by the expected interest rate and insurance premiums; if a line is not used, the amount of the line of credit increases each period.

Computing the periodic payments for a term mortgage requires three steps. First, the net principal limit of the mortgage is determined in the same manner as for a line of credit mortgage. If there is a line of credit set-aside, the amount of the set-aside is subtracted to arrive at the net principal limit associated with the term mortgage (HUD 1989, p. 6-8). Next, the amount of the net principal limit at the end of the fixed term is determined using the following formula:

$$
F V_{k}=P V_{0}(1+i)^{k}
$$

where FV is the future value;

PV is the present value;

$\mathrm{k}$ is the number of periods; and

$i$ is the interest rate (including insurance premium) .

The second step is to compute the expected mortgage balance (i.e., principal limit) at the end of the term. The third step involves taking the expected mortgage balance and to compute the periodic payment using Equation 3 in section 
2.4 (above). A tenure loan is computed as a term loan to age 100 (HUD 1989, p. 6-6).

2.4.3 Accounting for the Insured HECM

Whereas the SEC has developed rules that make accounting for non-insured HECMs very complex (see section 2.3.1), accounting for insured HECMs is very straight forward. The mortgagee will add any initial costs to the loan balance financed for the borrower, plus any other payments made to the borrower, and any interest, insurance premiums, or service fees accrued. Net earnings would equal the interest rate on the mortgage balance plus any net service fee income. Any profits from origination are amortized over the loan term (SFAS No. 91 1986, Para. 5). SFAS No. 107 (1991) requires disclosure of the fair market value of financial assets and liabilities.

2.4.4 Taxation of the HECM

The taxation of the financial institution is fairly simple as well. As accrual basis taxpayers, the financial institutions accrue tax on the interest (and net servicing fee) as earned (Reg. Sec. 1.451-128), the same as for accounting income. The same result would be expected for a cash basis taxpayer under the original issue discount rules of

${ }^{28}$ Unless stated otherwise, regulations referenced in this paper are Treasury Regulations found in volume 26 of the Code of Federal Regulations (CFR). 
sections 1271 to 1275 of the Internal Revenue Code of $1986^{29}$. Regulation Section 1.451-1 would probably require the financial institution to accrue income from origination fees on closing the loan, because all events necessary to earn the income are completed. 30

The taxation to the homeowner is also straightforward, but not as simple as for the financial institution. The homeowner does not include the annuity payments in income; they are loans, not income. As a cash basis taxpayer the homeowner cannot deduct the accrued interest until it is paid [see Reg. Sec. 1.461-1(a)(1)]. If the homeowner moves out, it is paid and the deduction is allowed on the first $\$ 100,000$ of loan balance [IRC Sec. $163(\mathrm{~h})(3)(\mathrm{C})(\mathrm{ii})]$. Temporary Regulation Section 1.163-11T appears to prorate total accrued interest between the portion of the loan above and below the $\$ 100,000$ threshold. The same rules would apply if the homeowner voluntarily prepaid the mortgage. Upon the homeowner's death, the homeowner's successor in interest gets the deductions. For purposes of this study, it is assumed the home is sold by the estate and all other assets distributed

${ }^{29}$ In this paper, the Internal Revenue Code of 1986, volume 26 of the U.S. Code is referred to as the "Code" or may be In references the code is abbreviated as "IRC" in accordance with convention.

${ }^{30}$ If the fees are non-refundable, using the same regulation, the IRS could argue that the fees are taxable upon receipt. 
immediately after the homeowner's death; without income to offset, the deductions have no value.

If the homeowner sells the house, gain is generally recognized in the amount of the difference between the sales price and its adjusted basis. If the value of the house is less than the mortgage, than the house is deemed sold for the mortgage balance. The homeowner may qualify for the code Section $121 \$ 125,000$ one time exclusion on the gain from the sale of the house. For purposes of this study, it is assumed that the homeowner qualifies.

Since the annuity payments do not affect income, there would be no secondary tax effects, such as taxation of Social Security income or alternative minimum tax; however, the sale of the house could have such an effect.

2.5 Split Interest

Under a split interest ("SI") plan, the homeowner sells a remainder interest in the home, while retaining a life estate. The proceeds of the sale are generally taken as a future series of annuity payments, although a lump-sum payment is possible. The annuity should either provide that the life tenant pays the costs of home maintenance and receives a larger annuity to pay for increased expenses or provide that the remainder interest pay for home maintenance, while reducing the life tenant's fixed annuity. "In either of these arrangements the party who benefits from appreciation on the 
property stands the burden of rising expenses (Guttentag 1980, 86)." Turner et al. (1982) note that since investors' returns are deferred until death and since returns are difficult to predict, private investors shy away from this type of plan. For financial institutions, uncertain or unfavorable accounting and tax implications can be added to the list.

The remainder of this discussion is divided into the following sections:

History of the SI plan;

Accounting for the SI plan;

Taxation of the SI plan; and

other policy aspects of the SI plan.

2.5.1 History of the SI Plan

There has been no successful attempt to market a for profit SI plan (Scholen 1992, 271). Some charitable organizations do have a form of SI, but it generally involves a contribution of all or part of the remainder interest to the charitable organization (Scholen 1991, 37). Code section $170(f)(3)$ allows a charitable deduction for contributions of a remainder interest in a personal residence or farm. In general, contributions of remainder interests in most property would not qualify for the charitable deduction. 31 The

${ }^{31}$ Code section $170(f)$ also permits a charitable deduction for the transfer of a remainder interest that qualifies under code section $170(\mathrm{~h})$ as a qualified conservation contribution 
charity generally provides an annuity (called a charitable gift annuity) that will produce a charitable deduction of 40 to 60 percent (Taylor 1992, 361). Taylor suggests that for some high income taxpayers, the charitable gift annuity can produce a higher annuity than some reverse mortgages. 32 A split purchase (a form of SI) has been touted as a tax shelter (see Auster 1990; Auster 1993a; Auster 1993b), but is not widely used. 33

One of the first studies of an SI plan was conducted by Chen (1973). The study focused on a survey of Los Angeles residents between the ages of 55 to 75 . The study was designed to test the degree of interest in the plan, categories of persons interested in the plan, and categories of persons not interested in the plan. Only 9 percent (41 of 455) of the respondents expressed some interest in the plan; seven respondents expressed great interest in the plan with the remainder being somewhat interested. Given the low level

or is the donor's entire interest in the property. A charitable contribution is also allowed for a remainder interest in the charity if the contribution is to a charitable remainder annuity trust, charitable remainder unitrust, or a pooled income fund (all specific trusts that must meet specific code requirements, intended to discourage tax avoidance).

32 The reason for this appears to be that the life estate is generally discounted at a lower rate than the interest rate used for uninsured reverse mortgages.

${ }^{33}$ The joint purchase tax shelter is not applicable to the joint purchase of the life tenant's personal residence. 
of interest in the plan, chen found five characteristics that were more likely to occur in the group that expressed interest in the plan than in the group that was not interested (some of which are surprising). The characteristics were: (1) having an existing mortgage, (2) having inadequate income, (3) being under age 65 , (4) being without family, and (5) having an internal (rather than external) psychological profile. ${ }^{34}$

To increase the validity of the study, the respondents were given the estimated income they would receive in exchange for the remainder interest in the house. To do this, Chen's plan had specific assumptions. In determining the value of the remainder interest and annuity, a 5 percent interest rate was used throughout. It was assumed that land values would increase by 5 percent each year, but the home itself would depreciate 4 percent each year on a straight line basis (i.e., a 25 year life). The homeowner would receive a life annuity with 10 years certain; married couples were given a joint life annuity. The annuity was computed using gender based annuity tables. The homeowner could withdraw from the transaction by

${ }^{34}$ Thus, a significant finding indicates that a given characteristic is more prevalent amongst interested homeowners than occurs in the public at large. The characteristics are not predictive; interested persons composed less than 18 percent of those with each of the characteristics. It also does not necessarily indicate that the characteristic occurs in a significant percentage of interested homeowners. For example, only 13 of 41 interested homeowners were without families. 
repaying annuity payments plus interest. 35 Finally, the plan allowed a set aside, so that the remainderperson would receive only part of the property on the homeowner's death. 36

In 1982 Buffalo instituted an SI plan, called the Home Equity Living Plan ("HELP"). HELP has a three fold purpose: (1) relieving financial burdens of the elderly, (2) improving the housing stock, particularly in certain neighborhoods with a large elderly population, and (3) creating a selfsustaining permanent program. As is clear from the objectives, the HELP program is generally limited to lower income homeowners in low income neighborhoods (i.e., inexpensive homes). Under HELP, a non-profit corporation acquires the remainder interest in the elderly homeowner's and in exchange the corporation does the following:

rehabilitates the house, (2) pays all expenses of major maintenance, insurance and taxes, and (3) makes a fixed

${ }^{35}$ This indicates that the homeowners did not fully understand chen's proposal. This provision makes the transaction a "heads I win, tails you lose" situation for the homeowner. If conditions are favorable to the remainderman (e.g., home value increase more than expected or the person expects to die before reaching life expectancy), the homeowner buys back the remainder at a favorable price. Otherwise, the homeowner lets the remainderperson get the property.

36 While this provision allows the homeowner to sell only that portion of the house that is necessary for additional income, it leads to the impractical result of the owner of the remainder interest sharing an interest in the home with the homeowner's heirs. This is not a desirable outcome for either the remainderperson or the heirs. 
annuity payment to the homeowner. After the homeowner dies, the house can be resold to provide capital to fund another homeowner (Garnett and Guttentag 1982). Although payments were initially limited to annuity payments, the current plan allows for lump-sum payments or an exchange of payments for essential services, such as for transportation or home nursing (Scholen 1991).

The HELP model contains some interesting assumptions which could be considered extremely generous. First, in order not to discourage some of those in most need of HELP, a formula was used for rehabilitation costs. The modelers conceded that the use of a formula could cause a problem of adverse selection. Second, the model assumes that house values will increase by 6 percent a year, a rate that is much higher than most other models. The exact methodology is unclear, but it appears that remainder interests are discounted at 6 percent per year based on current value and cash reserves are deemed to earn 12 percent per year (giving a total return of 11.66 percent, including appreciation). It also appears that standard annuity tables were used, with appropriate adjustment for joint lives (Garnett and Guttentag 1981). With such liberal assumptions, one would not expect the plan to be successful. However, a Buffalo counselperson advised in a telephone conversation on June 1, 1993 that the 
plan is quite successful. It continues to fund 60 homes $^{37}$ worth $\$ 1.9$ million (up from $\$ 1.6$ on inception). It is not clear whether the program is as successful as the counselperson believes. An increase in value of $\$ 0.3$ million over ten years represents an increase in value of 2 percent per year, not 6 percent as expected. It is possible that HELP is dying a slow death.

2.5.2 Accounting for the SI Plan

In the SI plan, the financial institution purchases a remainder interest (an asset) in exchange for an annuity (a liability). To account for the plan, the financial institution separately accounts for the remainder interest and the annuity. There is no accounting authority advising how to account for the remainder interest. There are three possible methods to account for the remainder interest and the costs associated with holding the remainder interest: (1) costs of holding the interest are expensed immediately (other than true capital expenditures) and no revenue is recognized for the reduced life estate of the homeowner; (2) costs of holding the interest (including annuity costs) are capitalized and no revenue is recognized for the reduced life estate of the homeowner; and (3) costs of holding the interest are expensed immediately and revenue is recognized over time for the

${ }^{37}$ Garnett and Guttentag (1982) anticipated the program to fund 80 homes. 
reduced life estate of the homeowner. It appears that the first option is closest to the GAAP model, even though the model does not closely reflect the economics of the plan. Income is recognized only on the sale of the property. This follows historical cost and is conservative. It appears that FAS 34 prohibits the capitalization of costs during the life tenancy: "The historical cost of acquiring an asset includes the costs necessarily incurred to bring it to the condition and location necessary for its intended use [emphasis provided]." For example, interest to hold land not under development cannot be capitalized (FAS 34, Para. 11). The home in an SI is already in the condition and location necessary for its intended use. The third method of accounting, which leads to the best matching of revenue and expense, does not appear to be supported by GAAP. Although the principles of FAS 60 should apply to this type of transaction, there is no evidence that the statement is intended to apply to all transactions requiring actuarial computations.

Unlike the treatment of the remainder interest, it appears that FAS 60 should be followed for the treatment of the liability to pay an annuity. FAs 60 requires that the cost of annuity payments be the difference between the present value of the annuity at the beginning of the year and the present value of the annuity at the end of the year 
(considering the annuitant's new life expectancy).

payments above that amount serve to reduce the liability account. Although FAS 60 is applicable only to insurance companies, it is reasonable to assume that it would apply to other businesses issuing insurance products.

2.5.3 Taxation of the SI Plan

Some tax aspects of the SI plan are not settled. It is not clear whether the absence of clear rules is due to the lack of interest by the public or whether the tax authorities wish to make the consequences unclear to discourage SIs. The reason for the uncertainty may not be clear, but the effect is clear. Uncertain tax consequences increase the risk of the transaction. To compensate for the increased risk, an investor will require a higher return, which makes the plan less attractive compared with other choices.

Although the taxation of an SI is not settled, a strong argument can be made that a financial institution purchasing a remainder interest is acquiring a capital asset (see IRC Sec. 1221), the sale of which (or the entire home, after the termination of the life estate) is subject to the capital gains tax. ${ }^{38}$ Although corporations are subject to the same tax rate on capital gains as ordinary income, it is advantageous to classify the income as capital gains because

${ }^{38}$ The IRS could argue that the interests purchased constitute inventory to the financial institution, and therefore ineligible for capital gains treatment. 
it can offset capital losses from other sources. Corporations may only deduct capital losses to the extent of capital gains. 39 The annual increases in value due to the depletion of the life estate is not subject to taxation.

The homeowner cannot receive the $\$ 125,000$ exclusion on the sale of a residuary interest. Revenue Ruling 84-43, 19841 C.B. 24 , held that code section 121 only applies if the elderly person disposes of his/her entire interest in the property. Thus, under current law, the SI is not appropriate if the person has a large gain on the sale of the house. If the payments were in the form of a mortgage, the installment sale rule of code section 453 could be used; however, since the SI payment is in the form of an annuity, the tax would be immediately payable.40 Unlike the reverse mortgage, the annuity payments are subject to tax. The taxation of annuity

${ }^{39}$ Capital losses not deductible in the current year may be carried back against net capital gains in the three preceding taxable years and carried forward against net capital gains in the succeeding 5 years (IRC Sec. 1212). Capital losses not deducted during this nine-year period are disallowed.

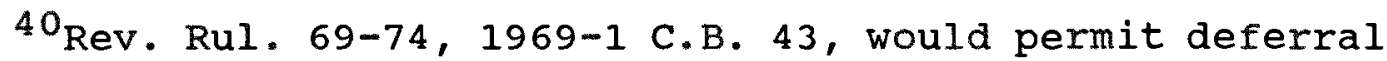
of the gain if this were a private annuity; a private annuity must be an unsecured mere promise to pay. The rule is based on the premise that this type of annuity cannot be fairly valued [GCM 37371 (1977) ]. For example, Estate of Lloyd G. Bell V. Commissioner, 60 T.C. 469 (1973), held that a secured promise to pay would not permit deferral of the gain. The case also noted that some commentators have said that the annuity must be issued by one who does not regularly issue annuities. It is unlikely that an annuity from a financial institution, even if uninsured, would qualify for private annuity status. 
payments is subject to the rules of Code section 72 , which bifurcate the annuity payments between income and return of capital based on the annuitant's life expectancy. This bifurcation is known as the "exclusion ratio." Once established, the income percentage remains constant until the annuitant's life expectancy is reached; after which, the entire annuity payment is taxed. If the annuitant dies before reaching the life expectancy, the remaining basis is deductible on the annuitant's final return as an itemized deduction not subject to the two percent floor under code section 67 (a) [IRC Sec. 67 (b)(11)].

Senator Arlen Specter introduced S. 831 on March 16, 1983. The bill provided that the sale of a remainder interest in a personal residence would be eligible for the section 121 exclusion. In addition, the bill would have allowed the purchaser of the remainder to treat the transaction as the sale of the entire interest, allowing the purchaser to depreciate the property. According to Richard D'Avino, Attorney/Advisor, office of Tax Policy, the Treasury Department officially supported the expansion of section 121, but was opposed to allowing the remainderperson a depreciation deduction. (U.S. Congress 1985, 73-79).

\subsubsection{Other Policy Aspects of the SI Plan}

The split interest plan has some beneficial features not available in a reverse mortgage. First, by transferring 
increased costs of maintenance, insurance and taxes to the financial institution, the homeowner is protected against inflation of these housing costs. Second, the homeowner is protected against unforseen or unusual costs, such as hurricane damage or the replacement of a roof (this is in contrast to the reverse mortgage where the homeowner may be forced to vacate the premises due to inability to pay for these costs). Finally, an elderly homeowner may wish to relieve the family from the responsibility of selling the house after death.

An apparent problem with the SI plan is that annuities received could constitute income for purposes of determining eligibility for Supplemental security Income. However, the American Bar Association convinced the Social Security Administration not to count the annuity given by Arkansas HELP (a plan modeled after Buffalo's HELP) as income for that purpose (ABA 1986, 14).

SIs cannot be easily securitized into a passive investment that can be sold to the public. However, SIs can be securitized by splitting the transaction into two components: the remainder interest (asset) and the annuity (liability). Remainder interests can be bundled into portfolios operated as partnerships. The partnership units would then be sold to non-profit organizations, pension plans, 
and others 41 interested in investing in single family housing.

\section{$2.6 \quad$ Sale-Leaseback}

In a sale-leaseback ("SL"), the homeowner sells his/her home to an investor, taking back a mortgage (or an annuity). The investor then rents the house back to the homeowner under a fixed long-term lease or for 1 ife. The homeowner receives mortgage or annuity payments from which he/she pays rent. Although an SL can be structured as a net lease, where the tenant pays all expenses of the property, its chief advantage is that it can also be structured so that the tenant is not responsible for maintenance. This offers partial protection against inflation. Since SLs have been used principally as tax shelters, it has been difficult to develop an SL plan that is favorable to the homeowner and the investor while meeting IRS standards for a valid SL.

The remainder of this discussion is divided into the following sections:

History of the sale-leaseback plan;

Accounting for the sale-leaseback;

Taxation of the sale-leaseback; and other policy aspects of the sale-leaseback.

${ }^{41}$ It would be of interest, for example, to corporations with histories of capital losses exceeding capital gains. since the remainder interest has a built in capital gain, the income could be considered tax free. 


\subsubsection{History of the Sale-Leaseback Plan}

The SL plan has a short history with a limited number of actual structured transactions. The Fouratt Corporation, a California real estate broker, is generally credited with developing the first SL plan not involving related parties in 1979. Under the Fouratt Senior Equity Plan (also called the Fouratt Plan), an investor purchased an elderly homeowner's home at a discount from market value. The discount, which depended on the age of the homeowner, varied from 15 to 30 percent depending on the life expectancy of the homeowner (the longer the life expectancy the higher the discount). The seller would provide a small down payment (generally 10 percent) with the remainder in a 10-to 15 -year mortgage. The buyer also purchased a deferred annuity to provide the homeowner with payments once the mortgage was repaid. Independent appraisers determined a range of fair market rent for the property and a rent in the lower end of the range was generally used. After three years the rent was increased by 40 percent of the homeowner's increase in retirement income (e.g., Social security). The seller-lessee paid for maintenance that did not exceed 10 percent of rent in a given month. Buyers were responsible for the rest (Henry 1980).

Using data from the 1977 Annual Housing Survey, Jacobs (1982) found that for all elderly homeowners 50 percent would increase their income by at least $\$ 600$ per year by using a 
reverse mortgage. ${ }^{42}$ Twenty-three percent would increase their income by at least $\$ 1,200$ per year. Using the Fouratt Plan, a slightly smaller percentage would increase their income by at least $\$ 600$ (49 percent). However, a much larger percentage would increase their income by $\$ 1,200$ (40 percent). Surprisingly, he found that the Fouratt plan produced a greater effect for those under age 75 than those over age 75 . The San Francisco Development Fund instituted a home equity conversion program in 1981. The fund acted as broker between the homeowner and an investor or financial institution. It offered reverse annuity mortgages (RAMs) 43 and SLs. While it arranged 118 RAMs from 1981 to 1985, only 8 SLs were arranged. The SLs followed the Fouratt Plan (HUD $1985,108)$.

Family-Backed Mortgage Association (FBMA), a for profit mortgage company, offered an SL called the Golden Retirement Annuity Mortgage or "Grannie Mae." Under Grannie Mae, an investor, generally a child of the homeowner, purchased the home from the homeowner using a conventional mortgage (except that the mortgage was subordinated to the seller's lease).

${ }^{42}$ The mortgage provided a sufficient annuity to reach 80 percent of initial home value at the end of the homeowner's life expectancy. In addition, a deferred annuity was purchased to continue the payments to the homeowner and to pay the mortgagee interest on the mortgage after that date. The mortgage was not due until the homeowner died.

${ }^{43}$ The RAM program was discussed in section 2.4 .1 above. 
The proceeds of the loan and down payment were used to purchase an annuity from an insurance company. The seller paid a fixed rent that included all maintenance, taxes and insurance. The plan was generally only applicable to family arrangements because the plan required the seller to find the purchaser and the latter would incur a negative cash flow during the tenancy of the seller (HUD 1985,111 ).

2.6.2 Accounting for the Sale-Leaseback

For accounting purposes, besides the initial accounting for the purchase of the building, the accounting rules for an SL consist of two parts: (1) accounting for the lease under FAS 13 and (2) accounting for the annuity payments using FAS 60. FAS 13 would require the lessor to treat the lease as an operating lease, since the lease would meet none of paragraph 7's requirements of a capital lease by the lessee (see Para. 8). An operating lease is accounted for as a "true" lease (e.g., rents are rents and the property is depreciated following the general rules of depreciating property); insurance would not affect this result. There is no provision for the accrual of the increase in the guaranteed sales price. FAS 60 requires that the cost of annuity payments be the difference between the present value of the annuity at the beginning of the year and the present value of the annuity at the end of the year (considering the annuitant's new life expectancy); any payments above that amount act to reduce the 
liability account. Although FAS 60 is applicable only to insurance companies, it is reasonable to assume that it would apply to other businesses issuing insurance products.

2.6.3 Taxation of Sale-Leasebacks

The tax treatment of the buyer-lessor of an SL transaction is well defined. The buyer obtains a cost basis in the property under code section 1012. Income from the lease would be calculated after deducting ordinary and necessary business expenses under code section 162. This is generally the same as for financial reporting (except for depreciation). Depreciation of the building is based on a 27.5 year life under code section $168(\mathrm{c})(1)$. The taxation of the annuity contract is similar to that for financial reporting (see IRC Sec. 807).

The IRS has taken the position that an SL transaction will be respected if it meets the following tests:

(1) The home is sold at fair market value (discounts are deemed to be prepaid rent);

(2) The lease provides a fair market value rent;

(3) The title to the property is transferred to the purchaser;

(4) The lease is not a lifetime lease (see below);

(5) The transaction is entered into for profit;

(6) The seller does not have an option to repurchase the property below-market value; and 
(7) The purchaser has all the responsibilities of ownership (taxes, maintenance, and insurance) and receives all appreciation in the building (HUD $1985,71-72$ ).

The first issue for the seller-lessee is the availability of code section 121, which exempts the first $\$ 125,000$ of gain from principal residences. The IRS has suggested that if the leaseback is for the life of the seller-lessee, then the transaction would likely be recharacterized as a sale of a remainder interest (U.S. Congress 1985), which is not eligible for the code section 121 exclusion.44 If the transaction is treated as an SL for tax purposes, any gain over the exclusion would be subject to tax. As with the SI, if the payments are in the form of a mortgage, the installment sale rules of code section 453 can be used; however, if the payment is in the form of an annuity, the tax would be immediately payable. The taxation of annuity payments was discussed under taxation of split interests (Section 2.5.3). The taxation of the annuity is less favorable than for an SI. In an SI, only part of the property is exchanged for an annuity; in an SL the entire

${ }^{44}$ It is not clear whether the use of a fixed term lease that extends beyond a homeowner's life expectancy would be treated in the same manner. However, if a term lease is for 30 years or more, the IRS would likely take the position that the lease is a retained interest in the property [see Reg. sec. $1.1031(a)-1(c)]$. As a result, the code section 121 exclusion would be denied, but the transaction would be treated as an SL for tax purposes. 
property is exchanged for an annuity, which is offset directly by non-deductible rent. This makes the SL the least favorable plan for the homeowner from a tax standpoint.

On October 3, 1983, senator Arlen Specter introduced S. 1914, which focused on the tax aspects of SLs used for home equity conversions. The Fouratt Plan did not meet the IRS's requirements for a bona fide SL arrangement; therefore, the tax consequences were not clear. S. 1914 provided safe harbor rules and leases that met the safe harbor rules would be considered sales at fair market value followed by true leases. For example, the homeowner would be eligible for the section 121 exclusion and the buyer would not be required to include the market discount as prepaid rent. In addition, the bill would exempt the transaction from the "anti-churning" provisions of the ACRS depreciation rules, allowing the buyer to use the favorable ACRS depreciation rates. 45 The safe harbor tests were consistent with the terms of the Fouratt Plan. Except for the provisions relating to code section 121,46 the Treasury was opposed to S. 1914 (U.S. Congress $1985,78-79)$.

${ }^{45}$ The "anti-churning provisions are no longer applicable to residential rental property [IRC Sec. 168(f)(5)(B)].

46 The brief statement by the Treasury clearly indicated that the department was not opposed to granting a Code section 121 exclusion where the homeowner sold the property and received back a lifetime lease. It was not clear whether the Treasury also agreed to treat the lease as a true lease to the buyer-lessor. 
An amended version of S. 1914 was included in the Senate's version of the Deficit Reduction Bill of 1984 . The bill provided that the provision would not apply to transactions between related individuals 47 and tax shelters. The bill would also have required that the sales price of the residence be fair market value (which is inconsistent with the Fouratt Plan). Finally the purchaser would have to use a 40year depreciable life, which was far longer than the depreciable lives available under the tax law. In short, the Senate, while accepting its general provisions, destroyed $\mathrm{S}$. 1914 in the details. The provision was later eliminated from the final bill in conference (U.S. Congress 1985, 79).

For purposes of this research it is assumed that the transactions qualify as true SLs and are not taxed as SIs. 2.6.4 Other Policy Aspects of the Sale-Leaseback

The SL is similar in many respects to the SI. It can provide the elderly seller-lessee with inflation protection by means of a fixed rent, relief against unexpected costs, and freedom from property management. It also avoids estate problems relating to the home, since the property has been sold. Like the SI, the transaction cannot be securitized but can be split between the asset (the leased property) and the

${ }^{47} \mathrm{~A}$ SL is often used in intra-family tax planning. For example Murphy (1992) found that from a family perspective, an intra-family SL with financially capable heirs would be preferable to using a reverse mortgage. 
liability (the annuity). Finally, like the SI, the annuity may be considered income for determining eligibility for SSI. 


\section{CHAPTER III}

METHODOLOGY

The methodology employed in this research uses Monte Carlo simulation with an after-tax discounted cash flow model. In the model, an elderly homeowner purchases a home for cash and immediately thereafter enters into a home equity conversion ("HEC") plan. This avoids questions relating to the taxation of built-in gains at the commencement of the HEC, which would be different for each taxpayer. Similar to Archer and Nye (1987) and Tate (1987), the home value is set at $\$ 100,000$, which is assumed to be below the FHA limit. Other than actuarial assumptions, all model parameters are fixed; however, separate computations are provided for alternative tax rates and homeowner's ages. At the end of the homeowner's tenure (move-out or death), the property is sold at 90 percent of fair market value (transaction costs on sale are set at 10 percent of market value). 48 The present value of housing costs and the return to the financial institution and the insurer (FHA) are then computed. Four plans are considered. The first is a standard FHA tenure HECM. The remaining three

48 The FHA assumption that the house is sold at fair market value is retained as the base case when testing the sensitivity of the FHA model to its assumptions. 
plans are designed to achieve, as closely as possible, the same basic pre-tax economics: a growth HECM, a split interest plan ("SI") , and a sale-leaseback ("SL"). These alternatives to the HECM are used to assess the economic and financial consequences to the homeowner, the financial institution, and the FHA relating to the homeowner's selection of a financing plan.

A single net present value ("NPV") model is used to assess the economic consequences to all subjects, $i$, in the financing plan ( the homeowner, the financial institution, and the FHA):

$$
\begin{aligned}
& \mathrm{NPV}_{i}=f \text { [Entity (ENT), Plan (PLAN), Initial Age (IA), } \\
& \text { Actuarial Assumptions (ACT), Death Year (DY), } \\
& \text { Move-out Year (MY), Interest Rate (INT), FHA } \\
& \text { Insurance Rate (FHA), Initial Home Value } \\
& \text { (IHV), Closing Costs (CC), Home Appreciation } \\
& \text { Rate (HAR), Inflation Rate (INF), Discount } \\
& \text { Rate (DR), Property Operating Costs (POC), } \\
& \text { Plan Servicing Costs (SC), Tax Rate (TRATE), } \\
& \text { Accounting Rules (AR), Tax Rules (TR)]. }
\end{aligned}
$$

The remainder of the chapter is divided into the following parts:

Overview of the methodology;

Descriptions of HEC plans;

Model variables and assumptions; and

Model tests and hypotheses. 
This research is conducted in four steps.

Step 1. Cumulative mortality tables are constructed from the government 1 ife tables at age 65 . In keeping with the FHA model assumptions, cumulative move-out rates are computed at $30 \%$ of mortality. This process is repeated for ages $70,75,80$, and 85 .

Step 2. Monte Carlo simulation determines the relative life expectancy and move-out potential for one thousand individuals. Both life expectancy and move-out expectations are uniform distributions with possible values between zero and one and are independent of each other.

Step 3. The relative life and move-out expectancies of each individual (step 2) are converted to a fixed age using the tables produced by step 1. The fixed death and move-out ages become the input data for step 4. This step is repeated for each base age assumption.

Step 4. The economic consequences to each entity are computed for each simulation using the data from step 3. Separate simulations are required for each plan, base age, and appreciation rate. An expected cash flow is found by adding each period's cash flow for each simulation and dividing by the number of simulations.

For example, a homeowner at age 65 obtains an HECM mortgage. The homeowner dies at age 70 and the move-out date is age 75 (where the homeowner dies on or before the move-out date, only the date of death is significant). The computation of cash flows is calculated as follows:

(1) At age 65, the homeowner has a negative cash flow of $\$ 100,000$ for the house. In addition, the homeowner incurs $\$ 2,000$ in closing costs and mortgage insurance, respectively. 
(2) From age 66 to 70 , the homeowner receives an HECM payment (net of mortgage administration costs) from which house operating costs are subtracted.

(3) At age 70, the house is sold at $90 \%$ of fair market value, and the homeowner receives a payment equal to the sales price net of the outstanding mortgage balance (but not below zero).

(4) Because the homeowner dies without selling the home, there are no tax effects (since estate taxes are ignored). If the homeowner had moved out at age 70 and died at age 75 , the homeowner would be entitled to a deduction for the current real estate taxes and all interest (including interest, administration fees, and mortgage insurance) incurred for the life of the mortgage, subject to limitations. The homeowner would also have to pay tax on any gain on the sale over $\$ 125,000$.

(5) The NPV of the cash flows of the homeowner is computed assuming no tax, $15 \%$ tax, and $28 \%$ tax. This information is retained for further analysis. The cash flow for each year is computed in a separate account to be aggregated for all homeowners.

(6) Steps 1 to 5 above are repeated for each homeowner in the simulation.

(7) After all homeowners' yearly cash flow is computed, the grand totals are averaged by the number of homeowners $(1,000)$. This results in an expected cash flow for each year. The expected cash flow can be discounted by the appropriate discount rate to get an NPV of the flows, with and without tax.

3.2 Descriptions of the HEC Plans

As previously stated, this research compares the FHA HECM with three alternative plans that are not presently available: a growth HECM mortgage, an SI; and an SL. Each of the three alternative plans is designed to provide the homeowner with inflation protection, which is not available in the current FHA plan. 
3.2.1. FHA Home Equity Conversion Mortgage

The FHA HECM plan is a tenure plan assuming the maximum allowed annuity payments. Interest is computed using an interest rate of 8 percent, before FHA mortgage costs. In addition to the FHA insurance of 2 percent of value, costs of 2 percent of value are deducted from the principal sum. Although the FHA permits the financial institution to transfer the loan to the FHA once the loan reaches 98 percent of the maximum claim amount $(\$ 98,000$ for homes in this study), the mortgages are assumed to be held to maturity.

3.2.2 Growth Home Equity Conversion Mortgage

The growth HECM uses the same assumptions as the FHA plan, but instead of the HECM annuity payments, payments in the growth HECM remain constant throughout the year, but increase 4 percent a year for the entire term of the mortgage. By providing inflation protection, this graduated plan is more similar to the SL and SI plans than the flat payment plan.

The initial payment for the growth HECM is computed using the future value of a growth annuity of \$1 ("FVGA"):

$$
F V G A_{k, g, n}=(1+g)^{n}\left[\frac{\left(1+i^{*}\right)^{n}}{i^{*}}-1\right] .
$$

where $\mathrm{k}$ is the nominal interest rate,

$\mathrm{g}$ is the growth rate, and

$$
i^{*}=(1+k) /(1+g) \text {. }
$$


The FVGA can be derived be adding growth to the future value of an annuity of $\$ 1$ ("FVA") formula. 49

${ }^{49}$ The annuity in a standard HECM is computed using the future value of annuity formula (FVA):

$$
F V A_{k, n}=\sum_{t=1}^{n}(1+k)^{t-1}
$$

which can be expressed as:

$$
F V A_{k, n}=(1+k)^{0}+(1+k)^{1}+\ldots+(1+k)^{n-1} .
$$

If growth value, $g$, is incorporated into Equation 2, the future value of the annuity is:

$$
\begin{gathered}
\text { FVGA }_{k, g, n}=(1+k)^{0}(1+g)^{n}+\ldots+(1+k)^{n-1}(1+g)^{1} \\
\left.=(1+g)^{n}\left[(1+k)^{0}(1+g)\right]^{-0}+\ldots+\left[(1+k)^{n-1}(1+g)\right]^{1-n}\right] .
\end{gathered}
$$

Equation 4 can be rearranged as:

$$
F V G A_{k, n, g}=(1+g)^{n}\left[\left(\frac{1+k}{1+g}\right)^{0}+\left(\frac{1+k}{1+g}\right)^{1}+\ldots+\left(\frac{1+k}{1+g}\right)^{n-1}\right] .
$$
becomes:

By letting $1+i^{*}$ equal $(1+k) /(1+g)$, the formula

$$
\text { FVGA }_{i^{*}, n}=(1+g)^{n}\left[\left(1+i^{*}\right)^{0}+\left(1+i^{*}\right)^{1}+\ldots+\left(1+i^{*}\right)^{n-1}\right] .
$$
as:

Equation 6 can be expressed in terms of the FVA formula

$$
F V G A_{k, g, n}=(1+g)^{n} \cdot F V A_{i^{*}, n} \cdot
$$

The FVA portion of Equation 7 can be expressed in a standard mathematical equivalence to yield:

$$
F V G A_{k, g, n}=(1+g)^{n}\left[\frac{\left(1+i^{*}\right)^{n}}{i^{*}}-1\right] \text {. }
$$


If the future value is known, the theoretical payment at time zero can be obtained by dividing the future value by the FVGA factor. The first payment is equal to the payment at time zero times one, plus the growth rate.

For purposes of this study, it is assumed that the growth mortgage balance will be equal to the standard mortgage balance at its theoretical termination at age 100. Therefore, the annual payments for the growth mortgage are computed by applying the FVGA formula to the mortgage balance of the standard mortgage at age 100 .

3.2.3. Split Interest

Under the SI plan, the financial institution purchases a remainder interest for the present value of the property (based on the individual's age) based on a discount rate of 8.5 percent (which includes the insurance premium). Closing costs, paid by the homeowner, are $\$ 4,000(\$ 2,000$ of which are paid to the insurance company). The net payment is used to purchase an annual life annuity computed at an 8 percent interest rate. The homeowner pays the current property operating costs; the financial institution pays any increases in operating costs. The FHA provides insurance for the same amount as the standard FHA HECM and insurance premiums are the same. If the homeowner moves out of the house, the value of the remainder interest in the home (assuming no appreciation) is converted to a life annuity at an 8 percent rate, but based 
on the life expectancy of the homeowner at the time of the move-out.

\subsubsection{Sale-Leaseback}

Under the SL plan, the homeowner sells the property to the financial institution for $\$ 100,000$, less the FHA insurance fees and closing costs. The homeowner pays rent equal to the deemed interest cost of 8.5 percent (which includes insurance costs) of $\$ 100,000$ plus estimated operating costs at current prices. In addition, the homeowner receives a life annuity with a value of $\$ 96,000$, based on an interest rate of 8 percent. Insurance coverage is initially equal to the value of the home, increasing by 4 percent per year and costs 0.5 percent of coverage.

\subsection{Variables and Assumptions of the Model}

The research uses an ex post net present value of cash flows for each subject to measure the relative attractiveness of each plan to each entity. 50 Net present value of cash flows for a particular subject is defined as follows:

$$
N P V C F_{E N T}=\sum_{i=I A}^{110} C F_{i}(1+y)^{I A-i}
$$

where $\quad \mathrm{CF}$ is the cash flow;

${ }^{50}$ Since each of the plans has features not measured by this research, it is possible that a plan with a low cash flow can have a high utility. For example, if it is important to relieve the heirs of the duty to sell the home, the homeowner may wish to use an SI or SL plan, even if the net present value of cash flows were less favorable than a mortgage plan. 
IA is the initial age of subject; and $Y$ is the discount (interest) rate.

Financial institutions are not only interested in cash flow, but also in accounting income. The timing of cash flows and accounting income can often differ, although over the life of the loan, the two will have the same cumulative totals. This research uses the net present value of accounting flows to measure the timing benefits of accounting income. The present value of accounting income (NPVAI) is computed using the same formula as NPVCF, except that accounting income (AI) is used instead of cash flow (CF).

The surrogate for measuring the ex ante attractiveness of a particular plan is the expected value of the net present value of cash flow:

$$
E(N P V C F)_{E N T}=\frac{\sum_{j=1}^{n} \sum_{i=I A}^{110} C F_{j, i}(1+y)^{I A-i}}{n}
$$

where $\mathrm{n}$ is the number of loans.

As with the NPVAI, the E(NPVAI) is the same formula as E(NPVCF), except that accounting income is substituted for cash flow.

A secondary measure of attractiveness for financial institutions is the internal rate of return of expected cash flows ("IRR"). The IRR is the discount rate (y) required to produce an $E(N P V C F)$ of zero. The IRR of accounting income is 
not used because it leads to an undefined result for mortgage plans.

3.4

\section{Model Variables and Assumptions}

The variables used in the model are listed in the generalized model at the beginning of this chapter. The variables Entity (ENT) and Plan (PLAN) were discussed previously. The remainder of the variables will be discussed in this section.

\subsubsection{Initial Age}

The initial age (IA) is the subject's age at the start of the plan. All subjects are deemed to start the plan at the following alternative ages: $65,70,75,80$, and 85 .

\subsubsection{Actuarial Assumptions}

This research follows the FHA model which uses the female mortality tables in the U.S. Decennial Life Tables for 1979$\underline{81}^{51}$ (U.S. Department of Health and Human Services 1985), for all computations, except the taxation of annuities. The mortality tables stop at age 110; therefore, it is assumed that no one survives beyond age 110. The taxation of annuity income is based on the annuity tables in the regulations under Code section 72 .

In keeping with the intent of the FHA model, a move-out rate of 30 percent of the mortality rate in the Life Tables is used. The probability of moving out, conditioned on survival,

${ }^{51}$ These tables are called Life Tables in this paper. 
is assumed to be independent of mortality. As discussed in Section 4.2 .2 .3 , the methodology used in the FHA model (which increases mortality each year by 30 percent to cover moveouts) is inconsistent with its desired aim.

From the life tables, the following variables are significant in this research: life expectancy (LE), probability of dying $(\mathrm{dx})$, and probability of moving out (dm).

Life expectancy is reported in the life tables and in the section 72 regulations. Life expectancy as reported in the Iife tables is used to compute the accounting and taxable incomes for the financial institution. The section 72 life expectancy (which is higher than the life tables) is used to compute the homeowner's taxable annuity income under the SI or SL plans.

The probability of dying is the cumulative probability of dying before a particular age and is used to compute the subject's age at death. The formula for the probability of dying at a given age is:

$$
d x_{i}=\frac{n I_{i}}{n I_{I A}}
$$

where

$\mathrm{nl}$ is cumulative number living and

$i$ is the age in question.

The probability of moving is the cumulative probability that the subject will move by a certain date, conditioned on survival, and is used to compute the subject's age at move- 
out. The formula for the probability of moving out at a given age is:

$$
d m_{i}=.3 d x_{i}
$$

3.4.3 Death Year

Death year (DY) is the age each subject dies. Using the computer's random number generator, each subject is randomly given a number (D) between 0 and 1 representing the value of $\mathrm{dx}$ at the time of the subject's death. Using the life tables discussed in the preceding section, DY equals the age of the subject at time $D$, rounded to the nearest whole year.

3.4.4 Move-out Year

Like Death year, move-out year (MY) is the age each subject would move out if still living. Using the computer's random number generator, each subject is randomly given a number (M) between 0 and 1 representing the value of $\mathrm{dm}$ at the time the subject moved. MY is the age of the subject at time $M$, rounded to the nearest whole year. The Life Tables produce a maximum $M$ of 0.3 at age 110. If $M$ is greater than 0.3 , then MY is assigned a value of 111. MY is only significant if it is less than DY; a move-out on or after a subject's death has no meaning.

\subsubsection{Interest Rate}

The fixed interest rate of $8 \quad(8.5$ if insurance is included) percent per annum compounded monthly is used. A 
variable rate 52 was deemed inappropriate because it could confound the results of the research. Interest rates are not a subject of this study. The addition of a variable rate could raise doubts whether the results were due to the respective HEC plans and their tax consequences or due to the effect of changing interest rates.

3.4.6 FHA Insurance Rate

The FHA insurance rate (FHA) for either the standard HECM or the growth HECM is the same as the one fixed by the FHA. The rate is 2 percent of the house value at closing plus an annual rate of 0.5 percent compounded monthly on the outstanding mortgage balance. The insurance rate for the SI is computed as if an HECM mortgage were granted at the closing instead of an SI. The SI'S insurance rate is 2 percent on closing and 0.5 percent per annum compounded monthly on the insured amount (which is the initial home value increased by 4 percent per annum).

3.4.7 closing costs

closing costs (CC) are fixed at $\$ 2,000$ (2 percent of the house value). Although this is at the lower end of costs (see HUD 1992) currently charged, it is higher than what other research has assumed (see speare 1992). The closing costs are considered the actual costs incurred by the financial

${ }^{52}$ As explained in chapter 2, virtually all FHA HECMs are variable rate mortgages. 
institution. Therefore, there is no need to separately account for these costs for either accounting or taxable income purposes.

\subsubsection{Home Appreciation Rate}

The home appreciation rate (HAR) is treated as a variable in this research. In keeping with other studies (see Scholen 1992), three alternative rates are used: 0 percent, 4 percent (the FHA model assumption) and 8 percent per annum. In each case the mean appreciation rate for each home is constant. One purpose of this research is to learn the effect of the HAR on HEC plan choice.

\subsubsection{Inflation Rate}

For simplicity, the inflation rate (INF) is set at a constant 4 percent per annum, the same as the FHA model's estimate of HAR.

\subsubsection{Discount Rate}

The discount rate (DR) is used for computing net present value of cash flows and accounting income. The rate used is 8 percent per annum compounded monthly, the same as INT. In short, is assumed that the homeowner, the financial institution and the FHA could invest excess funds in 8 percent mortgages. Since the discount rate is based on the purchase of mortgages, the income from which is taxable, the discount rate is deemed to be a pre-tax rate. The discount rate is adjusted for taxes, thus 


$$
D R_{T R A T E}=I N T(1-T R A T E)
$$

\subsubsection{Property Operating costs}

It is assumed that initial operating costs are 3.5 percent of property value, consisting of 1.8 percent for property tax, 1.5 percent for repairs, and 0.2 percent for insurance (see Ali et al. 1990). Costs are adjusted for changes in the value of the home. Repairs are adjusted for changes in inflation, if higher than the home appreciation rate.

\subsubsection{Plan Servicing costs}

Plan servicing costs are twenty-five dollars per month. After adjusting for the interest rate effect and rounding to the nearest dollar, the annual charge is 312 dollars. The charge is within the range generally charged by financial institutions (HUD 1992, p. 3-13). Twenty-five dollars is also used by other researchers (see Scholen 1992 and Speare 1992). The servicing costs are deemed to cover the costs of servicing the plan, with no profit.

\subsubsection{Tax Rate}

The tax rates (TRATEs) on December 31, 1992 are used. For individuals, rates of 15 and 28 percent are used. There was also a 31 percent rate, but it is not considered because (1) it is unlikely that an upper income individual would be 
interested in home equity conversion ${ }^{53}$ and (2) it is not materially different from the 28 percent rate. A 34 percent rate is used for financial institutions (it is assumed that any financial institution interested in home equity conversion would be subject to the 34 percent rate).

As part of the president's budget package, tax rates were increased effective January 1, 1993. The new 36 percent tax rate on individuals only affects individuals with taxable income above $\$ 115,000$ and the 39.6 percent rate applies to persons with taxable income over $\$ 250,000$; upper income individuals are unlikely to want home equity conversion. Corporations with incomes above $\$ 10$ million will have a tax rate of 35 percent. 54 The higher rate is not used in this study because (1) not all financial institutions will have the threshold income and (2) the difference between 34 and 35 percent is not material.

\subsubsection{Accounting Rules}

Accounting rules (AR) are only applicable to the financial institution. Except for the depreciation rate on

${ }^{53}$ The median income of FHA HECM borrowers is less than $\$ 7,600$ of which the median social security income is $\$ 7,000$. More than a quarter of borrowers had income of less than $\$ 3,200$, while less than 10 percent had income in excess of $\$ 15,000$. (HUD 1992, p. 2-6).

${ }^{54}$ Personal service corporations are subject to the 36 percent tax rate on all income. 
the building (which will be discussed in the next section), the rules are discussed in chapter 2.

3.4.14 Tax Rules

Tax rules (TR) are applicable to homeowners and to financial institutions. The tax rules are discussed in Chapter 2. As a practical matter, the financial institution has no book-tax differences, except that for the SL, depreciation for accounting purposes assumes a useful life of 50 years, while for tax purposes a useful life of 27.5 years is used. Since it is impossible to know the exact tax position of each homeowner or financial institution, secondary effects that depend on facts not included in the study are ignored. For example, the effect of added income on the taxation of Social security benefits is ignored. Also, it is assumed that the taxpayers are not subject to the alternative minimum tax (AMT).

\subsubsection{Annualization}

For convenience, all computations in this research are done on an annual basis. Each subject is deemed to move out or die on either the first or last day of each year. If the subject moves out or dies during the last half of the year, then the subject is deemed to die at the end of the year. Death or move-out within the first half of the year is deemed to occur at the beginning of the year. Interest or other charges often occur monthly. All rates are converted from 
nominal monthly compounding $\left(Y_{N}\right)$ to effective annual rates $\left(Y_{E}\right)$ using the following formula:

$$
Y_{E}=\left(1+\frac{Y_{N}}{12}\right)^{12} \text {. }
$$

For example, using the above formula, an 8.3 percent effective annual rate is used for all computations assuming 8 percent monthly compounding.

\subsubsection{Computation of Annuities}

Annuities to the homeowner are computed from the above assumptions. For the HECM, the monthly payment is determined using a computer program furnished by the FHA to FHA lenders. This method is necessary because the FHA uses a different method for computing the expected life of the loan than is used in this research (see section 3.4.2). The payment is annualized using the future value of an annuity formula in the footnote to section 3.2 .2 (i.e, the future value of an annuity of 12 periods using a nominal interest rate of 8 percent). The interest rates used to determine the initial payment of the growth mortgage (see section 3.2 .2 ) are also adjusted for annualization.

Since the annuities in the SI and the SL are paid for life, even if the homeowner moves, the annuities are valued based on the formula for the present value of an annuity of $\$ 1.00$ per period (PVA\$1) over the homeowner's Iife expectancy (LE) : 


$$
P V A \$ 1_{k, L E}=\sum_{t=1}^{L E} \frac{1}{(1+k)^{L E}}=\frac{1-\frac{1}{(1+k)^{L E}}}{k}
$$

If the present value of the annuity (PVA) is known, such as when property is exchanged for an annuity, the annuity payment (AP) is computed as:

$$
A P_{k, L E}=\frac{P V A_{k, L E}}{P V A \$ 1_{k, L E}}
$$

If $A P$ is known but PVA is unknown, such as the financial institution's annual valuation of the annuity for accounting and tax purposes, the PVA can be found with the following formula:

$$
P V A_{k, L E}=P V A \$ 1_{k, L E} \cdot A P_{k, L E}
$$

The tax rules use a longer life expectancy $\left(\operatorname{LET}_{\mathrm{T}}\right)$ than the life expectancy (LE) used to calculate the value of the annuities. For tax purposes, the exclusion ratio, ER, (the untaxed portion of each payment) is determined using the following formula:

$$
E R=\frac{A P \cdot L E_{T}}{P V A}
$$

The untaxed amount of each payment is obtained by multiplying the amount of the payment (AP) by the exclusion ratio (ER). The remaining amount of the payment is subject to tax. The taxation of annuity payments is discussed in chapter 2 . 
The analysis portion of the research is divided into three parts. The first part consists of a comparison of the four HEC plans for the homeowner, the financial institution, and the insurer (FHA) using different age, tax, and house appreciation rate assumptions. The second portion tests to find if any of the plans are inconsistent with the tax policy assumptions discussed in chapter 2. The last part of the analysis is to examine the sensitivity of some of the FHA model's assumptions.

\subsubsection{Plan Comparison}

As previously stated, the net present value of expected returns is the primary measure used to compare the plans. Both the expected value and the standard deviation of the value are computed for each scenario. A $z$ test is used to find if the expected values between two plans are significantly different (see Iman and Conover, 283). For financial institutions, a similar examination is made for the internal rate of return of expected cash flows ("IRR").

Individuals are in a different situation from the financial institution and the FHA. First, at least some individuals may consider using the home equity conversion as an investment. Therefore, for individuals, the additional choice of doing nothing is analyzed. Secondly, individuals cannot obtain a portfolio of HECs; consequently, the expected 
value has little significance. For this reason, a test of ranks is also used.

For each subject in each scenario, the actual net present value is computed for each HEC plan (including doing nothing). The net present value of each plan is ranked, so that each plan has a value between 1 (best) and 5 (worst); ties were averaged (there are ties between two plans, but no ties between three or more plans). The ranks are analyzed in three ways. The first is an overall test of expected ranks (instead of expected NPV). The second are two overall mini-max tests to determine the number of times a plan is the best (or best two) or the worst (or worst two), with 0.5 points awarded for ties. The computer program that analyzes ranks also collects data for a head to head test between each plan, with ties being ignored.

For testing purposes, the test of expected ranks is analyzed using the same methodology described in the first paragraph of this section. The other tests use a binomial distribution. For test two, a significant $(p=.05)$ likelihood of having at least a 50 percent chance of being in the best or worst categories is deemed significant. The likelihood of not being in the best or worst categories is also tested. The head to head data is tested only for doing nothing, since comparison between the other plans is not particularly 
interesting. The head-to-head test assumes an expected rate of 50 percent.

\subsubsection{Tax Policy Assumptions}

As stated in section 2.3.2, there are two tax policy issues relating to home equity conversion that are tested in this research. The first issue is vertical equity. Vertical equity seeks to have taxpayers with more income pay more tax than persons with less income. A vertical equity problem is indicated if a person makes an investment decision such that the decision is different given different tax rates. A tax exempt bond is an example of a vertical equity violation. Persons in high tax brackets find the bonds more profitable than competing investments, while lower taxed persons do not. Therefore, in this research, a change in an investment decision based on changes in the tax rate is treated as a surrogate for a violation of the vertical equity principle. 55 This idea can be expressed in the following research hypothesis:

$\mathrm{H}_{\mathrm{R}} \quad$ Ceteris paribus, if choice $\mathrm{A}$ has a greater expected NPV than choice B before tax then choice $A$ has an equal or greater expected NPV than choice B after taxes, using a tax adjusted discount rate.

${ }^{55}$ As hinted by the example of tax exempt bonds, the tax law has many violations of the vertical equity principle. However, from a policy standpoint, it is necessary that congress be aware of the violations. 
In its broadest sense, a tax subsidy exists where the tax law provides a benefit for a particular transaction not available for other transactions. Therefore, in this sense, the vertical equity issue and the tax subsidy are the same. However, "tax subsidy" is often given a more narrow definition. Under this definition, and the definition used in this research, a person receives a tax subsidy if the expected return after $\operatorname{tax}$ is greater than the expected return before tax. Some tax shelters before 1986 were set up as tax subsidies. The out of pocket costs of the tax shelters were more than offset by current tax savings from the investments. Although taxes would ultimately be due, the gain would be taxed at a lower rate than the initial deductions and gain would not be taxed for several years, reducing the present value of the tax due. This definition leads to the following research hypothesis for a tax subsidy:

$H_{R}$ Ceteris paribus, the before-tax NPV from choice $A$ is less than the after-tax NPV of choice A after tax, where the after-tax discount rate is not adjusted for the tax rate.

3.5.3 Sensitivity of FHA Assumptions

Although the assumptions of the FHA model appear consistent with the assumptions used by other organizations in establishing their plans (see Chapter 2 for the model 
assumptions of other plans), the FHA plan has been criticized for having assumptions that are too liberal.

Toward a better understanding of the risks inherent in the FHA's plan, this research explores the sensitivity of the assumptions in the FHA model. The base model employs the same model as used for evaluating the profitability of the FHA plan as discussed in this chapter, except for the sales price of the home. The sales price is deemed to be 100 percent of fair market value instead of 90 percent of fair market value. A fixed initial age of 75 is used as it is close to the 76.7 median age of FHA HECM borrowers (HUD 1993, p. 2-3).56 specifically, the following assumptions are examined: (1) the discount rate (i.e., the assumed rate of return on assets), (2) the move-out rate (as a percentage of mortality), (3) the house sales price (as a percentage of market value), (4) the average house appreciation rate, and (5) the standard deviation of the house appreciation rate (assuming the average house appreciation rate is 4 percent per year).

The FHA break-even point is computed using the same sample of 1000 subjects as is used for comparisons between plans. Variances across samples are not examined. The variance of a sample mean decreases in proportion to the

${ }^{56}$ The use of a lower age than the median age can be considered conservative. The results of this research suggest that the FHA earns a higher return from older borrowers than younger borrowers. 
number in the sample. For instance, for samples of one thousand loans, the variance of the mean return is 0.1 percent of the variance of an individual return. 57 For items 1 to 4 , the break-even point is computed to the nearest reasonable interval (e.g., within one-tenth of a percent for the home appreciation rate). For item 5, NPV's are computed for rates of return varying from -4 percent to 8 percent.

Given these outcomes, the standard deviation producing a zero NPV about a mean of 4 percent (assuming returns are normally distributed) is computed using a trial and error procedure. The method of computing standard deviation of returns is that used by speare (1992) instead of that used by Szymanoski (1990) in developing the FHA model. The difference is explained in chapter 2 .

57 The standard deviation of the sample's mean return is about 3.2 percent of the standard deviation of an individual return. 


\section{CHAPTER IV}

\section{DATA ANALYSIS AND EMPIRICAL RESULTS}

This chapter is divided into three parts. The first part summarizes the results of the simulation described in chapter 3. It compares the four HEC plans from the prospective of the homeowner, the financial institution, and the insurer (FHA) under different age, tax, and house appreciation rate assumptions. The second part examines the results of the simulations with respect to consistency with tax policy assumptions. The final part of the analysis examines the sensitivity of some of the FHA model assumptions.

\subsection{Plan Comparison}

The main purpose of this study is to evaluate the need for the FHA to insure additional forms of home equity conversion ("HEC"), namely a growth mortgage ("GR"), a split interest plan ("SI"), and a sale-leaseback ("SL"). The assumption is made that a HEC plan will not be successful unless it produces satisfactory results to the homeowner, the financial institution, and the FHA. In general, the net present value of cash flow is used to measure the results, but other measures are used as well. In determining net present value, it is assumed that each person or entity can invest 
surplus funds in similar mortgages, thereby producing a discount rate of 8.3 percent annually (equivalent to $8 \%$ compounded monthly) before tax. For taxpayers subject to tax, the discount rate is reduced by the tax on the interest earned. For example, for an individual in the $15 \%$ tax bracket, the discount rate is 7.055 percent $(8.3$ percent less $15 \%$ of $8.3 \%)$.

\subsubsection{Homeowner}

Unlike a financial institution or the FHA, the homeowner is not in a position to form a portfolio of HEC instruments that is likely to average the expected cash flow from the instrument over time. The homeowner has only one opportunity to enter into a HEC plan. Therefore, the homeowner's review process is likely to be different from that of the financial institution or the FHA. For that reason, different performance measures are used to evaluate the HEC plans for the homeowner.

Among the least sophisticated but possibly the most important selection criterion for many homeowners is the initial annual payment to be received under each plan. Table $2^{58}$ shows the initial payment received under each plan for each age. The initial payment for the SL is reduced by the

58 For all tables, each of the plans is abbreviated as follows (abbreviation in parentheses): do nothing (NO); standard HECM mortgage (FH); growth HECM mortgage (GR); split interest (SI); and sale-leaseback (SL). 
interest (including FHA insurance), since it must be immediately repaid to the financial institution as rent. Note that up to age 75 , the standard HECM mortgage ("FH") produces the highest initial payment. Somewhere between age 75 and 80 , the SI and SL produce higher initial payments, with the SI being the higher. Since the FH model contains a 4 percent growth factor for the house (which is not part of the SI model), one would assume that the FH should produce a higher initial payment. However, the $\mathrm{FH}$ model also includes an assumption that all homeowners live to age 100, whereas the SI and SL models use actual life expectancy (which is 8.69 years at age 80 ). The differences in assumed life expectancy eventually lead SI and SL to have higher payments at about age 80.

A more sophisticated method of analyzing the results to the homeowner is to examine the net present value ("NPV") of expected cash flow ${ }^{59}$ based on the homeowner's age, tax rate, and expected appreciation rate of the home. In this study, the expected cash flow is the expected cash flow of home ownership. Since home ownership is an expense, expected cash flows are all negative. Table 3 (with parts $A, B$, and $C$ ) shows the homeowner's expected cash flow and its standard deviation at each age, tax rate, and appreciation rate. Since

${ }^{59}$ Unless clearly indicated otherwise the term "expected cash flow" refers to the NPV of expected cash flow. 
some homeowners may choose not to borrow, an additional choice of doing nothing ("NO") is added to the analysis.

Except where the appreciation rate is zero, No results in the highest expected value. Depending on the home appreciation rate, either the FH or the GR tends to have the second highest expected value. The FH has higher expected values than the GR for home appreciation rates less than 4 percent and lower expected values for home appreciation rates greater than 4 percent. Although the FH's expected value is slightly higher than the GR's where the home appreciation rate equals 4 percent, the differences are generally not significant. The SI consistently has the lowest expected values at all ages, appreciation rates, and tax rates. The SL did better than expected; since the SI receives better tax treatment than the SL, it was expected that the SL would have the lowest expected cash flow.

As indicated by the high standard deviations of the expected cash flow, expected cash flow may be unimportant to the homeowner. Another way to analyze expected cash flow is to use expected cash flow rank. The methodology used is discussed in section 3.4.1. Table 4 (with parts $A, B$, and C) shows the expected cash flow rank for each HEC choice, age, tax rate, and house appreciation rate (1 represents the highest expected cash flow). The use of ranks generally results in the same ordering as the use of expected cash flow. 
The primary difference is that the SI generally has a higher rank than the SL, although it has a lower expected cash flow. The apparent reason for this is that the SL probably has a greater skewness and may have had its expected cash flow increased by a few events. Likewise, the GR in some situations has a higher expected rank than the $\mathrm{FH}$, even though the FH has a higher expected value.

Instead of using rank order comparisons, a homeowner may wish to choose among the plans using probability of achieving the highest expected cash flow (maxi-max type of analysis) or the probability of not generating the lowest expected cash flow (min-min type of analysis). Table 5 (with parts $A, B$, and C) presents the maxi-max type of analysis and Table 6 (with parts A, B, and C) presents the mini-min type of analysis. Since No may not be a choice for some homeowners, the tables also show whether a plan is among the highest or lowest two expected values.

The results are generally consistent with the analysis of ranks. NO is clearly the best choice for almost all homeowners using maxi-max type of analysis. The GR consistently (with a few exceptions) gives the best mini-min results. Although the $\mathrm{FH}$ is more likely than the GR to have the highest expected value, the GR is more likely to have one of the two highest expected values. This suggests that conservative homeowners may prefer the GR, even if it is less likely to result in the 
highest expected value. The SI and SL consistently have the lowest probability of having the highest return and the highest probability of the lowest return (SI is worst for those over 75 and SL is worst for those under 80).

\subsubsection{Age Effect}

As discussed in the previous section, the relative ranks of the HEC plans are largely unaffected by the homeowner's initial age. Due to the lower variance of life expectancy and reduced effects of compounding, differences in expected values and ranks tend to converge with increases in age. As in the overall analysis, No tends to have the highest expected rank at all ages. Of the HEC plans, the GR tends to have the highest expected rank at all ages. The SI and SL consistently provide the two lowest NPVs of cash flows, with the SL being the worst at lower ages and the SI being the worst at higher ages. Contrast this with the size of initial payments (Table 2), indicating that comparisons of initial payments may mislead elderly homeowners.

Table 7 provides a convenient mechanism for displaying these rank relationships. It averages the ranks for each initial age without regard to tax rate or home appreciation rate. 60 The table confirms that No is generally the

${ }^{60} \mathrm{~A}$ limitation of this methodology is that it assumes an equal likelihood of each tax rate and home appreciation rate. similar limitations apply to Tables 8 and 9, discussed in the next two sections. 
preferred choice at any age. Of the HEC plans, the GR shows the lowest expected rank at all ages, except for age 65 . Although the FH shows a higher expected rank at age 65, the difference between it and the $G R$ is not statistically significant. The table shows that the expected ranks of No or using the $\mathrm{FH}$ tend to get worse as the initial age increases. on the other hand, the expected ranks of the GR, the SI and the SL tend to improve as the initial age increases. Although the SL tends to have a lower incidence of the worst returns at higher ages than the SI, the SI has a superior expected rank for all age groups (although the margin narrows as initial age increases).

An examination of the times that No had the highest or lowest returns to the homeowner shows that No consistently (i.e., over 90 percent of the time) had either the highest or lowest returns where home appreciation rates were at least 4 percent. From this, it can be concluded that doing nothing results in a higher expected cash flow unless the homeowner greatly outlives the life expectancy. The number of times (in one thousand simulations) that doing nothing leads to the best result can be interpreted as the percentage of homeowners of the same age that the homeowner must out-live to increase NPV (i.e., to profit) by using home equity conversion. An interesting characteristic of this number is that the percentage decreases with initial age. Assuming a zero tax 
rate and 4 percent home appreciation, a 65 year old homeowner must outlive 79.7 percent of homeowners of the same age to profit by using home equity conversion, but a 85 year old homeowner only needs to outlive 63.1 percent of homeowners of the same age. Where the home appreciation rate is zero, there is less likelihood that No will be at the extremes (particularly at younger ages) and the likelihood of having the best result increases with initial age. However, the expected rank of No (see Table 4A) tends to decrease as the initial age increases. These results suggest that initial age is an important variable in determining the relative cost of home equity conversion to the homeowner.

\subsubsection{Tax Effect}

The relative tax advantage of any plan can best be examined by analyzing ranks (Table 4) and to a lesser extent the likelihood of the highest (Table 5) and lowest (Table 6) ranks. Table 8 summarizes parts A, B, and C of Table 4 by showing the expected rank of each plan without regard to initial age or home appreciation rate. A plan can be considered relatively favorably taxed if the plan consistently improves its rank, increases its likelihood of the highest ranks and decreases its likelihood of the lowest ranks as taxes are increased for a given age and appreciation rate. On the other hand, if the opposite is true, then the plan can be 
considered relatively unfavorably taxed in comparison with the other choices.

No not only tends to have the best outcomes for all ages and for most appreciation rates, but the relative advantage of NO (in relation to the other plans) consistently increases with the homeowner's marginal tax rate. This shows that none of the HEC plans offer the homeowner an effective tax shelter. Table 8 also shows that although the expected rank of each HECM changes with tax rates, the order of the rankings between instruments is not affected by the tax rate. This clearly shows that the tax effect is not significant to the homeowner.

Table 8 shows an unexpected outcome of this study. While the expected rank of SI is higher than that of SL for all tax brackets, the difference between their respective ranks decreases as the tax rate increases. Since the SL has particularly unfavorable tax consequences to the homeowner, the differences would be expected to increase.

\subsubsection{Home Appreciation Rate Effect}

The home appreciation rate effect also can be seen from the ranks of the alternative vehicles (Table 4) and from the likelihood of having the best (Table 5) and worst results (Table 6). Table 9 summarizes parts A, B, and $C$ of Table 4 by providing the average rank of each vehicle for each home appreciation rate without regard to the homeowner's initial age or tax rate. 
From the tables it is evident that the SI and SI plans display their best relative performance at 4 percent appreciation, the model assumption, and tend to get more disadvantageous as appreciation deviates above or below this rate. If appreciation rates fall below 4 percent, mortgage plans are at a relative advantage to the homeowner because the mortgage plans assume a 4 percent growth while the homeowner does not have a 4 percent increase in housing costs. As appreciation rates increase above 4 percent, the added appreciation goes to the financial institution. The appreciation in the home value more than offsets the increase in housing expenses (i.e., repairs, insurance, and taxes) paid by the financial institution.

The relative advantage of No increases as home appreciation rates increase. Where the home appreciation rate is less than 4 percent, the mortgage choices have a relative advantage to the homeowner because mortgage annuity payments are predicated on a 4 percent rate of appreciation. As the appreciation rate increases, the mortgage balance is less likely to exceed the mortgage balance (a major advantage of the mortgage option) and is therefore less likely to produce a windfall to the homeowner.

Table 9 shows that although the ranks of the five choices vary with different appreciation rates, the order of the ranks between choices remains the same. This suggests that the 
homeowner's choice should be independent of the expected home appreciation rate. Of particular significance to the insurer, the table shows that doing nothing tends to have the best overall rank even assuming zero appreciation. Table 10 gives further evidence that this adverse selection problem is small. Assuming zero appreciation, doing nothing is more likely to yield a higher NPV than any HEC plan at any age or tax rate, except that the FH is more likely to have a higher NPV at age 65 or 70 in the zero tax bracket and at age 65 in the 15 percent tax bracket. The likelihood of any of the exceptions does not exceed 60 percent. 61

\section{1 .1 .4 Summary}

With few exceptions most homeowners expect to be better off by No than by using home equity conversion, suggesting that a need for additional cash flow should be the most important criterion for deciding whether to use home equity conversion. If home equity conversion is needed, the GR tends to have the highest likelihood of producing a superior NPV, except for certain persons at lower ages where the $\mathrm{FH}$ tends to have the highest likelihood. However, even for those persons, the advantage tends to be small. The superior NPV of the GR must be tempered by its low initial payment, which may be too

$61_{\text {This }}$ indicates that the homeowner is unlikely to use home equity conversion as an investment device. It does not address the possibility that homeowners who need home equity conversion may be more likely to live in deteriorating neighborhoods. 
low to benefit some homeowners. Neither the SI nor the SL is a favorable choice for the homeowner if NPV is used as a criterion.

4.1.2 Financial Institution

Unlike the homeowner, the financial institution may (and is expected to) invest in a portfolio of HEC instruments. This creates two major differences in the analysis of the financial institution. First, the expected NPV of cash flow is far more significant to the financial institution. Secondly, rather than comparing the HEC vehicles to each other, they can be analyzed individually. That is, each vehicle can be examined independently to find if its expected NPV is such that an investment is prudent.

Table 11 (with parts A, B, and C) shows the expected NPV of cash flows for each vehicle, broken down by expected appreciation, initial age, and tax rate. Note that, as expected, the mortgage options result in a NPV and standard deviation of zero; i.e., the mortgages produce a certain return equal to the discount rate. Both the SI and the SL always result in a positive NPV to the financial institution. However, the standard deviation of the NPVs is very high, indicating a need for a large portfolio to reduce risk. The high standard deviations suggest that the financial institutions may be unwilling to make these vehicles more attractive to the homeowner. Even if the financial 
institutions were willing to do this, the expected NPVs to the homeowner usually would still be worse than the mortgage plans (i.e., the combined NPVs of the homeowner (Table 3 ) and the financial institution (Table 11) are less favorable than the mortgage plans).

Table 12 (with parts $A, B$, and C) shows the internal rate of return ("IRR") of expected cash flows to the financial institution of each plan. This was developed by averaging the cash flows for all one thousand subjects by year and computing the IRR using the average cash flows. IRRs over 100 percent are not considered meaningful. As expected, the two mortgage plans have an IRR of 8.3 percent before tax and 5.478 (rounded in the table) percent after tax, the same as the discount rate used.

The IRRs of the SI and SL plans are extremely high, especially at advanced initial ages. Although the expected NPV decreases with age, the IRR increases. This is due, in part, to the extremely high leverage used in the these two plans. At the initial age of 85 , the income generated by the death of the homeowners is sufficient to cover the expected cash outflow from annuity payments and costs, even in the first years of the plan.

Table 11 shows that taxes do not play a material role in the financial institution's decision to invest in a particular plan. The NPVs of the mortgage plans are zero whatever the 
tax rate. The SI and SL plans have higher after-tax NPV's for ages 65 and 70, but lower after-tax NPV's starting at age 75 . Table 12 adds additional evidence of this; post-tax IRRs are consistently lower than pre-tax IRRs.

As with the other variables discussed above, the home appreciation rate does not affect the financial institution's return from the mortgage plans. Since the SI and SL give the benefit of additional appreciation to the financial institution, the financial institution generally has a higher expected NPV (Table 10) and IRR of expected NPV (Table 11) as the appreciation rate of the home increases. Due to lower property taxes and insurance costs, zero appreciation yields a better return than 4 percent appreciation at initial age 65 . For accounting policy, a major concern is whether adverse accounting rules may discourage the use of the SI or SL. The adverse accounting rules are most pronounced for the SI, under which the financial institution would report income only in the year the house was sold or the year the homeowner died (forfeiting the remaining annuity value). The financial institution shows a loss for all other years. Table 13 (with parts $A, B$, and $C$ ) shows the NPV of accounting flows of each plan. As demonstrated by the table, the expected NPVs for all plans are positive. The expected NPVs of the SI and SL always exceed that of the GR and, except for ages below 75 or at a zero home appreciation rate, exceed that of the FH. Clearly, 
given a portfolio of investments, the adverse effects are largely averaged away. In fact, a year-by-year analysis indicates that the expected accounting income tends to be positive for all but a few years, even at initial age 65 . 4.1.3 The FHA

Table 14 shows the NPV of the FHA expected cash flows from insuring each of the four plans. The minimum return on investment (IRR) needed for the FHA to break-even (Table 15) provides some additional information. Since the insured amount under the SI is the same as the FH, the values for the two plans are the same. At 8 percent appreciation, the FHA has positive expected cash flow for each year under all plans. Since negative returns are unlikely, for convenience, the table reports the minimum return as zero.

Assuming a house appreciation rate of 4 percent, Table 15 shows that the FHA should break-even under its current plan; expected cash flow is significantly different from zero only at age 80. At that appreciation rate, the IRR needed to break-even varies from 7.28 to 8.60 percent. At that rate, the break-even rate for the $G R$ is lower, ranging from 4.17 to 5.29 percent. This lower rate is due to the way the GR is organized. The balance due on the GR is lower than the mortgage balance on the FH until age 100. The higher NPVs of the GR for growth rates of zero and 4 percent are consistent with IRRs. At an 8 percent home appreciation rate, the FH has 
a higher NPV than the GR, because more premiums are collected and no claims are paid.

An examination of the SL suggests that the plan presented is adverse to the FHA. At a zero home appreciation rate, the FHA's NPV of expected losses is more than triple that of any other plan. At 4 percent appreciation, rather than breakingeven, the plan shows a significant profit for an initial age of 65, while showing significant losses for initial ages of 75 and over. Although the NPV of expected cash flows is higher than any other plan if the home appreciation rate is 8 percent, it is probably not enough to offset the negative results at lower appreciation rates.

4.2 Tax Policy Questions

This section addresses two important issues. The first is the concept of vertical equity (i.e., higher income taxpayers pay more taxes). The second is the existence of a tax subsidy (i.e., it is more profitable to pay taxes than not pay taxes). The discussion in section 4.1 foreshadows the examination of to these two issues. Since tax is not a significant factor for either the homeowner or the financial institution, there is not likely to be a problem with either issue.

Section 4.1 .1 .2 , noted that the ranking of plans to the homeowner is not affected by tax rates. A study of Table 3 suggests that the choice between plans using NPV is also not 
affected by tax rates, except in a few instances where the differences between the NPV's of the two plans are small. All these instances involved a choice between the $\mathrm{FH}$ and the GR, which are not actually different from a tax standpoint. In Table 11, the ranking of NPV's of each plan for any given age and home appreciation rate is the same before- and after-tax. This shows that the tax system does not favor one plan over another.

The second question is closely related to the findings in section 4.1.1.2. The results show that most homeowners would be better off doing nothing than using any form of HEC. The second question raises a different issue: Is there a negative effective tax rate on expected cash flows for any plan? To evaluate this, the NPV of expected cash flows was examined for both the homeowner and financial institution at all possible tax rates $(0,15$ and 28 percent for the homeowner and 0 and 34 percent for the financial institution). A discount rate of 8.3 percent was used regardless of tax rate. The expected NPV of cash flows for a higher tax rate is always lower than that for a lower tax rate (given the same initial age and home appreciation rate). Therefore, the hypothesis that there is a tax subsidy cannot be supported. 
The simulation used to test the sensitivity of the FHA model resulted in a base expected net present value of $\$ 1,200$ with a standard deviation of $\$ 5,077$. Considering the number of simulations $(1,000)$, the standard deviation of the sample mean is $\$ 161$. The confidence intervals for testing the equality of the means in subsequent tests are $\$ 316$ at the 95 percent confidence level and $\$ 415$ at the 99 percent confidence level.62 The tests each have 1,000 data points and assume a two tailed test.

The base analysis shows that the minimum expected discount rate to break-even is 5.79 percent. The expected values are not significantly different from zero $(p=.05)$ for interest rates ranging from about 5.4 percent to 6.3 percent (see Table 16). The differences in expected value with increasing discount rates (in Table 16) show that the differences decrease as interest rates increase.

The move-out rate does not appear to be a significant factor for the FHA. As shown by Table 17, assuming no moveouts, the FHA would expect a net present value of cash flows of $\$ 728$, which is significantly different from zero $(p=.01)$.

${ }^{62}$ These confidence intervals are used for all tests of the FHA assumptions. In computing changes in the mean value of expected return with changes in the values of the assumptions, changes in the standard deviation of the returns were not computed. It is possible that confidence levels for different changes in assumptions may differ from these levels. However, the changes are likely to be small. 
The table also shows that a five percentage point change in the move-out rate seldom made a difference exceeding $\$ 100$. This suggests that differences in expected move-out rates of 15 percent cannot be said to be statistically different $(p=.05)$.

As demonstrated by Table 18, the effect of the sales price as a percent of fair market value by itself is not an important variable. The net present value is not significantly different from zero $(p=.05)$ if the sales price discount is between 10 and 14 percent. 63 Discounts greater than 14 percent are probably unusual.

The expected home appreciation rate is a major component of the FHA model. As demonstrated by Table 19, FHA's risk of overestimating the home appreciation rate is great. The mean rate $^{64}$ for breaking even is 3.3 percent. Rates of 3.2 to 3.4 percent are not statistically different $(p=.05)$ from zero, a narrow range. The table also shows that most of the profits resulting from appreciation rates higher than assumed by the model primarily benefit the homeowner. For example, appreciation in excess 7 percent only benefits the homeowner. This relationship demonstrates the importance of the variance of the mean appreciation rate between homes. Table

${ }^{63}$ The methodology of this research considers the discount a fixed variable, no analysis is performed as to the effect of variance.

${ }^{64} \mathrm{Th}$ is assumes all homes appreciate at the same rate. 
20 shows that if the mean home appreciation rate is 4 percent, the expected net present value would be approximately zero if the standard deviation of returns between homes is 2.8 percent. A standard deviation of between 2.2 percent and 3.4 percent is not statistically different $(p=.05)$ from zero. Assuming a mean 4 percent appreciation rate and using the 2.2 standard deviation, the FHA could expect to break even if about two-thirds of the homes have an appreciation rate between 1.8 percent and 6.2 percent and less than one-sixth of the homes have an appreciation rate of less than 1.2 percent. It appears that the range is reasonable. 
TABLE 2

HOMEOWNER'S INITIAL ANNUAL PAYMENT (in dollars)

\begin{tabular}{|c|c|c|c|c|c|}
\hline & \multicolumn{5}{|c|}{ INITIAL AGE } \\
\cline { 2 - 7 } & 65 & 70 & 75 & 80 & 85 \\
\hline $\mathrm{FH}$ & $3,065.90$ & $3,756.34$ & $4,646.82$ & $5,828.06$ & $7,570.46$ \\
\hline $\mathrm{GR}$ & $1,492.31$ & $2,021.35$ & $2,756.75$ & $3,812.86$ & $5,481.51$ \\
\hline $\mathrm{SI}$ & $1,517.00$ & $2,613.11$ & $4,300.09$ & $7,103.76$ & $10,980.58$ \\
\hline $\mathrm{SL}^{*}$ & $1,194.09$ & $2,333.85$ & $4,066.18$ & $6,916.71$ & $10,831.52$ \\
\hline
\end{tabular}

*Net of interest and FHA insurance. 
TABLE 3A

\section{HOMEOWNER'S NPV OF EXPECTED CASH FLOW ZERO APPRECIATION (in dollars)}

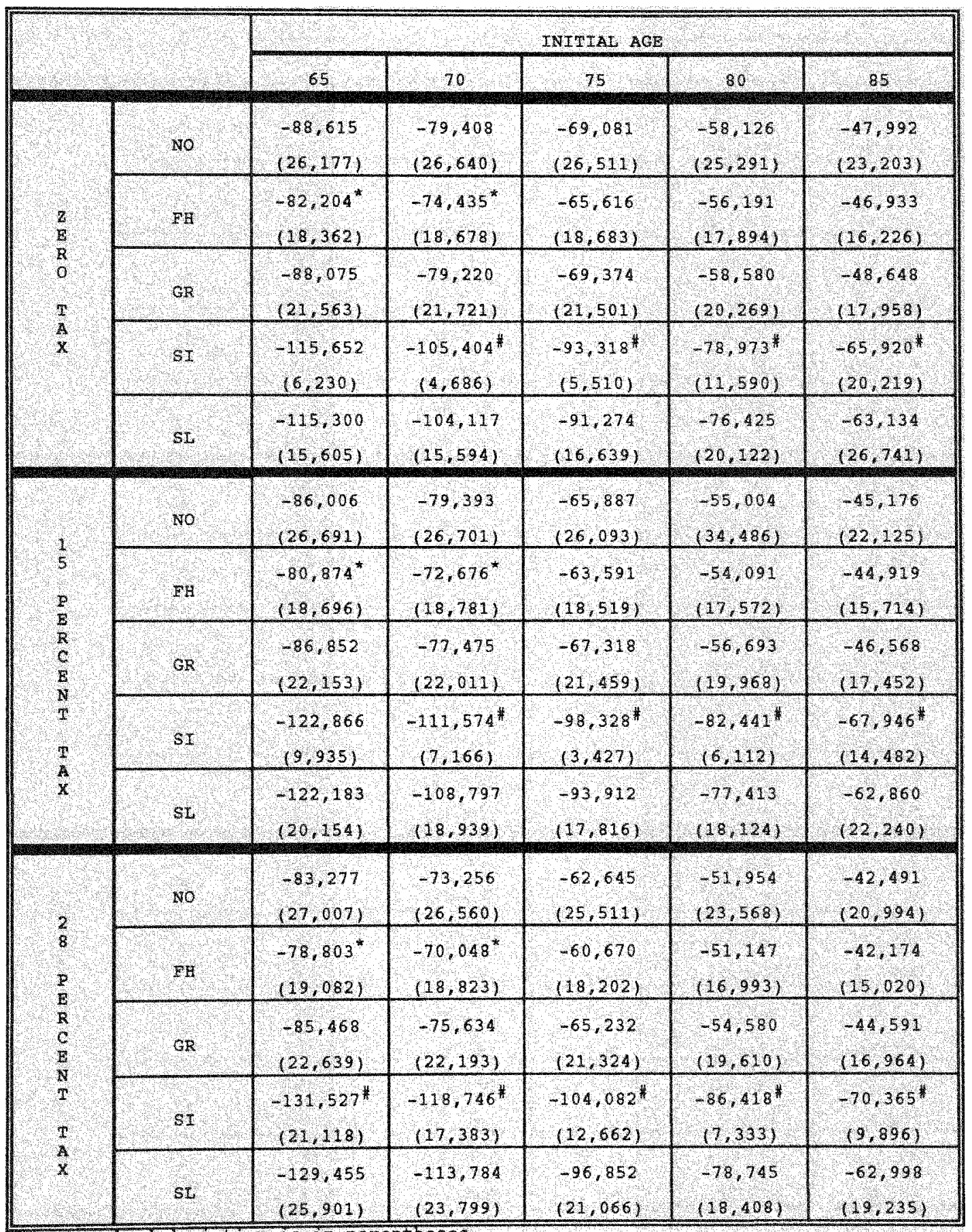

Standard deviation is in parentheses.

* Highest expected NPV ( $p=.05$ )

\# Lowest expected NPV $(p=.05)$ 
TABIE $\quad 3 \mathrm{~B}$

HOMEOWNER'S NPV OF EXPECTED CASH FLOW

48 APPRECIATION

(in dollars)

\begin{tabular}{|c|c|c|c|c|c|c|}
\hline & & \multicolumn{5}{|c|}{ INITIAL AGE } \\
\hline & & 65 & 70 & 75 & 80 & 85 \\
\hline \multirow{5}{*}{$\begin{array}{l}Z \\
E \\
R \\
0\end{array}$} & \multirow{2}{*}{ no } & $-81,929^{\circ}$ & $-78,938^{*}$ & $-66,370^{\circ}$ & $-43,738^{*}$ & $-43,738^{*}$ \\
\hline & & $(32,522)$ & $(31,190)$ & $(29,166)$ & $(26,272)$ & $(22,871)$ \\
\hline & \multirow{2}{*}{$\mathrm{FH}$} & $-95,317$ & $-83,126$ & -70.545 & $-58,193$ & $-46,933$ \\
\hline & & $(30,058)$ & $(28,799)$ & $(26,810)$ & $(23,920)$ & $(16,226)$ \\
\hline & \multirow{2}{*}{ GR } & $-97,638$ & $-84,992$ & $-71,946$ & $-59,159$ & $-47,912$ \\
\hline \multirow{2}{*}{$\begin{array}{l}\mathrm{T} \\
\mathrm{A}\end{array}$} & & $(32,550)$ & $(31,046)$ & $(28.716)$ & $(25,414)$ & $(21.121)$ \\
\hline & \multirow{2}{*}{51} & $-115,652$ & $-105,404^{f}$ & $-93,318^{I}$ & $-78,973^{t}$ & $-65,920^{\prime \prime}$ \\
\hline & & $(6,230)$ & $(4,686)$ & $(5,510)$ & $(11,590)$ & $(20.219)$ \\
\hline & \multirow{2}{*}{ SL } & $-115,300$ & -104.117 & $-91,274$ & $-76,425$ & $-63,134$ \\
\hline & & $(15,605)$ & $(15,594)$ & $(16,639)$ & $(20,122)$ & $(26,714)$ \\
\hline \multirow{3}{*}{3} & \multirow{2}{*}{ No } & $-86,788^{*}$ & $-74,221^{*}$ & $-61,811^{*}$ & $-50,058^{\prime}$ & $-40,219^{k}$ \\
\hline & & $(32,881)$ & $(30.782)$ & $(28,123)$ & $(24,804)$ & $(21,200)$ \\
\hline & \multirow{2}{*}{$\mathrm{FH}$} & $-95,625$ & -82.252 & $-68,907$ & $-56,200$ & $-45,200$ \\
\hline P & & $(32,665)$ & $(30,568)$ & $(27,749)$ & $(24,178)$ & $(19,727)$ \\
\hline R & \multirow{2}{*}{ GR } & -97.204 & $-83,519$ & $-69,880$ & $-56,899$ & $-45,7116$ \\
\hline E & & $(35,232)$ & $(32,806)$ & $(29.588)$ & $(25,573)$ & $(20,738)$ \\
\hline T & \multirow{2}{*}{ SI } & $-122,866$ & $-111,547^{t}$ & $-98,328^{t}$ & $-82,441$, & $-67,946^{f}$ \\
\hline \multirow{3}{*}{$\frac{T}{A}$} & & $(9,935)$ & $(7,166)$ & $(3,427)$ & $(6,112)$ & $(14,482)$ \\
\hline & \multirow{2}{*}{ SL } & $-122,183$ & $-108,797$ & $-93,9124$ & $-77,413$ & -62.860 \\
\hline & & $(20,154)$ & $(18,939)$ & $(17,816)$ & $(18,124)$ & $(22,240)$ \\
\hline \multirow{3}{*}{$\begin{array}{l}2 \\
8\end{array}$} & \multirow{2}{*}{ No } & $-81,929^{\circ}$ & $-69,245^{*}$ & $-57,123^{*}$ & $-45,960^{\circ}$ & $-42,491^{\prime}$ \\
\hline & & $(32,711)$ & $(29,913)$ & $(26,735)$ & $(23,115)$ & $(20,994)$ \\
\hline & \multirow{2}{*}{ H } & -95.877 & $-81,302$ & -67.245 & $-54,248$ & $-43,285$ \\
\hline \multirow{4}{*}{$\begin{array}{l}P \\
E \\
A \\
C \\
E \\
\text { N } \\
T\end{array}$} & & $(35,508)$ & $(32,394)$ & $(28,652)$ & $(24,374)$ & $(19,406)$ \\
\hline & \multirow{2}{*}{ GR } & $-96,637$ & $-81,954$ & $-66,768$ & $-54,658$ & $-43,632$ \\
\hline & & $(38,083)$ & $(34,580)$ & $(30,402)$ & $(25.599)$ & $(20,331)$ \\
\hline & \multirow{2}{*}{ sI } & $-131,527$ & $-118,746^{\mathrm{m}}$ & $-104,082^{z}$ & $-86,418$ & $-70.365^{\#}$ \\
\hline \multirow{3}{*}{$\frac{T}{\mathrm{~A}}$} & & $(21,118)$ & $(17,383)$ & $(12,662)$ & $(7,333)$ & $(9,896)$ \\
\hline & \multirow{2}{*}{51} & $-129,455$ & $-113,784$ & $-96,852$ & $-78,745$ & $-62,998$ \\
\hline & & $(25,901)$ & $(23,799)$ & $(21,066)$ & $(18,908)$ & $(19,235)$ \\
\hline
\end{tabular}

Standard deviation is in parentheses.

$\begin{array}{ll}* & \text { Highest expected NPV }(p=.05) \\ \text { Lowest expected NPV }(p=.05)\end{array}$ 
TABLE $3 \mathrm{C}$

\section{HOMEOWNER'S NPV OF EXPECTED CASH FLOW $8 \%$ APPRECIATION (in dollars)}

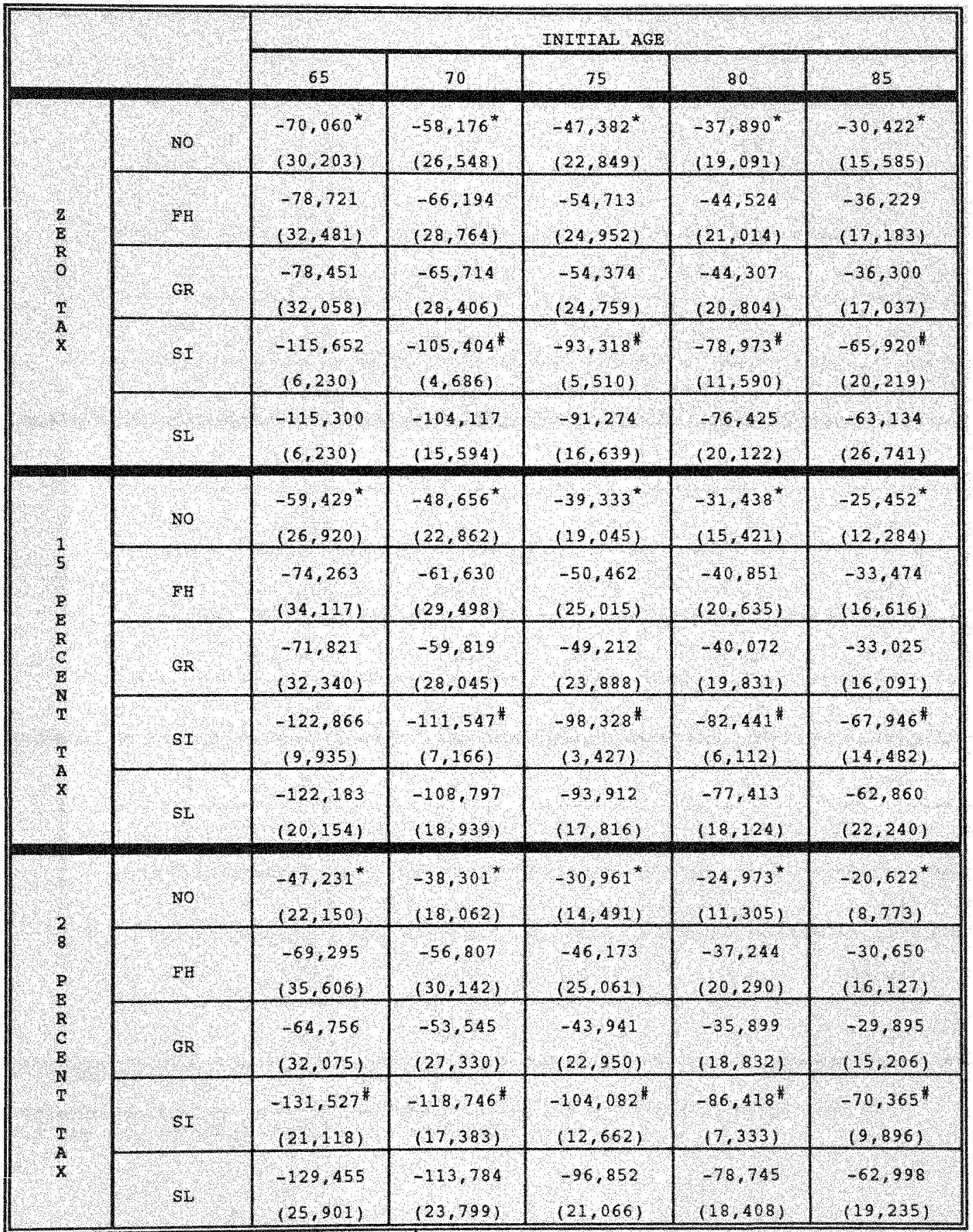

standard deviation is in parentheses.

* Highest expected NPV $(p=.05)$

Lowest expected NPV $(p=.05)$ 
TABLE 4A

\section{HOMEOWNER'S NPV OF EXPECTED CASH FLOW RANK ZERO APPRECIATION}

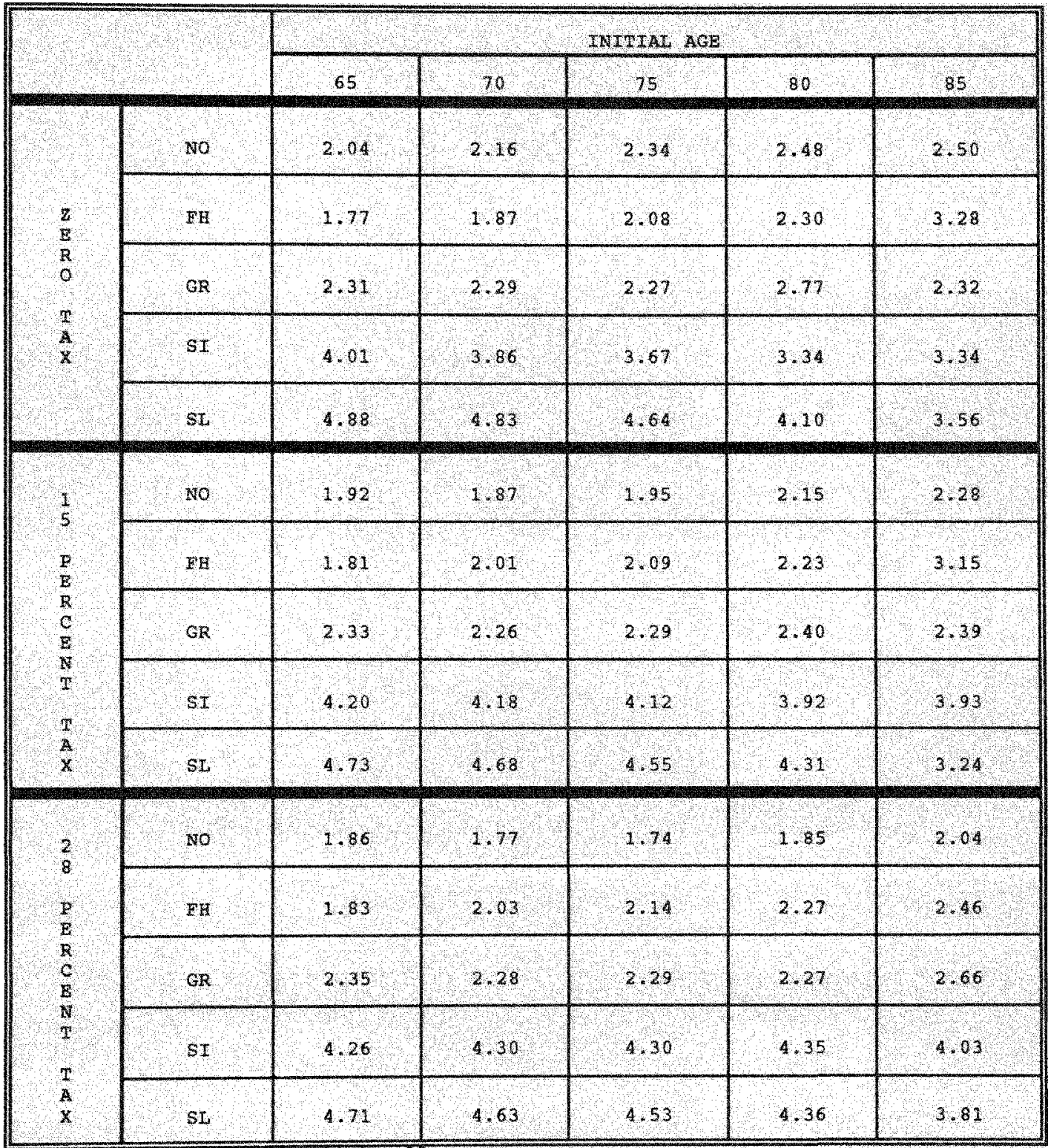

standard deviation 1s 1.4h in all cases.

Differences between ranks of more than .10 and .15 are significant at the .05 and the .01 levels of significance respectively. 
TABLE 4B

HOMEOWNER'S NPV OF EXPECTED CASH FLOW RANK $4 \%$ APPRECIATION

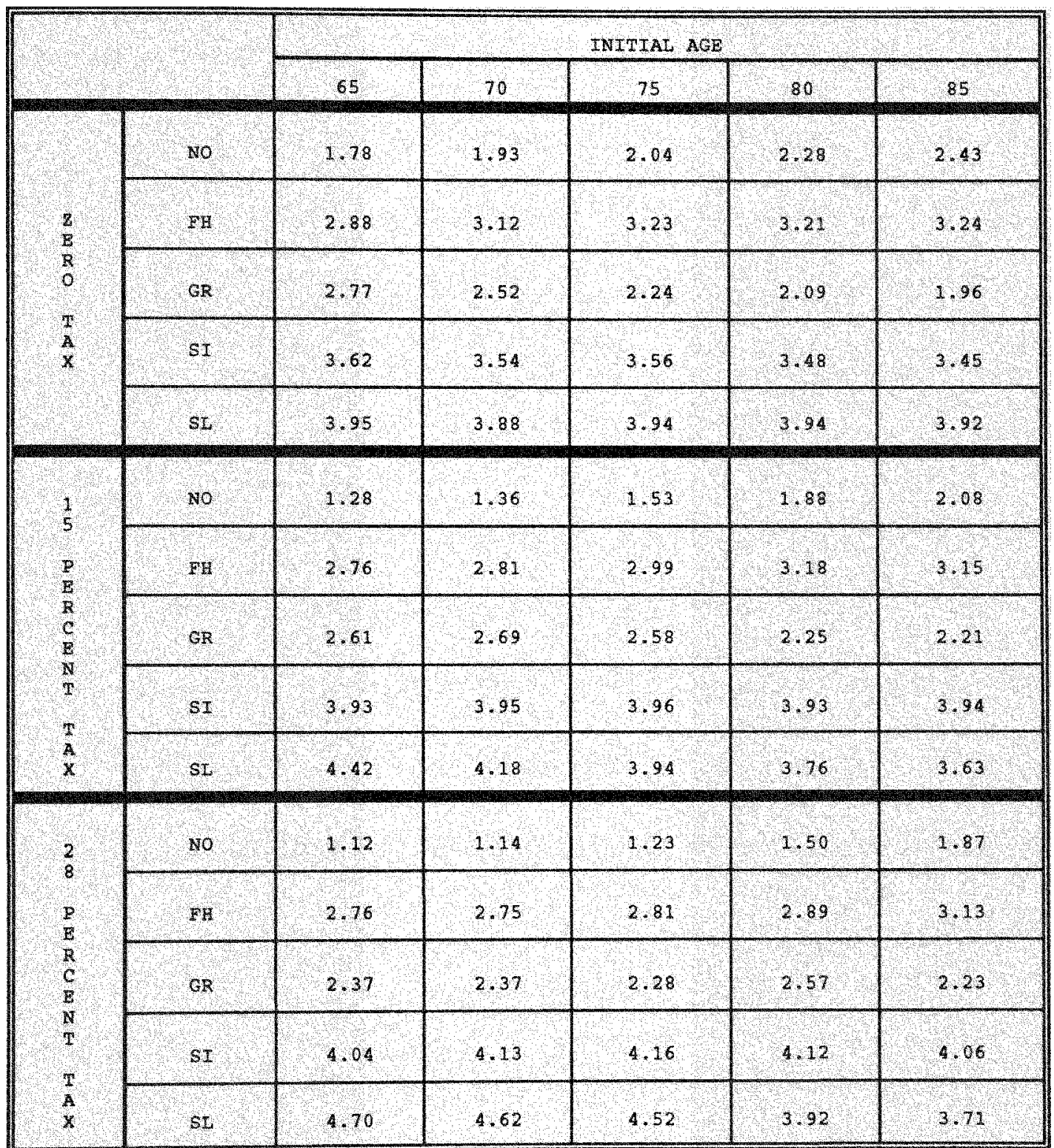

standard deviation is 1.4T in al cases.

Differences between ranks of more than .10 and .15 are gignificant at the .05 and the .01 levels of significance respectively. 
TABLE $4 \mathrm{C}$

HOMEOWNER'S NPV OF EXPECTED CASH FLOW RANK

8\% APPRECIATION



Standard deviation 19 T. 414 in all cases.

Differences between ranks of more than .10 and .15 are significant at the .05 and the .01 levels of significance respectively. 
TABLE 5A

TIMES PLAN HAD HIGHEST TWO NPV TO HOMEOWNER ZERO APPRECIATION

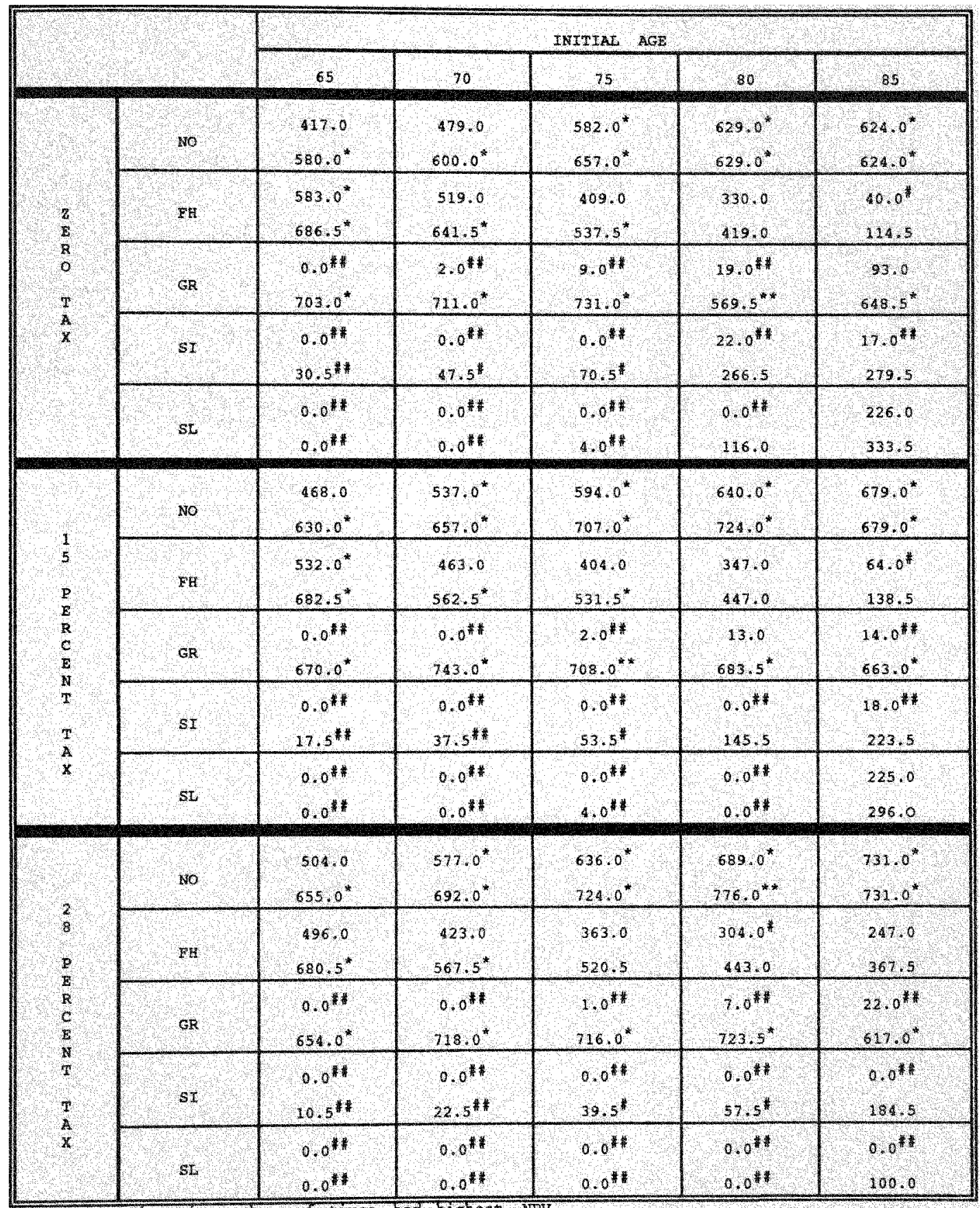

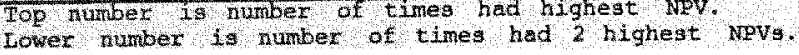

* Probability of highest (or highest 2) NPV(s) $>508(\mathrm{P}=.05$ ),

* Probability of highest (or highest 2) NPV(s) $>758(P .05)$.

* Probability of highest (or highest 2) NPV(s) $>908(p=.05)$.

* Probability of highest (or highest 2 ) NPV(s) $<208(\mathrm{P} \approx .05)$.

* Probability of highest (or highest 2 ) NPV(s) $<58(\mathrm{~g} \approx .05)$. 
TABIE $5 B$

TIMES PLAN RAD HIGHEST TWO NPVS TO HOMEOWNER 48 APPRECIATION

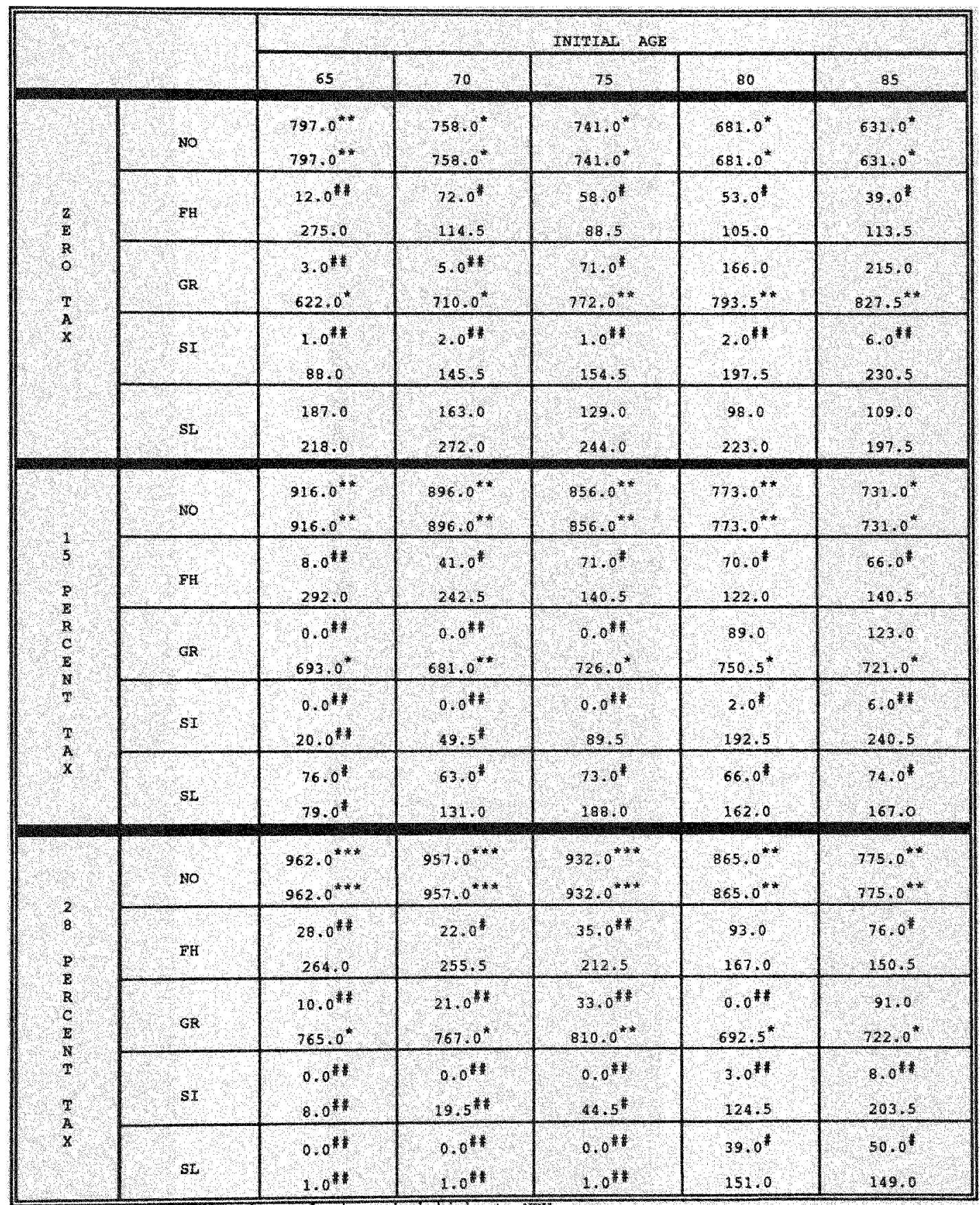

Top number. 13 number of thes hac highegt Nov.

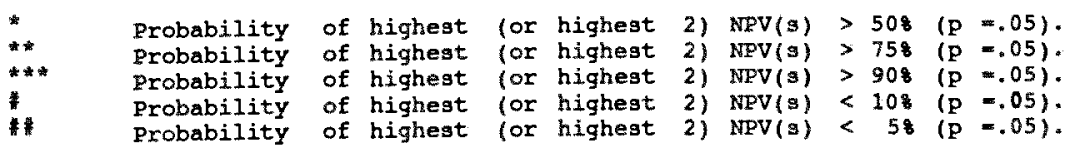


TABLE $5 \mathrm{C}$

TIMES PLAN HAD HIGHEST TWO NPV TO HOMEOWNER 88 APPRECIATION

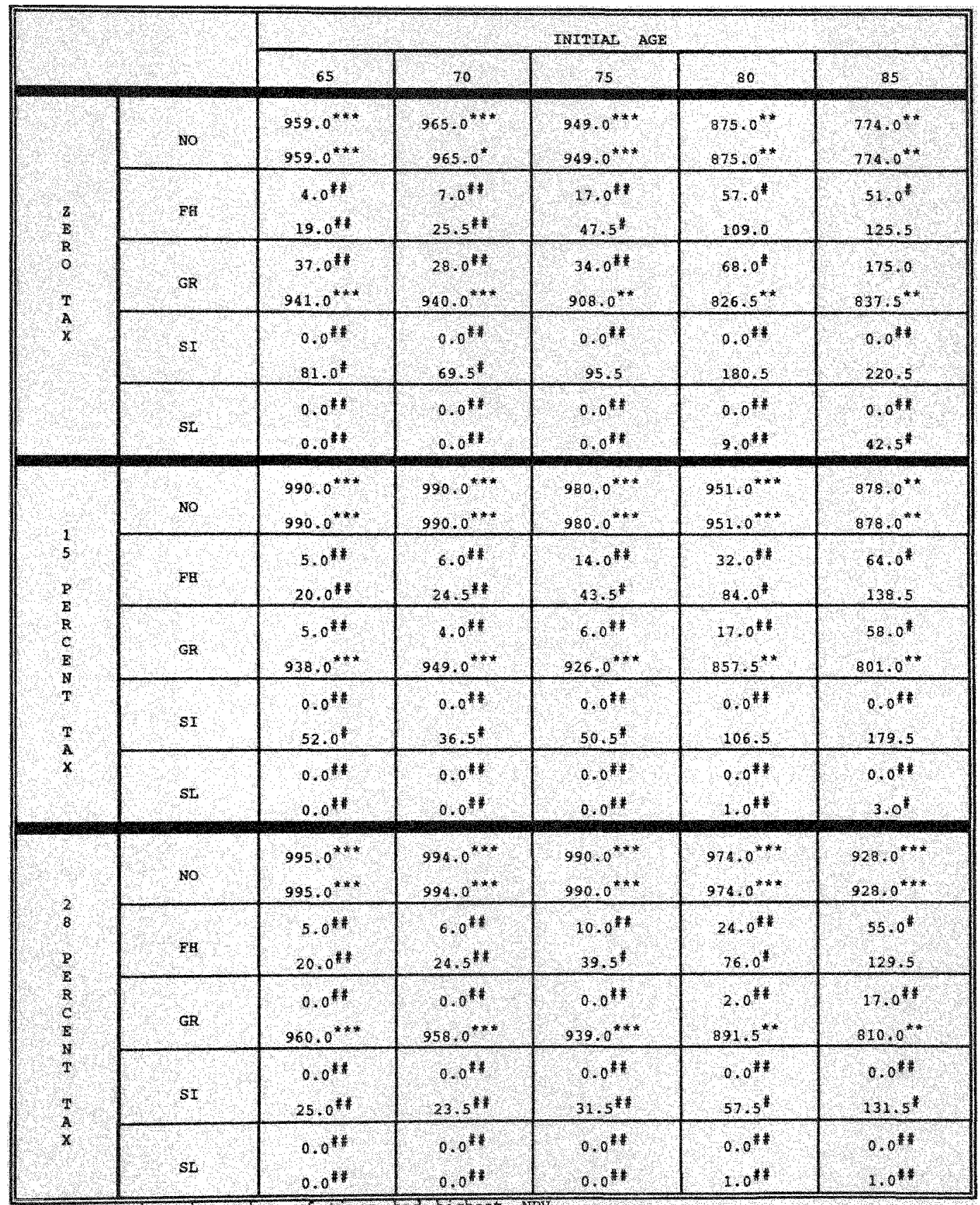

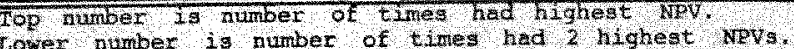

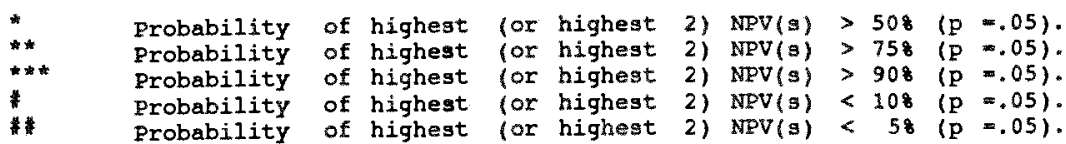


TABLE 6A

TIMES PLAN HAD IOWEST TWO NPVS TO HONEOWNER ZERO APPRECIATION

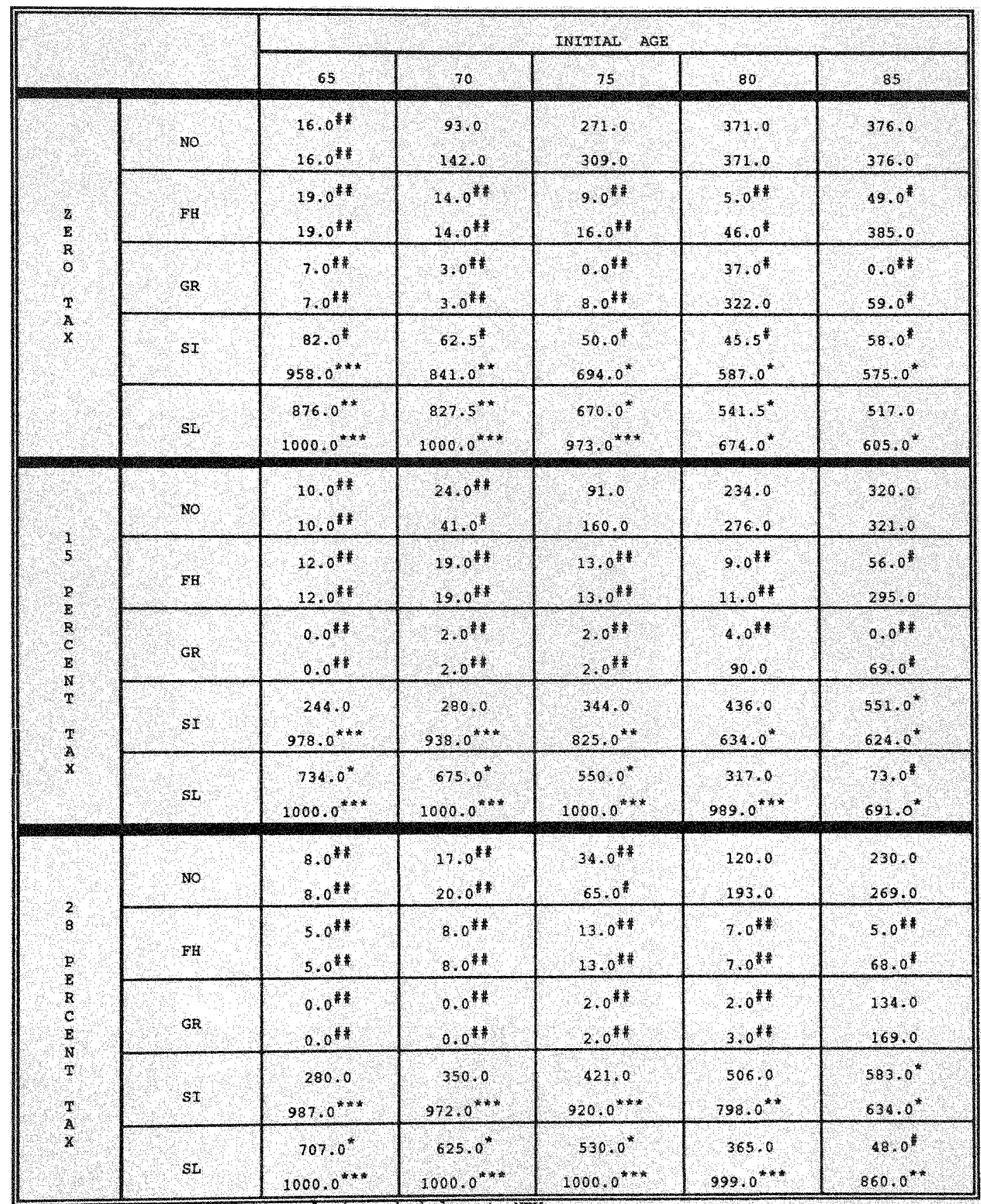

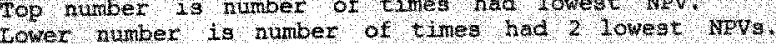

\begin{tabular}{|c|c|c|c|c|c|c|c|c|c|c|c|}
\hline * & robability & of & lowest & for & lowegt & 2) & $\operatorname{MPV}(\mathrm{s})$ & $>$ & 508 & ( & $=.051$ \\
\hline * & & of & lowest & lor & lowest & $2 j$ & $\mathrm{NPV}(\mathrm{s})$ & $>$ & 758 & $(p$ & $=$ \\
\hline$* *$ & Probability & of & lowest & for & lowest & 2) & $\operatorname{NPV}(s)$ & $>$ & 908 & ip & $=0$ \\
\hline 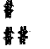 & $\begin{array}{l}\text { Probability } \\
\text { Probability }\end{array}$ & $\begin{array}{l}\text { of } \\
\text { of }\end{array}$ & $\begin{array}{l}\text { lowest } \\
\text { lowest }\end{array}$ & $\begin{array}{l}\text { for } \\
\text { for }\end{array}$ & & 2) & $\begin{array}{l}\text { NPV (s) } \\
\text { NEV (s) }\end{array}$ & $<$ & $\begin{array}{r}108 \\
58\end{array}$ & (p & \\
\hline
\end{tabular}


TABLE 6B

TIMES PLAN HAD LOWEST TWO NPVS TO HOMEOWNER 48 APPRECIATION

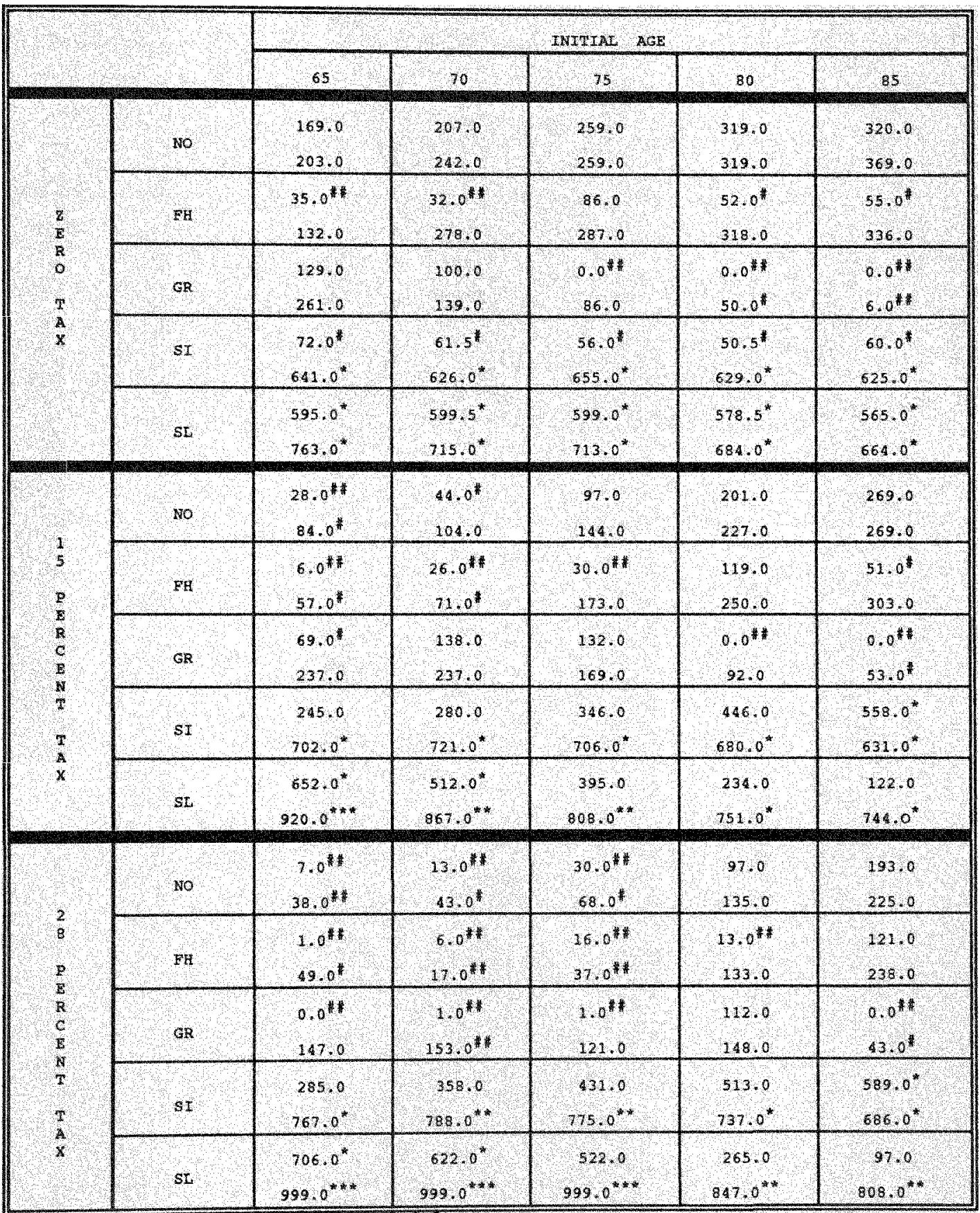

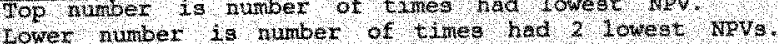

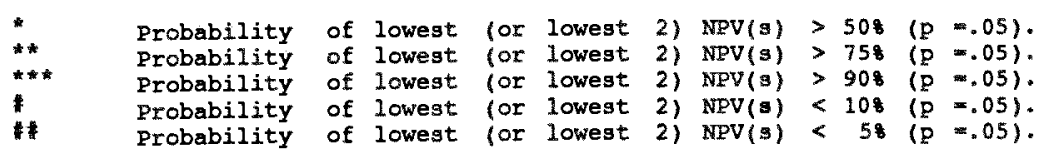


TABLE 6C

TIMES PLAN HAD LOWEST TWO NPVS TO HOMEOWNER 88 APPRECIATION

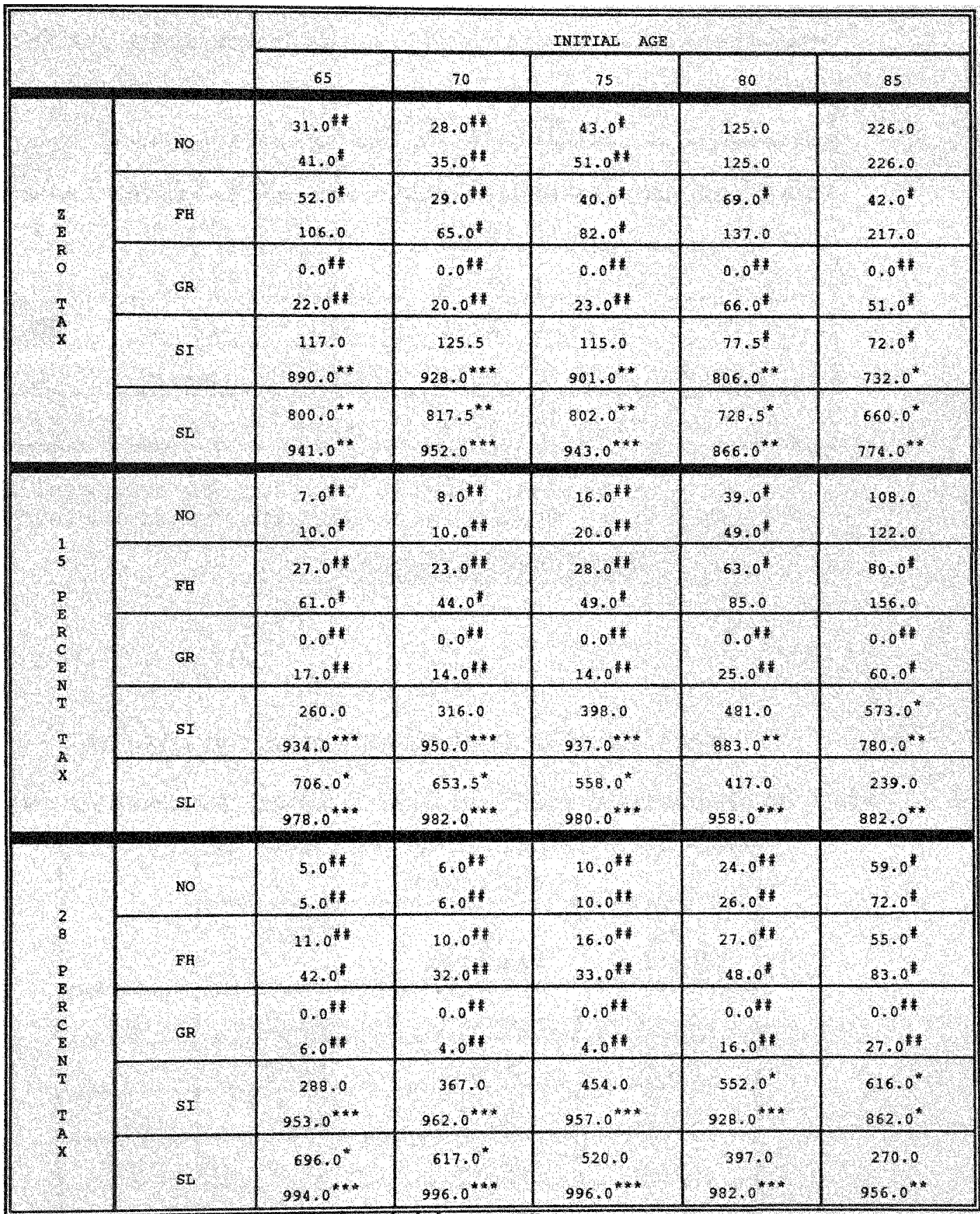

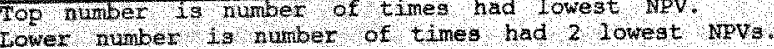

* Probability of lowest (or lowest 2) NPV(s) > $508(0 \mathrm{~m} .05)$.

* $\quad$ Probability of lowegt (or lowest 2) NPV(s) $>758(\mathrm{p}=.05)$

* * Probability of lowest (or lowest 2) NPV(g)>90 (P $\$ .05)$.

* Probability of lowest (or lowest 2) NPV(s) < 108 (p .05 ).

* Probability of lowest (or lowest 2) $\operatorname{MPV}(\mathrm{s})<58(\mathrm{p}=.05)$. 
TABLE 7

HOMEOWNER'S EXPECTED RANK BY AGE

(without regard to tax or home appreciation rates)

\begin{tabular}{|c|c|c|c|c|c|}
\hline & \multicolumn{5}{|c|}{ INITIAL AGE } \\
\cline { 2 - 6 } & 65 & 70 & 75 & 80 & 85 \\
\hline NO & 1.47 & 1.49 & 1.56 & 1.74 & 1.98 \\
\hline FH & 2.56 & 2.63 & 2.70 & 2.78 & 3.05 \\
\hline GR & 2.52 & 2.29 & 2.25 & 2.30 & 2.25 \\
\hline SI & 4.04 & 4.05 & 4.08 & 4.01 & 3.87 \\
\hline SL & 4.61 & 4.54 & 4.41 & 4.17 & 3.85 \\
\hline
\end{tabular}

Differences of .05 are significant at $p=.05$.

Differences of .09 are significant at $p=.01$.

TABLE 8

HOMEOWNER'S EXPECTED RANK BY TAX RATE

(without regard to initial age or home appreciation rate)

\begin{tabular}{|c|c|c|c|}
\hline \multirow{2}{*}{} & \multicolumn{3}{|c|}{ TAX RATE } \\
\cline { 2 - 4 } & ZERO & $\begin{array}{c}15 \\
\text { PERCENT }\end{array}$ & $\begin{array}{c}28 \\
\text { PERCENT }\end{array}$ \\
\hline NO & 1.90 & 1.61 & 1.44 \\
\hline FH & 2.81 & 2.76 & 2.67 \\
\hline GR & 2.26 & 2.30 & 2.28 \\
\hline SI & 3.73 & 4.08 & 4.22 \\
\hline SL & 4.30 & 4.25 & 4.39 \\
\hline
\end{tabular}

Differences of .05 are significant at $p=.05$. Differences of .06 are significant at $p=.01$. 
TABLE 9

HOMEOWNER'S EXPECTED RANK BY HOME APPRECIATION RATE

(without regard to initial age or tax rate)

\begin{tabular}{|c|c|c|c|}
\hline \multirow{2}{*}{} & \multicolumn{3}{|c|}{ APPRECIATION RATE } \\
\cline { 2 - 4 } & ZERO & $\begin{array}{c}4 \\
\text { PERCENT }\end{array}$ & $\begin{array}{c}8 \\
\text { PERCENT }\end{array}$ \\
\hline NO & 2.06 & 1.70 & 1.19 \\
\hline FH & 2.22 & 2.99 & 3.02 \\
\hline GR & 2.37 & 2.38 & 2.09 \\
\hline SI & 3.99 & 3.86 & 4.19 \\
\hline SL & 4.36 & 4.07 & 4.51 \\
\hline
\end{tabular}

Differences of .05 are significant at $p=.05$. Differences of .06 are significant at $p=.01$. 
TABLE 10

TIMES HOMEOWNER'S NPV EXCEEDS DOING NOTHING ZERO APPRECIATION

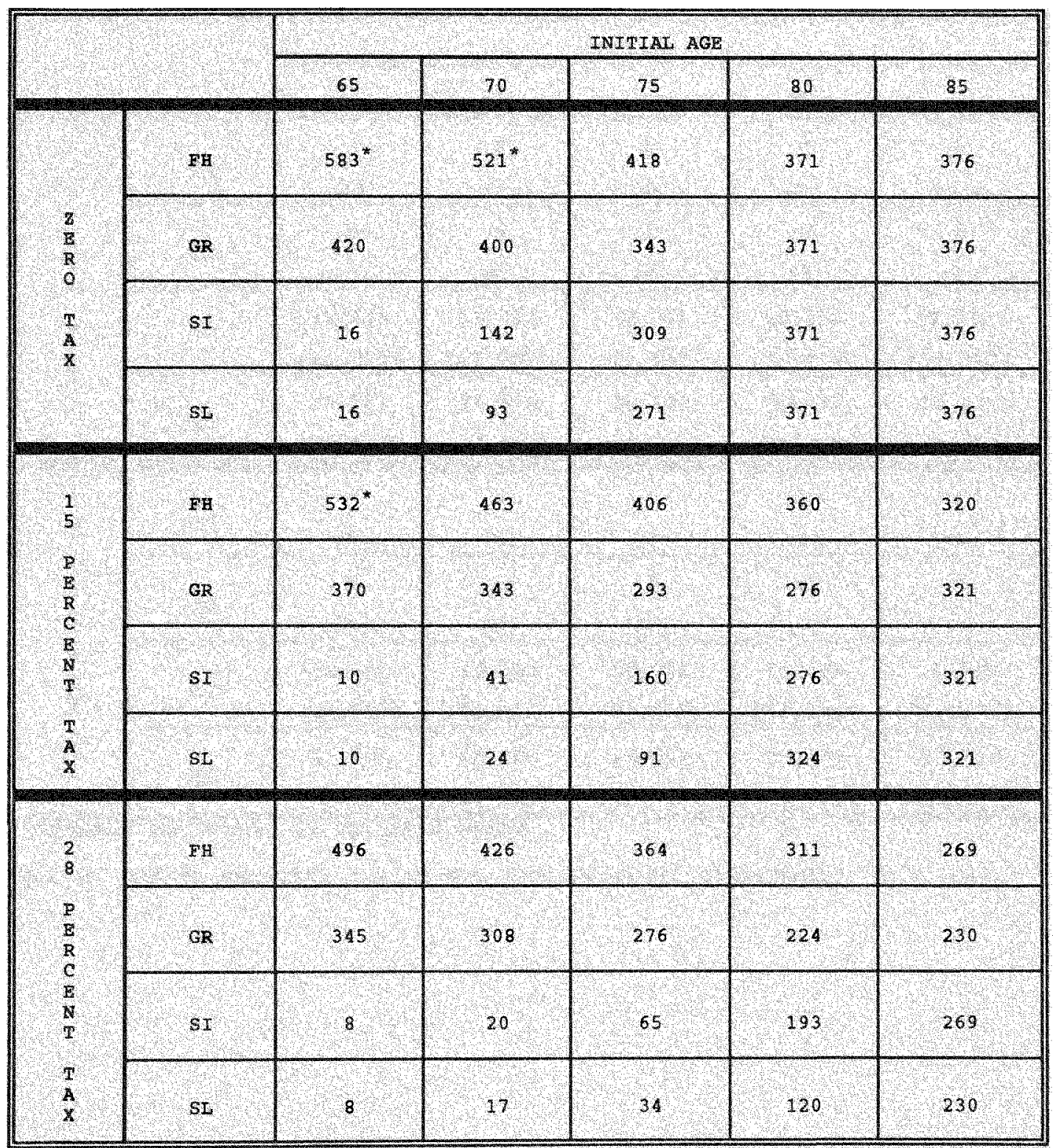

* Probability that plan's NPV is greater than doing nothing $>508(p=.05)$.

** Probability that plan's NPV is greater than doing nothing $>758(p=.05)$.

** Probability that plan's NPV is greater than doing nothing $>908(p=.05)$. 
TABLE 11A

FINANCIAL INSTITUTION'S NPV OF EXPECTED CASH FLOW ZERO APPRECIATION

(in dollars)

\begin{tabular}{|c|c|c|c|c|c|c|}
\hline & & & & \\
\hline
\end{tabular}

standard deviation is in parentheses.

AII SI and SI expected values are statistically significant $(p=.01)$. 
TABLE 11B

FINANCIAL INSTITUTION'S EXPECTED CASH FLOW $4 \%$ APPRECIATION

(in dollars)

\begin{tabular}{|c|c|c|c|c|c|c|}
\hline & & \multicolumn{5}{|c|}{ INITIAL AGE } \\
\hline & & 65 & 70 & 75 & 80 & 85 \\
\hline \multirow{4}{*}{$\begin{array}{l}\mathrm{Z} \\
\mathrm{E} \\
\mathrm{R} \\
0 \\
\mathrm{~T} \\
\mathrm{~A} \\
\mathrm{X}\end{array}$} & $\mathrm{FH}$ & $\begin{array}{l}0 \\
(0) \\
\end{array}$ & $\begin{array}{l}0 \\
101\end{array}$ & $\begin{array}{l}0 \\
101 \\
\end{array}$ & $\begin{array}{l}0 \\
(0) \\
\end{array}$ & $\begin{array}{r}0 \\
(0) \\
\end{array}$ \\
\hline & GR & $\begin{array}{l}0 \\
(0) \\
\end{array}$ & $\begin{array}{r}0 \\
(0) \\
\end{array}$ & $\begin{array}{l}0 \\
10) \\
\end{array}$ & $\begin{array}{l}0 \\
(0) \\
\end{array}$ & $\begin{array}{l}0 \\
(0) \\
\end{array}$ \\
\hline & SI & $\begin{array}{l}17,314 \\
(24,010) \\
\end{array}$ & $\begin{array}{r}18,952 \\
(26,188) \\
\end{array}$ & $\begin{array}{r}19,281 \\
(29,589) \\
\end{array}$ & $\begin{array}{l}17,307 \\
(34,854)\end{array}$ & $\begin{array}{l}15,357 \\
(40,430)\end{array}$ \\
\hline & SL & $\begin{array}{l}16,818 \\
(30,287)\end{array}$ & $\begin{array}{c}19,725 \\
(32,196)\end{array}$ & $\begin{array}{l}21,336 \\
(35,329)\end{array}$ & $\begin{array}{l}20,640 \\
(40,341)\end{array}$ & $\begin{array}{l}19,534 \\
(46,084)\end{array}$ \\
\hline 3 & FH & $\begin{array}{l}0 \\
(0) \\
\end{array}$ & $\begin{array}{r}0 \\
(0) \\
\end{array}$ & $\begin{array}{l}0 \\
(0) \\
\end{array}$ & $\begin{array}{l}0 \\
(0) \\
\end{array}$ & $\begin{array}{l}0 \\
(0)\end{array}$ \\
\hline \multirow{2}{*}{$\begin{array}{l}\mathrm{P} \\
\mathrm{E} \\
\mathrm{R} \\
\mathrm{C} \\
\mathrm{E} \\
\mathrm{N} \\
\mathrm{T}\end{array}$} & GR & $\begin{array}{l}0 \\
(0) \\
\end{array}$ & $\begin{array}{l}0 \\
(0) \\
\end{array}$ & $\begin{array}{l}0 \\
(0) \\
\end{array}$ & $\begin{array}{l}0 \\
10) \\
\end{array}$ & $\begin{array}{l}0 \\
10) \\
\end{array}$ \\
\hline & ST & $\begin{array}{l}22,202 \\
(26,150)\end{array}$ & $\begin{array}{r}21,166 \\
(26,313) \\
\end{array}$ & $\begin{array}{r}19,135 \\
(26,525) \\
\end{array}$ & $\begin{array}{l}15,640 \\
(27,395) \\
\end{array}$ & $\begin{array}{r}12,780 \\
(29,584) \\
\end{array}$ \\
\hline $\begin{array}{l}\mathrm{T} \\
\mathrm{A} \\
\mathrm{X} \\
\end{array}$ & SI & $\begin{array}{l}21,733 \\
(19,154)\end{array}$ & $\begin{array}{c}21,655 \\
(20,483)\end{array}$ & $\begin{array}{r}20,556 \\
(22,881) \\
\end{array}$ & $\begin{array}{l}18,056 \\
(26,711) \\
\end{array}$ & $\begin{array}{r}15,674 \\
(31,043) \\
\end{array}$ \\
\hline
\end{tabular}

standard deviation is in parentheses.

AII SI and SL expected values are statistically significant $(p=.01)$. 
TABLE $11 C$

FINANCIAL INSTITUTION'S NPV OF EXPECTED CASH FLOW 8\% APPRECIATION

(in dollars)

\begin{tabular}{|c|c|c|c|c|c|c|}
\hline & & \multicolumn{5}{|c|}{ INITIAL AGE } \\
\hline & & 65 & 70 & 75 & 80 & 85 \\
\hline \multirow{4}{*}{$\begin{array}{c}\mathrm{Z} \\
\mathrm{E} \\
\mathrm{R} \\
\mathrm{O} \\
\mathrm{T} \\
\mathrm{A} \\
\mathrm{X}\end{array}$} & $\mathrm{EH}$ & $\begin{array}{l}0 \\
(0) \\
\end{array}$ & $\begin{array}{c}0 \\
(0) \\
\end{array}$ & $\begin{array}{l}0 \\
(0) \\
\end{array}$ & $\begin{array}{l}0 \\
101 \\
\end{array}$ & $\begin{array}{l}0 \\
(0) \\
\end{array}$ \\
\hline & GR & $\begin{array}{l}0 \\
(0) \\
\end{array}$ & $\begin{array}{r}0 \\
(0) \\
\end{array}$ & $\begin{array}{r}0 \\
(0) \\
\end{array}$ & $\begin{array}{l}0 \\
(0) \\
\end{array}$ & $\begin{array}{r}0 \\
(0) \\
\end{array}$ \\
\hline & SI & $\begin{array}{r}41,827 \\
(21,795) \\
\end{array}$ & $\begin{array}{c}41,427 \\
(22,779) \\
\end{array}$ & $\begin{array}{r}38,796 \\
(25,531) \\
\end{array}$ & $\begin{array}{l}33,273 \\
(30,625) \\
\end{array}$ & $\begin{array}{l}27,536 \\
(37,000)\end{array}$ \\
\hline & St & $\begin{array}{r}57,662 \\
(17,203)\end{array}$ & $\begin{array}{l}54,760 \\
(18,819)\end{array}$ & $\begin{array}{r}49,763 \\
(22,319) \\
\end{array}$ & $\begin{array}{l}42,051 \\
(28,207)\end{array}$ & $\begin{array}{l}34,792 \\
(35,517)\end{array}$ \\
\hline $\begin{array}{l}3 \\
4\end{array}$ & $\mathrm{FH}$ & $\begin{array}{l}0 \\
(0) \\
\end{array}$ & $\begin{array}{l}0 \\
(0) \\
\end{array}$ & $\begin{array}{l}0 \\
(0) \\
\end{array}$ & $\begin{array}{l}0 \\
(0) \\
\end{array}$ & $\begin{array}{l}0 \\
(0) \\
\end{array}$ \\
\hline \multirow{2}{*}{$\begin{array}{l}\text { P } \\
\text { E } \\
\text { R } \\
\text { C } \\
\text { E } \\
\text { I } \\
\text { T }\end{array}$} & $\mathrm{GR}$ & $\begin{array}{r}0 \\
(0) \\
\end{array}$ & $\begin{array}{l}0 \\
(0) \\
\end{array}$ & $\begin{array}{l}0 \\
(0)\end{array}$ & $\begin{array}{r}0 \\
(0) \\
\end{array}$ & $\begin{array}{r}0 \\
(0) \\
\end{array}$ \\
\hline & SI & $\begin{array}{r}50,572 \\
(51,473) \\
\end{array}$ & $\begin{array}{r}44,430 \\
(45,788) \\
\end{array}$ & $\begin{array}{r}37,456 \\
(39,901)\end{array}$ & $\begin{array}{l}29,409 \\
(34,582) \\
\end{array}$ & $\begin{array}{r}22,545 \\
(32,585) \\
\end{array}$ \\
\hline $\begin{array}{l}\mathrm{T} \\
\mathrm{A} \\
\mathrm{A}\end{array}$ & sL & $\begin{array}{r}65,892 \\
(11,869) \\
\end{array}$ & $\begin{array}{r}56,484 \\
(11,481)\end{array}$ & $\begin{array}{c}46,782 \\
(12,682)\end{array}$ & $\begin{array}{c}36,578 \\
(16,435)\end{array}$ & $\begin{array}{l}28,202 \\
(22,067)\end{array}$ \\
\hline
\end{tabular}

Standard deviation is in parentheses.

AII SI and SI expected values are statistically significant $(p=.01)$. 
TABLE 11C

FINANCIAL INSTITUTION'S NPV OF EXPECTED CASH FLOW $8 \%$ APPRECIATION

(in dollars)

\begin{tabular}{|c|c|c|c|c|c|c|}
\hline & & \multicolumn{5}{|c|}{ INITIAL AGE } \\
\hline & & 65 & 70 & 75 & 80 & 85 \\
\hline \multirow{4}{*}{$\begin{array}{l}\mathrm{z} \\
\mathrm{E} \\
\mathrm{R} \\
\mathrm{O} \\
\mathrm{T} \\
\mathrm{A} \\
\mathrm{x}\end{array}$} & $\mathrm{FH}$ & $\begin{array}{l}0 \\
(0)\end{array}$ & $\begin{array}{l}0 \\
(0)\end{array}$ & $\begin{array}{l}0 \\
(0)\end{array}$ & $\begin{array}{c}0 \\
(0)\end{array}$ & $\begin{array}{l}0 \\
(0) \\
0\end{array}$ \\
\hline & $\mathrm{GR}$ & $\begin{array}{l}0 \\
(0) \\
\end{array}$ & $\begin{array}{r}0 \\
(0) \\
\end{array}$ & $\begin{array}{l}0 \\
0\end{array}$ & $\begin{array}{l}0 \\
(0) \\
\end{array}$ & $\begin{array}{c}0 \\
(0) \\
\end{array}$ \\
\hline & $\mathrm{SI}$ & $\begin{array}{l}41,827 \\
(21,795)\end{array}$ & $\begin{array}{c}41,427 \\
(22,774)\end{array}$ & $\begin{array}{r}38,796 \\
(25,531)\end{array}$ & $\begin{array}{l}33,273 \\
(30,625)\end{array}$ & $\begin{array}{c}27,536 \\
(37,000)\end{array}$ \\
\hline & SL & $\begin{array}{l}57,662 \\
(17,203)\end{array}$ & $\begin{array}{c}54,760 \\
(18,819)\end{array}$ & $\begin{array}{c}49,763 \\
(22,319)\end{array}$ & $\begin{array}{l}42,051 \\
(28,207)\end{array}$ & $\begin{array}{l}34,792 \\
(35,517)\end{array}$ \\
\hline $\begin{array}{l}3 \\
4\end{array}$ & $\mathrm{FH}$ & $\begin{array}{r}0 \\
(0) \\
\end{array}$ & $\begin{array}{r}0 \\
(0) \\
\end{array}$ & $\begin{array}{r}0 \\
(0) \\
\end{array}$ & $\begin{array}{r}0 \\
(0) \\
\end{array}$ & $\begin{array}{r}0 \\
(0) \\
\end{array}$ \\
\hline $\begin{array}{l}\mathrm{P} \\
\mathrm{E} \\
\mathrm{R} \\
\mathrm{C}\end{array}$ & $\mathrm{GR}$ & $\begin{array}{l}0 \\
(0) \\
\end{array}$ & $\begin{array}{l}0 \\
0) \\
\end{array}$ & $\begin{array}{l}0 \\
109 \\
\end{array}$ & $\begin{array}{l}0 \\
(0)\end{array}$ & $\begin{array}{c}0 \\
(0) \\
\end{array}$ \\
\hline $\begin{array}{l}\mathrm{E} \\
\mathrm{V} \\
\mathrm{T}\end{array}$ & SI & $\begin{array}{c}50,572 \\
(51,473)\end{array}$ & $\begin{array}{r}44,430 \\
(45,788)\end{array}$ & $\begin{array}{c}37,456 \\
(39,901)\end{array}$ & $\begin{array}{r}29,409 \\
(34,582)\end{array}$ & $\begin{array}{c}22,545 \\
(32,585)\end{array}$ \\
\hline $\begin{array}{l}\mathrm{T} \\
\mathrm{A} \\
\mathrm{X}\end{array}$ & SL & $\begin{array}{l}65,892 \\
(11,869)\end{array}$ & $\begin{array}{r}56,484 \\
(11,481)\end{array}$ & $\begin{array}{r}46,782 \\
(12,682)\end{array}$ & $\begin{array}{c}36,578 \\
(16,435)\end{array}$ & $\begin{array}{l}28,202 \\
(22,067)\end{array}$ \\
\hline
\end{tabular}

standard deviation is in parentheses.

AlI SI and SL expected values are statistically significant $(p=.01)$. 
TABLE 12A

FINANCIAL INSTITUTION'S IRR OF EXPECTED CASH FLOW ZERO APPRECIATION

(in percent)

\begin{tabular}{|c|c|c|c|c|c|c|}
\hline & & & & \\
\hline \\
\end{tabular}


TABLE 12B

FINANCIAL INSTITUTION'S IRR OF EXPECTED CASH FLOW 4\% APPRECIATION

(in percent)

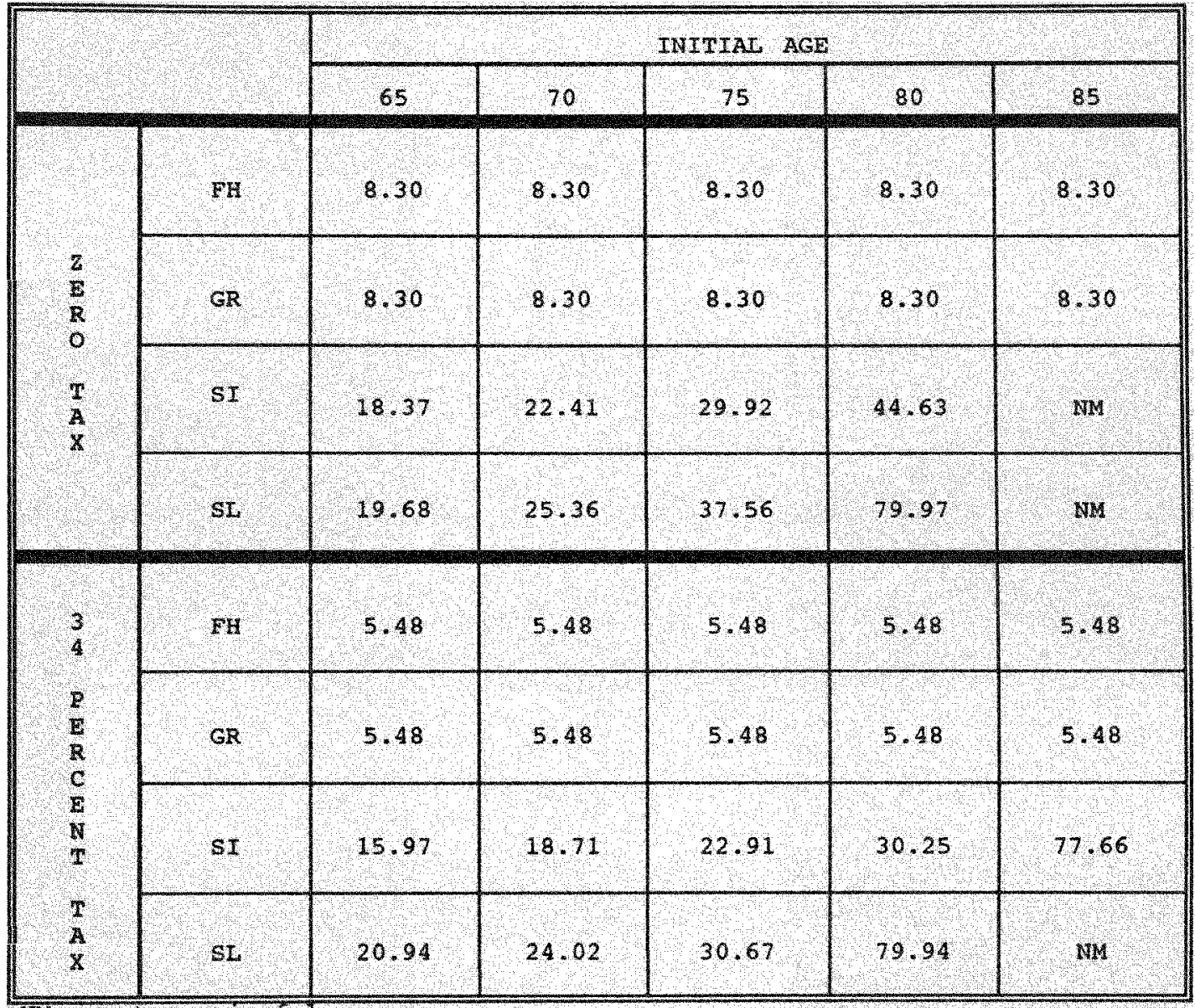

MM $=$ not meaningrul 
TABLE $12 \mathrm{C}$

FINANCIAL INSTITUTION'S IRR OF EXPECTED CASH FLOW 8\% APPRECIATION

(in percent)

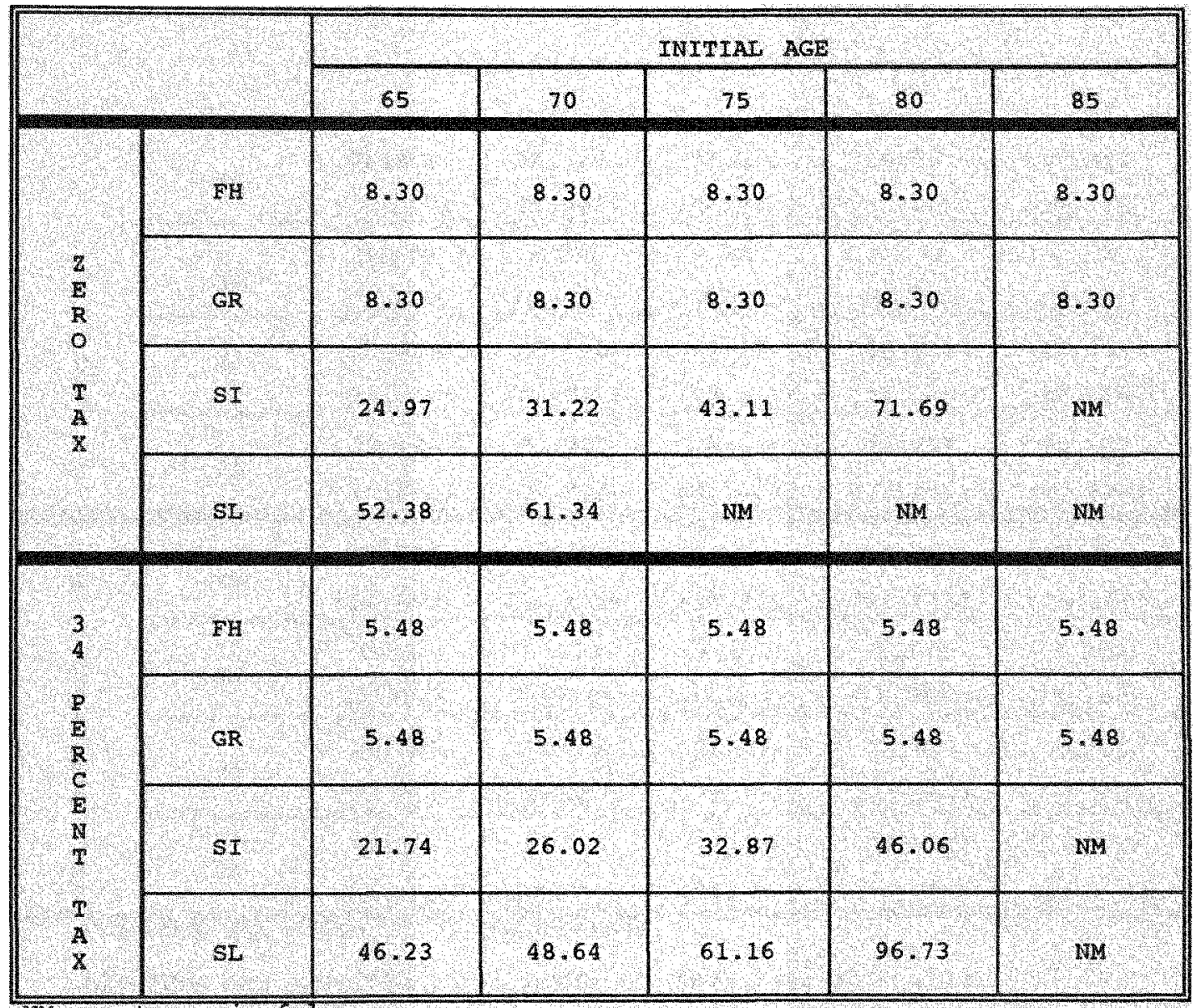

MM $=$ not meaningtul 
TABLE 13A

FINANCIAL INSTITUTION'S NPV OF ACCOUNTING INCOME ZERO APPRECIATION

(in dollars)

\begin{tabular}{|c|c|c|c|c|c|c|}
\hline & & \multicolumn{5}{|c|}{ INITIAL AGE } \\
\hline & & 65 & 70 & 75 & 80 & 85 \\
\hline \multirow{4}{*}{$\begin{array}{l}\mathrm{Z} \\
\mathrm{Z} \\
\mathrm{R} \\
0 \\
\mathrm{~T} \\
\mathrm{~A} \\
\mathrm{X}\end{array}$} & FH & $\begin{array}{l}32,498 \\
(23,213)\end{array}$ & $\begin{array}{l}27,114 \\
(21,868) \\
\end{array}$ & $\begin{array}{c}21,618 \\
(20,055) \\
\end{array}$ & $\begin{array}{l}16,337 \\
(17,771)\end{array}$ & $\begin{array}{l}12,249 \\
(15,712)\end{array}$ \\
\hline & GR & $\begin{array}{c}9,830 \\
(5,830) \\
\end{array}$ & $\begin{array}{c}8,073 \\
(5,200) \\
\end{array}$ & $\begin{array}{r}6,497 \\
(4,627) \\
\end{array}$ & $\begin{array}{l}5,142 \\
(4,116) \\
\end{array}$ & $\begin{array}{l}4,157 \\
(3,758) \\
\end{array}$ \\
\hline & SI & $\begin{array}{l}22,021 \\
(21,166)\end{array}$ & $\begin{array}{l}20,372 \\
(24,097)\end{array}$ & $\begin{array}{r}18,220 \\
(28,128)\end{array}$ & $\begin{array}{l}14,270 \\
(33,965)\end{array}$ & $\begin{array}{c}11,297 \\
(40,465)\end{array}$ \\
\hline & st & $\begin{array}{l}30,184 \\
(25,343)\end{array}$ & $\begin{array}{c}31,242 \\
(27,745)\end{array}$ & $\begin{array}{l}30,575 \\
(31,640)\end{array}$ & $\begin{array}{l}26,882 \\
(37,614)\end{array}$ & $\begin{array}{l}23,295 \\
(44,426)\end{array}$ \\
\hline $\begin{array}{l}3 \\
4\end{array}$ & $\mathrm{FH}$ & $\begin{array}{r}32,356 \\
(27,186) \\
\end{array}$ & $\begin{array}{r}25,444 \\
(23,692) \\
\end{array}$ & $\begin{array}{l}19,218 \\
(20,254) \\
\end{array}$ & $\begin{array}{l}13,833 \\
(16,811) \\
\end{array}$ & $\begin{array}{c}9,959 \\
(14,104)\end{array}$ \\
\hline \multirow{2}{*}{$\begin{array}{l}\mathrm{P} \\
\mathrm{E} \\
\mathrm{R} \\
\mathrm{C} \\
\mathrm{E} \\
\mathrm{N} \\
\mathrm{T}\end{array}$} & GR & $\begin{array}{l}9,320 \\
(6,958) \\
\end{array}$ & $\begin{array}{r}7,173 \\
(5,419) \\
\end{array}$ & $\begin{array}{l}5,471 \\
(4,471) \\
\end{array}$ & $\begin{array}{r}4,131 \\
(3,708) \\
\end{array}$ & $\begin{array}{l}3,217 \\
(3,197) \\
\end{array}$ \\
\hline & SI & $\begin{array}{r}26,887 \\
(19,156) \\
\end{array}$ & $\begin{array}{l}22,710 \\
(19,500) \\
\end{array}$ & $\begin{array}{l}18,496 \\
(20,703) \\
\end{array}$ & $\begin{array}{r}13,423 \\
(23,633) \\
\end{array}$ & $\begin{array}{c}9,816 \\
(27,678) \\
\end{array}$ \\
\hline $\begin{array}{l}T \\
A \\
X\end{array}$ & SL & $\begin{array}{l}32,457 \\
(16,864)\end{array}$ & $\begin{array}{c}30,565 \\
(18,573)\end{array}$ & $\begin{array}{r}27,465 \\
(21,273) \\
\end{array}$ & $\begin{array}{l}22,502 \\
(25,463)\end{array}$ & $\begin{array}{l}18,273 \\
(30,326)\end{array}$ \\
\hline
\end{tabular}

standard deviation is in parentheses.

All NPVs are significantly different from zero $(p=.01)$. 
TABLE 13B

FINANCIAL INSTITUTION'S NPV OF ACCOUNTING INCOME $4 \%$ APPRECIATION

(in dollars)

\begin{tabular}{|c|c|c|c|c|c|c|}
\hline & & & \\
\hline
\end{tabular}

standard deviation is in parentheses.

All NPVs are significantly different from zero $(p=.01)$. 
TABLE $13 \mathrm{C}$

FINANCIAL INSTITUTION'S NPV OF ACCOUNTING INCOME 8\% APPRECIATION

(in dollars)

\begin{tabular}{|c|c|c|c|c|c|c|}
\hline & & \multicolumn{5}{|c|}{ INITIAL AGE } \\
\hline & & 65 & 70 & 75 & 80 & 85 \\
\hline \multirow{4}{*}{$\begin{array}{l}\mathrm{Z} \\
\mathrm{E} \\
\mathrm{R} \\
\mathrm{O} \\
\mathrm{T} \\
\mathrm{A} \\
\mathrm{X}\end{array}$} & $\mathrm{FH}$ & $\begin{array}{r}32,498 \\
(23,213) \\
\end{array}$ & $\begin{array}{r}27,114 \\
(21,868) \\
\end{array}$ & $\begin{array}{l}21,618 \\
(20,055) \\
\end{array}$ & $\begin{array}{r}16,337 \\
(17,771) \\
\end{array}$ & $\begin{array}{r}12,249 \\
(15,712) \\
\end{array}$ \\
\hline & GR & $\begin{array}{r}9,880 \\
(5,830)\end{array}$ & $\begin{array}{c}8,073 \\
(5,200)\end{array}$ & $\begin{array}{c}6,497 \\
(4,627)\end{array}$ & $\begin{array}{c}5,142 \\
(4,116)\end{array}$ & $\begin{array}{c}4,157 \\
(3,758)\end{array}$ \\
\hline & SI & $\begin{array}{r}44,335 \\
(23,774) \\
\end{array}$ & $\begin{array}{r}44,076 \\
(24,853) \\
\end{array}$ & $\begin{array}{l}41,441 \\
(27,613)\end{array}$ & $\begin{array}{r}35,393 \\
(32,357) \\
\end{array}$ & $\begin{array}{l}28,921 \\
(38,537)\end{array}$ \\
\hline & sL & $\begin{array}{l}60,726 \\
(20,805)\end{array}$ & $\begin{array}{c}58,565 \\
(22,356)\end{array}$ & $\begin{array}{c}53,569 \\
(25,506)\end{array}$ & $\begin{array}{l}44,672 \\
(30,726)\end{array}$ & $\begin{array}{l}36,317 \\
(37,587)\end{array}$ \\
\hline $\begin{array}{l}3 \\
4\end{array}$ & FH & $\begin{array}{r}32,356 \\
(27,186) \\
\end{array}$ & $\begin{array}{r}25,444 \\
(23,692) \\
\end{array}$ & $\begin{array}{r}19,218 \\
(20,254) \\
\end{array}$ & $\begin{array}{c}13,833 \\
(16,811) \\
\end{array}$ & $\begin{array}{c}9,959 \\
(14,104) \\
\end{array}$ \\
\hline \multirow{2}{*}{$\begin{array}{l}\mathrm{P} \\
\mathrm{E} \\
\mathrm{R} \\
\mathrm{C} \\
\mathrm{E} \\
\mathrm{N} \\
\mathrm{T}\end{array}$} & GR & $\begin{array}{r}9,320 \\
(6,598) \\
\end{array}$ & $\begin{array}{r}7,173 \\
(5,419) \\
\end{array}$ & $\begin{array}{r}5,471 \\
(4,471) \\
\end{array}$ & $\begin{array}{l}4,131 \\
(3,708) \\
\end{array}$ & $\begin{array}{r}3,217 \\
(3,197) \\
\end{array}$ \\
\hline & SI & $\begin{array}{r}52,618 \\
(15,858) \\
\end{array}$ & $\begin{array}{r}46,585 \\
(16,637) \\
\end{array}$ & $\begin{array}{r}39,578 \\
(18,217) \\
\end{array}$ & $\begin{array}{l}31,073 \\
(21,179) \\
\end{array}$ & $\begin{array}{r}23,605 \\
(25,541) \\
\end{array}$ \\
\hline $\begin{array}{l}\mathbf{T} \\
\mathbf{A} \\
\mathbf{X}\end{array}$ & SL & $\begin{array}{r}66,705 \\
(18,744) \\
\end{array}$ & $\begin{array}{l}58,341 \\
(18,549) \\
\end{array}$ & $\begin{array}{r}48,953 \\
(18,683) \\
\end{array}$ & $\begin{array}{r}38,053 \\
(20,820) \\
\end{array}$ & $\begin{array}{l}29,004 \\
(24,981)\end{array}$ \\
\hline
\end{tabular}

standard deviation is in parentheses.

All NPVs are significantly different from zero $(p=.01)$. 
TABLE 14

FHA'S NPV OF EXPECTED CASH FLOW

(in dollars)

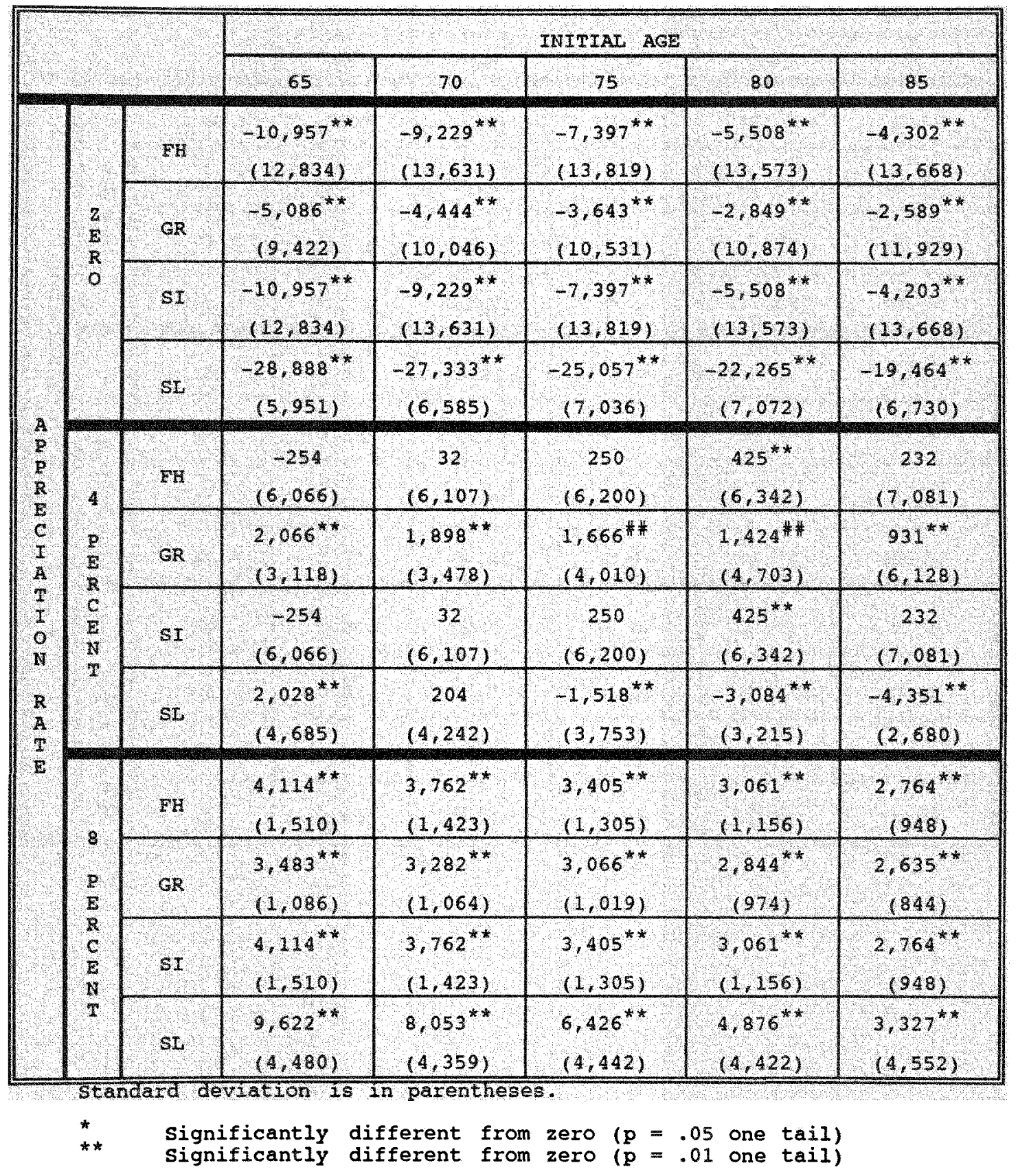


TABLE 15

FHA BREAK-EVEN RETURN ON INVESTMENTS

(in percent)

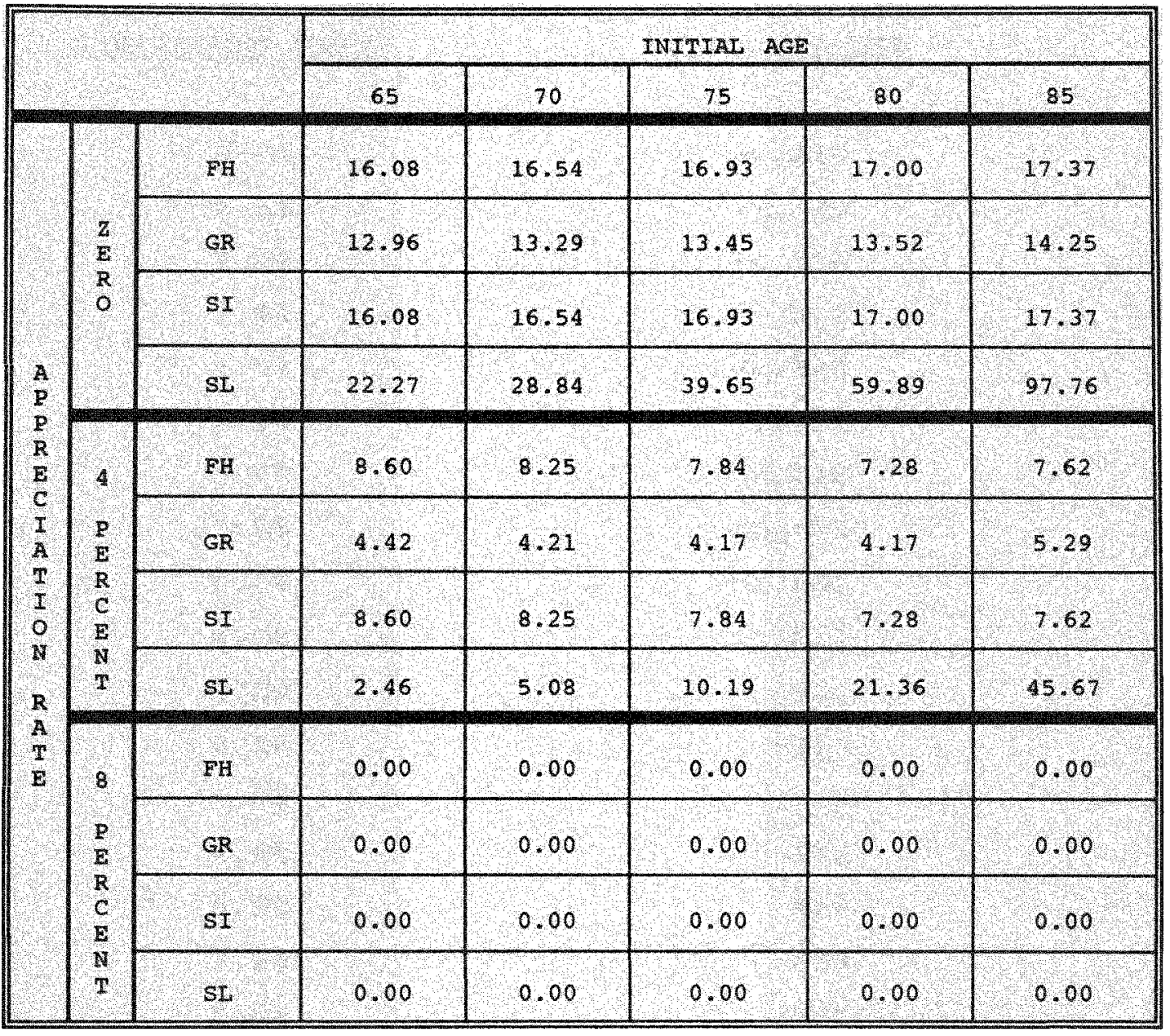


EFFECT OF DISCOUNT RATE ON FHA'S EXPECTED NPV (in dollars)

DISCOUNT RATE

$0.0 \%$

$0.5 \%$

$1.0 \%$

$1.5 \%$

$2.0 \%$

$2.5 \%$

$3.0 \%$

$3.5 \%$

$4.0 \%$

$4.5 \%$

$5.0 \%$

$5.5 \%$

$5.8 \%$

$6.0 \%$

$6.5 \%$

$7.0 \%$

$7.5 \%$

$8.0 \%$

$8.3 \%$

$8.5 \%$

$9.0 \%$

$9.5 \%$

$10.0 \%$

\section{EXPECTED NPV}

$-9,215$

$-7,729$

$-6,436$

$-5,311$

$-4,329$

$-3,474$

$-2,728$

$-2,076$

$-1,508$

$-1,011$

$-576$

$-197$

8

135

426

680

902

1,096

1,200

1,265

1,413

1,542

1,655 
TABLE 17

EFFECT OF MOVE-OUT RATE ON FHA'S EXPECTED NPV

MOVE-OUT RATE

(percent of mortality)
EXPECTED NPV

(in dollars)

728

759

911

968

1,009

1,104

1,200

1,298

1,443

1,556

1,631

1,701

1,784

1,885

1,985

2,103

2,216

2,332

2,403

2,472

2,529 
TABLE 18

EFFECT OF SALES PRICE DISCOUNT ON FHA'S EXPECTED NPV

DISCOUNT

(percent of FMV)
EXPECTED NPV

(in dollars)

$\begin{array}{rr}0 & 1,200 \\ 1 & 1,115 \\ 2 & 1,030 \\ 3 & 944 \\ 4 & 859 \\ 5 & 774 \\ 6 & 678 \\ 7 & 571 \\ 8 & 464 \\ 9 & 357 \\ 10 & 250 \\ 11 & 142 \\ 12 & 35 \\ 13 & -88 \\ 14 & -216 \\ 15 & -345 \\ 16 & -473 \\ 17 & -602 \\ 18 & -730 \\ 19 & -864 \\ 20 & -1,029\end{array}$


EFFECT OF HOME APPRECIATION RATE ON FHA'S EXPECTED NPV (in dollars)

$-4.0 \%$

$-3.5 \%$

$-3.0 \%$

$-2.5 \%$

$-2.0 \%$

$-1.5 \%$

$-1.0 \%$

$-0.5 \%$

$0.0 \%$

$0.5 \%$

$1.0 \%$

$1.5 \%$

$2.0 \%$

$2.5 \%$

$3.0 \%$

$3.3 \%$

$3.5 \%$

$4.0 \%$

$4.5 \%$

$5.0 \%$

$5.5 \%$

$6.0 \%$

$6.5 \%$

$7.0 \%$

$7.5 \%$

$8.0 \%$
$-12,537$

$-11,779$

$-11,089$

$-10,353$

$-9,562$

$-8,749$

$-7,926$

$-7,039$

$-6,156$

$-5,243$

$-4,307$

$-3,371$

$-2,419$

$-1,441$

$-520$

16

193

1,200

1,926

2,527

2,955

3,232

3,365

3,401

3,405

3,405 
EFFECT OF APPRECIATION'S STANDARD DEVIATION ON FHA'S EXPECTED NPV

(in dollars)

STANDARD DEVIATION

EXPECTED NPV

\begin{tabular}{rr}
$0.0 \%$ & 1,200 \\
$0.5 \%$ & 1,146 \\
$1.0 \%$ & 1,001 \\
$1.5 \%$ & 775 \\
$2.0 \%$ & 500 \\
$2.5 \%$ & 199 \\
$2.8 \%$ & 13 \\
$3.0 \%$ & -112 \\
$3.5 \%$ & -425 \\
$4.0 \%$ & -735 \\
$4.5 \%$ & $-1,038$ \\
$5.0 \%$ & $-1,330$ \\
$5.5 \%$ & $-1,609$ \\
$6.0 \%$ & $-1,873$ \\
$6.5 \%$ & $-2,121$ \\
\hline $7.0 \%$ & $-2,353$ \\
\hline $7.5 \%$ & $-2,569$ \\
$8.0 \%$ & $-2,771$ \\
$8.5 \%$ & $-2,958$ \\
$9.0 \%$ & $-3,132$ \\
\hline $9.5 \%$ & $-3,294$ \\
$10.0 \%$ & $-3,444$
\end{tabular}




\section{CHAPTER V}

CONCLUSION

This chapter is divided in three parts: (1) a summary of the research, (2) public policy recommendations, and (3) limitations of the model, suggesting areas of further research.

5.1

Summary

As expected, this research demonstrates that none of the plans are Pareto optimal. For example, each of the plans had the highest and the lowest net present value for some homeowners. This suggests that none of the plans should be prohibited or discouraged. The most significant finding of the study is that neither the SI or SL is an effective economic substitute for the FHA HECM. Although the SI and SL are profitable for financial. institutions, their profits are more than offset by additional costs to the homeowner and, in the case of the SL, the FHA. Financial institutions may be reluctant to pass on any excess cash flow to the homeowner due to the high variance of expected returns. Although these two plans have features that may make them more desirable to the homeowner then the HECM, they consistently have a higher expected cost (as measured by NPV) than the HECM. 


\subsubsection{Homeowners}

The effects of the homeowner's age, expected home appreciation rate, and tax rate on plan choice are unexpectedly small. In general, most homeowners can expect to be better off not using a HEC plan than using one. If the homeowner requires a HEC plan, a mortgage plan provides the highest expected NPV and the growth mortgage generally provides the highest expected NPV.

\section{$5.1 .2 \quad$ Adverse Selection}

The research suggests that the FHA need not be concerned that homeowners will use the HECM if they expect their homes not to increase in value. Most homeowners would be better off not using a HEC plan, even if they assumed that the property would not appreciate at all. Homeowners at age 65 or 70 who pay no tax or at age 65 in the 15 percent tax bracket have a slightly better than 50 percent chance of being better off by using the standard HECM. However, the benefits are too speculative and for too narrow a group to present a significant problem. It is likely that homeowners in lower tax brackets would be less likely to speculate than those in higher tax brackets. Although this addresses the adverse selection risk of homeowner speculation, it does not address Speare's (1992) concern that those homeowners that need home equity conversion are the ones most likely to live in 
neighborhoods with home appreciation rates below the national average.

5.1.3 Tax Policy

From the standpoint of tax policy, the results show that any tax effect is not significant enough to influence a decision either by the homeowner or a financial institution. There is less incentive for a homeowner to enter a HEC plan as tax rates increase, indicating that the HEC plans are consistent with vertical equity. In addition, the specific tests for vertical integration and tax subsidy indicate there is no violation of these tax policy principles.

5.1 .4 Accounting Policy

At first glance, the accounting treatment of the SI and the SL under current rules do not appear to fully reflect the economics of their respective transactions. This suggests that financial institutions may be reluctant to enter into these arrangements, particularly if they were concerned with maintaining regulatory income and capital. However, the results of this research show that given a large portfolio of investments, the accounting flows from the portfolio should be large enough not to discourage the investments in the plans. The NPV of expected accounting income of the SI and the SL is consistently higher than the NPV of expected cash flow. This indicates that accounting flows generally precede cash flow. 5.1.5 FHA Assumptions 
Although many of the FHA assumptions appear generous, they do not appear to be more generous than the assumptions used in other HEC plans. The liberal assumptions are in part driven by the FHA policy not to profit by its plan. This policy permits the FHA little leeway for errors in their assumptions. This research shows that FHA met its goal by being marginally profitable, excluding administrative costs, based on its assumptions. The simulations indicate that it is not likely that a violation of any assumption tested will by itself cause a loss. However, a change in the appreciation rate to below 3.3 percent or the standard deviation of the appreciation rate (assuming a 4 percent average rate) to more than 2.8 percent would result in a loss. This research assumes that the FHA could fund their premiums with investments with the same return as the mortgages. If the returns are significantly (about 2.5 percentage points) below that of the mortgages, then the FHA will incur a loss. Homeowner move-out rates do not have a significant effect on the model. Even if the move-out rate is zero, the FHA still has a margin of profit. The low significance of the move-out rate suggests that the FHA need not stringently enforce repayment upon move-out. In fact, it may consider loosening it rules to permit the loan to remain in effect after moveout. This will allow the homeowner to use rents from the house to provide additional income for long term care. 
$5.2 \quad$ Recommendations

5.2.1. FHA Recommendations

The results show that neither the SI or the SL is expected to result in a NPV to the homeowner that is as favorable as a mortgage plan. In addition, the $\mathrm{SL}$ is unprofitable for the FHA. This suggests that the FHA should not insure the SL plan. Insuring the SI plan under the terms of this research would impose no additional cost to the FHA (since the insurance is based on the standard HECM mortgage). However, the need for the insurance can be questioned. The plan is not particularly beneficial to the homeowner and it is unclear whether financial institutions would be interested in this form of insurance.

The FHA should institute a growth mortgage option. This would provide inflation protection to the homeowner and is profitable for the FHA. The growth option could be changed to a cost of living option. Although the FHA will bear the risk of higher inflation, this should be more than offset by reduced home appreciation rate risk. Over time, homes tend to appreciate with inflation.

5.2.2 Public Assistance Recommendations

Even though the SI and SL plans are not sufficiently beneficial to the homeowner to encourage financial institutions to offer them, uninsured plans should not be discouraged. For example, congress or the social security 
Administration should consider establishing rules that allow elderly homeowners to convert their home equity into an annuity without affecting their SSI payments. There appears to be no policy reason for allowing HECM mortgage payments to be exempt from the income rules while annuity payments are not. This is clearly a question of "form over substance." An exemption for home equity conversion should also produce more liquidity in the housing market since the elderly would not be forced to stay in their home in order to continue SSI benefits.

\subsubsection{Tax Recommendations}

Both the SI and SL have unneeded tax clouds over their heads. These are clouds that the Treasury Department has indicated a willingness to change. Consistent with this Treasury Department policy, Congress should amend section 125 to allow the $\$ 125,000$ exemption for the sale of a remainder interest to an unrelated party. The transaction would be treated as the sale of the entire property followed by a buyback of the life estate. In addition, a sale-leaseback of a residence to an unrelated party should be recognized as such, regardless of the term of the lease.

\section{$5.3 \quad$ Limitations}

The limitations of this research are a result of the assumptions used in the model and the FHA model. Further research is needed to test the appropriateness of the model 
assumptions. For example, both the FHA model and this research assume that life expectancy can be estimated by the HEW life expectancy tables. Almost all commentators have been critical of this assumption. In addition, FHA does not use joint life tables for joint owners. Joint owners were not included in this study because the effect of a joint owner's death on the move-out and mortality of the other joint owner is not known. Further research is necessary on the actual life expectancy of homeowners using home equity conversion as well as the effect of the death of one owner on the mortality and move-out rate of the survivor. The HECM program may be unprofitable if the FHA mortality assumptions are too liberal, particularly if the average initial age of the borrowers should decrease. This research suggests that the FHA's expected profit from a HECM mortgage is lower for younger borrowers.

Virtually all current FHA HECM mortgages have a variable interest rate. To avoid confounding, this research does not explore the effect of variable rates on the homeowner or the FHA. There is a need for further research in this area. For example, does the FHA's method of computing annuity payments for variable mortgages result in a subsidy to the homeowner? This study only analyzed the sensitivity of the tenure mortgage to the FHA assumptions. Further research is 
necessary to explore the sensitivity of the line of credit and term mortgages to the assumptions.

The SI and SL plans protect the homeowner against unforseen expenses (e.g., a new roof). This is a risk that is not measured by the methodology of this research. Further research is necessary to find if the problem is significant and if so develop methods to protect homeowners using the HECM. For example, some other HECM products require the homeowner to leave a reserve for repairs.

This research model assumes that the homeowner will continue the mortgage until death or move-out. Further research is needed to develop costs and benefits to the homeowner, the financial institution, and the FHA for either refinancing at lower interest rates or refinancing if the property appreciates more than expected in the FHA model.

Financial institutions may elect to "put" the mortgage to the FHA when the mortgage equals 98 percent of the maximum claim amount. This study assumes that the interest rate remains constant and that the financial institution will elect to continue to hold the mortgage. Further research is necessary as to the interest rate exposure of the FHA relating to this put.

The simulation of the SI and SL assumed that homeowners would not use the plan as a device for selling their homes. 
If either of these plans are developed, specific provisions would have to be included to avoid this problem.

Finally, the test of the FHA model examined a single parameter at a time. Further research is necessary to determine the joint risk of changes in more than one parameter. 


\section{REFERENCES}

Ali, Chunrong, Jonathan Feinstein, Daniel McFadden, and Henry Pollakowski. 1990. The dynamics of housing demand by the elderly: User cost effects. In Issues in the economics of aging, edited by David A. Wise. Chicago: University of Chicago Press.

American Association of Retired Persons [AARP]. 1992. The home equity conversion (HEC) numbers game. Fact sheet (April), AARP.

American Bar Association [ABA]. Commission on Legal Problems of the Elderly. Final Report: Home equity conversion: Enhancing legal awareness. 1986. By Nancy Coleman, Staff Director and Barbara Nelson, Project Director. Washington, D.C.: ABA. NTIS, SHR-0013872/XAB.

Archer, wayne R. and David J. Nye. 1987. An insurance approach to risk analysis of debt home equity conversion programs. AREUEA Journal 15 (Fall): 185-98.

Artel, Roland and Pravin Varaiya. 1978. Life cycle consumption and homeownership. Journal of Economic Theory 18 (June): 38-58.

Auster, Rolf. 1991. Split Purchase: One of the Few remaining tax shelters. Real Estate Review 20 (Winter): 36-43.

1993a. Leveraged split purchase: It's to your advantage to understand the gray! The National Public Accountant 38 (January): $30-38$.

1993b. Tax advantages in joint purchases. Real Estate Review 23 (Spring): 49-61.

Barriere, Laura A. 1991. Funding and servicing reverse mortgages. In National leadership conference on home equity conversion, September 5-6, 1991, by American Association of Retired Persons. Washington, D.C. AARP. Faculty Briefing Papers [no page numbers].

Bernheim, B. Douglas. 1987. Dissaving after retirement: Testing the pure life cycle hypothesis. In Issues in pension economics. Edited by Bodie, zvi, John B. Shoven, 
and David A. Wise, 237-79. Chicago: University of Chicago Press.

Chen, Alexander and Helen H. Jensen. 1985. Home equity use and the life cycle hypothesis. The Journal of Consumer Affairs 19 (Summer): 37-56.

Chen, Yung-Ping. 1973. A pilot survey study of the HousingAnnuity Plan (HAP). Occasional Paper No. 6. [Los Angeles: UCLA]. NTIS, PB-220 293/3.

D'Avino, Richard. 1983. [Remarks to conference]. In Home equity conversion options for older homeowners "House rich, but cash poor": A sale - leaseback fact finding session, September 14, 1983, by Federal Council on the Aging. Washington, D.C: Federal Council on the Aging. 8-9.

Dicks-Mireaux, L. and M. A. King. 1984. Pension wealth and household savings: Tests of robustness. Journal of Public Economics 23 ( ): 115-40.

Financial Accounting standards Board. 1976. Statement of financial accounting standards no. 13: Accounting for leases. Norwalk, Conn.: FASB.

- 1978. statement of financial accounting concepts no. 1: Obectives of financial reporting by business enterprises. Norwalk, Conn.: FASB.

- 1979. Statement of financial accounting standards no. 34: Capitalization of interest cost. Norwalk, Conn.: FASB.

- 1982. Statement of financial accounting standards no. 60: Accounting and reporting by insurance enterprises. Norwalk, Conn.: FASB.

- 1986. Statement of financial accounting standards no. 91: Accounting for nonrefundable fees and costs associated with originating or acquiring loans and initial direct costs of leases. Norwalk, Conn.: FASB.

1991. Statement of financial accounting standards no. 107: Disclosures about fair value of financial instruments. Norwalk, Conn.: FASB.

Friedman, Milton. 1957. A theory of the consumption function. Princeton, N.J.: Princeton University Press. 
Garnett, Robert and Jack M. Guttentag. 1982. HELP in Buffalo. Housing Finance Review I (Winter): 387-406.

and - 1984. The reverse-shared-appreciation mortgage. Housing Finance Review 3 (January): 63-84.

Gasper, Juli-Ann. 1984. Asset depletion and cash flow increase effects of reverse mortgage use by elderly households. Ph.d. diss., University of Nebraska Lincoln.

Gibler, Karen Martin. 1990. Economic life cycle hypothesis and home equity dissaving behavior of the elderly. Ph.d. diss., Georgia state University.

Guttentag, Jack. 1980. An overview of home equity conversion plans. In Unlocking home equity for the elderly, edited by Ken Scholen and Yung-Ping Chen, 79-89. Cambridge, Mass.: Ballinger.

Harney, Kenneth. 1992. Future of reverse mortgages suddenly brightens. Washington Post. 3 October, F2.

Henry, G. Robert. 1980. The Fouratt Plan. In Unlocking home equity for the elderly, ed. Ken Scholen and Yung-Ping Chen, 127-30. Cambridge, Mass: Ballinger.

Higgins, David P. and W. Edward Folts. 1992. Principles and cash flow expectations of reverse mortgages. The Journal of Applied Gerontology 11 (June): 187-199.

Howard, Sue Ann. 1987. Impact of home equity conversion plans for local elderly. Ph.D. diss. Ohio state University.

Iman, Ronald L. and W. J. Conover. 1983. Modern Business Statistics. New York: John Wiley \& Sons.

Jacobs, Bruce. 1982. An overview of the National Potential for home equity conversion into income for the elderly. University of Rochester Discussion Paper No. 8205.

and William Weissert. 1987. Using home equity to finance long-term care. Journal of Health Politics, Policy and Law. 12 (Spring): 77-94.

Katsura, Harold M., Raymond J. Struyk, and Sandra J. Newman. 1989. Housing for the elderly in 2010: Projections and policy options. Urban Institute Report 89-4. Washington, D.C.: The Urban Institute Press. 
Klein, Linda and C. F. Sirmans. 1993. Financial Innovation and the development of reverse mortgage programs. Benefits Quarterly. 9 (First Quarter): 29-38.

Kummerow, Max. 1980. Marketing. In Unlocking home equity for the elderly, edited by Ken scholen and Yung-Ping Chen, 143-61. Cambridge, Mass.: Ballinger.

Leban, Abbott A. 1984. The American Homestead program. Housing Finance Review 3 (January): 87-90.

Li, Mingche M. 1977. A logit model of homeownership. Econometrica 45 (July): 1081-97.

Mankiw, N Gregory and David N. Weil . 1988. The baby boom, the baby bust, and the housing market. Cambridge, Mass.: National Bureau of Economic Research.

Manning, Ric. 1993. Capital Holding Does an about-face on reverse mortgages. The [Louisville] Courier-Journal 10 April, p. B10.

Mirer, T. W. 1979. The wealth-age relationship among the aged. American Economic Review 69 (June): 435-43.

Modigliani, Franco. 1975. The Life cycle hypothesis of savings twenty years later. In Contemporary issues in economics, edited by M. Parkin, 2-36. Manchester, Eng.: Manchester University Press, 33-81.

and Albert Ando. 1960. The "Permanent Income" and the "Life Cycle" hypothesis of savings behavior: comparison and tests. In vol.2, Consumption and savings. Philadelphia: Whatron School of Finance and Commerce, University of Pennsylvania, 74-108, 138-47.

and Richard Brumberg. 1954. Utility Analysis and the consumption function: An interpretation of crosssection data. In Post Keynesian economics, edited by Kenneth K. Kurihara, 388-436. New Brunswick, N.J.: Rutgers University Press.

Nelson, Douglas. 1980. A profile of elderly homeowners. In Unlocking home equity for the elderly, edited by Ken Scholen and Yung-Ping Chen, 9-24 and 267-276. Cambridge, Mass.: Ballinger.

Pastalan, Leon A. 1983. Home equity conversion: A performance comparison with other housing options. Journal of housing for the elderly. 1 (Fall): 83-90. 
Phillips, William A. 1991. Reverse mortgages: Private sector perspective. In National leadership conference on home equity conversion, September 5-6, 1991, by American Association of Retired Persons. Washington, D.C.: AARP. 34-37.

Providential Corporation. 1992a. Prospectus (February 10).

- 1992b. Form 10-Q for the quarterly period ended June 30, 1992. Securities and Exchange Commission file no. 0-19675.

Rielly, Frank K. 1985. Investment analysis and portfolio management. 2d edition. Dryden Press: Chicago.

Rivlin, Alice M., Joshua M. Wiener, Raymond J. Hanley, and Denise A. Spence. 1988. Caring for the disabled elderly: Who will pay? Washington, D.C.: The Bookings Institution.

Roma, Mary K. 1991. Federal legal and regulatory issues. In National leadership conference on home equity conversion, September 5-6, 1991, by American Association of Retired Persons. Washington, D.C.: AARP. 38-41.

Scholen, Ken. 1991. Consumer's guide to home equity conversion: Home made money. 3d edition. Washington, D.C.: AARP.

- 1992. Retirement Income on the house: Cashing in on your home with a "Reverse mortgage. Marshall Minnesota: NCHEC Press.

Scholes, Myron S., Wilson, G. Peter, Mark A. Wolfson. 1989. Tax planning, regulatory capital planning and financial reporting strategy for commercial banks. Unpublished manuscript, Graduate School of Business, Stanford University (February).

Sichelman, Lew. 1991. A tough sell. Mortgage Banking 52 (November): 73-81.

Speare, Alden, Jr. 1992. The demography of reverse equity mortgages. Prepared for the annual meeting of the Population Association of America in Denver, April 30, 1992 .

springer, Philip B. 1985. Home equity conversion plans as a source of retirement income. Social security Bulletin 48 (September): 10-19. 
Szymanoski, Jr., Edward J. 1990. The FHA Home Equity Conversion Mortgage Insurance Demonstration: A model to calculate borrower payments and insurance risk. Washington, D.C.: U.S. Department of Housing and Urban Development, office of Policy Development and Research. NTIS, PB92-164599/XAB.

1992. Comments on "The demography of reverse equity mortgages" by Alden Speare, Jr. Prepared for the annual meeting of the Population Association of America in Denver, April 30, 1992.

1993a. A risk analysis framework for the Home Equity Conversion Mortgage insurance demonstration. Unpublished manuscript. January 3, 1993.

1993b. Letter from Washington, D.C., to Lowell Cramer.

Tate, William H. 1987. Reverse mortgages for the low-income elderly: An economic analysis. Ph.d. diss., University of Florida.

Taylor, Rick J. 1993. Charitable gift annuities as a planning technique. The Tax Adviser 24 (June): 361-62.

Turner, Lloyd, Carol Schreter, Bonnie Zetick, Glen Weisbrod, and Henry Pollakowski. 1982. Housing options for the community resident elderly: Policy report of the housing choices of older americans study. Bryn Mawr, Penns.: The Graduate School of Social Work and Social Research, Bryn Mawr College. NTIS, PB83-118687.

Transamerica HomeFirst. [1993]. The Reverse Mortgage Primer. San Francisco: Transamerica HomeFirst.

U.S. Congress. 1985. Home equity conversion: Issues and options for the elderly homeowner, Joint briefing by the subcommittee on Housing and consumer Interests, House Select committee on Aging, and the senate special Committee on Aging. 99 th Cong., 1st Sess, 28 January.

U. S. Congress, senate special Committee on Aging; the American Association of Retired Persons; the Federal council on the Aging; and the U.S. Administration on Aging. 1991. Aging America: Trends and Projections. 1991 ed. Washington, D.C.: U.S. Department of Health and Human Services. 
U.S. Department of Health and Human Services. Public Health Service. National Center for Health Statistics. 1985. U.S. decennial life tables for 1979-81.

U.S. Department of Housing and Urban Development [HUD] . Office of Policy Development and Research. 1985. Home equity conversion mechanisms. [Washington, D.C.]: U.S. Department of Housing and Urban Development.

- Office of Housing. 1989. Home equity conversion mortgages: Program participants. Handbook 4235.1. [Washington, D.C.]: U.S. Department of Housing and Urban Development, Office of Housing.

- Office of Policy Development and Research. 1990. Interim report to congress on the home equity conversion mortgage demonstration. [Washington, D.C.]: U.S. Department of Housing and Urban Development. Office of Policy Development and Research. NTIS, PB-92-140920/XAB.

- 1992. Preliminary Evaluation of the Home Equity Conversion Mortgage Insurance Demonstration. Report to Congress (December 30).

U.S. Securities and Exchange Commission. Chief Accountant's Office. 1992. Accounting for pools of uninsured residential reverse mortgage contracts. An unpublished staff position paper dated october 1, 1992 .

Vaughan, Emmett J. 1986. Fundamentals of Risk and Insurance. 4 th ed. New York: John Wiley \& Sons.

Venti, Steven F. and David A. Wise. 1990. But they don't want to reduce housing equity. In Issues in the economics of aging, edited by David A. Wise. Chicago: University of Chicago Press, 13-29.

and housing wealth. Journal of Public Economics 44 (April): $371-97$.

Weinrobe, Maurice. 1987. An analysis of home equity conversion in the RAM program. AREUEA Journal 15 (Summer): $65-78$.

1988. An insurance plan to guarantee reverse mortgages. Journal of Risk and Insurance 55 (December): 64459. 
VITA

October 2, 1947

1968

1969

1972

1972

1973

$1973-1976$

$1976-1977$

$1977-1980$

$1980-1983$

$1983-1985$

1986
Born, Miami, Florida

B.S., Accounting and Finance Florida state University

Tallahassee, Florida

A.A.B., University of Florida Gainesville, Florida

J.D., University of Florida

Gainesville, Florida

M.B. A., Accounting

Florida state University

Tallahassee, Florida

LL.M. , Taxation

New York University

New York, New York

Associate Tax Counsel

CBS Inc.

New York, New York

Associate Attorney

Tracy Baxter, P.A.

Jacksonville, Florida

Senior, International Tax Price Waterhouse \& Co. New York, New York and Chicago, Illinois

Tax Attorney

Texaco Inc.

Coral Gables, Florida

Tax and Legal Consultant

T. C. Miller \& Co., CPAs

Ft. Lauderdale, Florida

M.S.T., Taxation

Florida International University Miami, Florida 
Parhizgairi, A., Cramer, L. and Auster, R. (1988). Strategies to Reduce Foreign Tax Credits. Corporate Taxation, 1 (4) :21-26.

Parhizgairi, A., Cramer, L. and Auster, R. (1989). Managing Excess Foreign Tax Credits. Management Accounting, 71 (2) $: 28-35$.

Cramer, L. (1990). A single Taxable Entity: A Simplification Proposal. Tax Analysts' Daily Tax Highlights \& Documents, $18(22): 1215-24$.

Cramer, L. and Sennetti, J. (August 1991). The Use of Corporate Tax Choices to Smooth Reported Earnings. Paper presented at The American Accounting Association National Meeting.

Auster, R., Cramer, L. and Lau, P. C. (Fall 1993). Tax Advantages of a split Purchase Partnership. Real Estate Review, 23 (3):85-89. 